\title{
Ciência da Informação: 32 anos (1972- 2004) no caminho da história e horizontes de um periódico científico brasileiro*
}

\author{
Lena Vania Ribeiro Pinheiro \\ Instituto Brasileiro de Informação em Ciência e Tecnologia - Ibict \\ Doutora em Comunicação e Cultura, UFRJ/ECO \\ E-mail: lenavania@Ibict.br \\ Marisa Bräscher \\ Universidade de Brasília-UnB / Departamento \\ de Ciência da Informação \\ Doutora em Ciência da Informação, UnB \\ E-mail:marisab@unb.br \\ Sonia Burnier \\ Instituto Brasileiro de Informação em Ciência e Tecnologia -Ibict \\ Bibliotecária \\ E-mail:sdesouza@Ibict.br
}

\section{Resumo}

Análise da revista Ciência da Informação, do Ibict, nas suas qualidades extrínsecas e intrínsecas. As primeiras, relativas à forma, incluem seções, padrões bibliográficos e sistema de avaliação. As características intrínsecas abrangem a análise de conteúdo dos artigos, a produtividade de autores e os padrões de autoria, tendo sido constatada tanto a sua repercussão nacional quanto internacional. O processo evolutivo da Ciência da Informação, na sua transformação para formato eletrônico, potencializou a disseminação e acesso universal à informação. Os resultados demonstram que o periódico Ciência da Informação é um espaço de discussão de temas relevantes e atuais da área, nos seus avanços, contribuindo para a consolidação e expansão da ciência da informação no Brasil. Palavras-chave

Periódico científico brasileiro Comunicação científica formal. Ciência da Informação. Análise de conteúdo. Produtividade de autores. Periódicos eletrônicos.

Information Science: 32 years (19722004) on the way of the history and the horizons of a Brazilian scientific journal

\footnotetext{
Abstract

Analysis of Information Science (Ciência da Informação) journal of lbict, in its extrinsic and intrinsic qualities. The former are related to form and include the sections, the bibliographic patterns and the refereeing system. The intrinsic characteristics cover the analysis of paper's contents, the productivity of authors and the authorship patterns. Results give evidence of its national and international repercussion. The evolution process of Information Science in its change to the electronic format accentuate the dissemination and universal access to information. Results demonstrate that the Information Science journal is a space to discuss relevant and current themes of the Area in its advancements and it contributes to the consolidation and expansion of Information Science in Brazil.

Keywords

Brazilian scientific journal. Formal scientific communication. Information Science. Content analysis. Author productivity. Electronic journals.
}

Caminante no hay camino

Se hace camino al andar

(Antonio Machado)

\section{BREVE INTRODUÇÃO HISTÓRICA SOBRE O PERIÓDICO NA COMUNICAÇÃO CIENTÍFICA}

O periódico nasceu no século XVII, em plena revolução científica, mais precisamente em 1665, tendo sido os primeiros o Journal de Sçavants e o Philosophical Transactions of the Royal Society of London (ZIMAN, 1979**, p.118). Durante mais de três séculos, passou por transformações, embora sua relevância tenha se mantido, bem como suas funções primordiais de registro, propriedade intelectual, comunicação entre pares e prestígio, continuando a ser o canal formal de comunicação científica mais importante para as comunidades de C\&T, mesmo no ciberespaço das redes eletrônicas de comunicação e informação.

Sobre o período de surgimento do periódico, Price (1976a, p.21) explicou, nos anos 70 do século XX, quando escreveu sua obra A ciência desde a Babilônia, que o desenvolvimento da ciência moderna ocorreu de forma " ordenada e regular desde o auge da revolução científica...”, tendo como centro o século XVII. Essa revolução teria sido produto da Renascença e da invenção da imprensa e sua rápida disseminação pela Europa, a partir do século XV, que desempenhou fundamental papel para o conhecimento científico.

Ainda segundo Price (1976a, p.145), o periódico científico e o artigo representam "uma das inovações mais características e notáveis da revolução científica", e o artigo científico moderno é mais um "instrumento social", e da função de propriedade intelectual decorre o seu aparecimento e manutenção (1976b, p.42).

Uma das iniciativas da ciência foi exatamente a publicação de artigos individuais curtos, pois anteriormente a forma

\footnotetext{
*Este trabalho é oriundo do projeto de pesquisa "Ciência da Informação no Brasil: historiografia de uma área do conhecimento contemporânea no cenário nacional", apoiado pelo CNPq e coordenado por Lena Vania Ribeiro Pinheiro, do Ibict. Participam, entre outros, os pesquisadores Diana F. C. Lima, da Unirio, Isa Maria Freire, do Ibict, José Mauro Matheus Loureiro, da Unirio, Marisa Brascher, da UnB, e Sonia Burnier, do Ibict, e as bolsistas Maria das Graças L. dos Santos (AP), Julia N.L. de Moraes (IC) e Aline M. Ribeiro (IC).

** Publicado, originalmente, em 1968.
} 
dominante era de livros ou publicações monográficas. Inicialmente os periódicos publicavam notícias científicas, e somente no século XIX o artigo assumiu a forma que tem hoje.

O caráter cumulativo da ciência e o crescimento exponencial de periódicos especializados e artigos em sua "regularidade extraordinária" e rara foram algumas das conclusões dos estudos de Price (1976a, p.145-46).

Foi este historiador da ciência que identificou o crescimento exponencial dos periódicos especializados e apontou, "com grande grau de precisão, que o número cresceu por um fator dez durante cada meio século", levantando importantes dados sobre esse crescimento: 10 revistas científicas a partir de 1750, 100 no início do século XIX, cerca de mil em meados desse mesmo século (XIX) e de “aproximadamente dez mil por volta de 1900". Na época em que realizou esses estudos, nos anos 70 do século XX, ele constatou, de acordo com o World List of Scientific Periodicals, que eram editados cerca de 100 mil periódicos e, por seus cálculos, para cada 100 autores existia um periódico (PRICE,1976b, p. 47 e 41).

Hoje, por acesso ao Centro Internacional do ISSNInternational Serial Standard Number (www.issn. org:8080/pub), identificou-se o total de revistas registradas (1.176.459), incluindo as de divulgação, as científicas e de outra natureza, bem como as eletrônicas. No entanto, não foi possível obter o número de periódicos científicos dentro dessa totalidade.

Sobre o volume de periódicos existentes no mundo, Wieers (1994) realiza um levantamento e faz uma projeção para os anos 2000, conforme gráfico apresentado a seguir, cujos dados são próximos aos do ISSN.

\section{GRÁFICO 1}

Volume de periódicos no mundo - 1700-2000

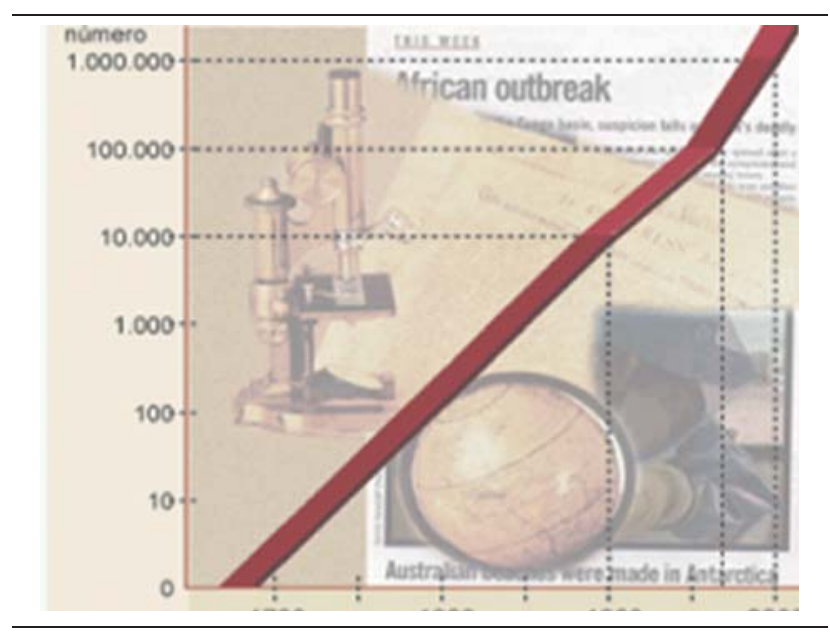

Da mesma maneira, expandiu-se a comunidade científica que, ainda segundo Price (1976 b, p.55), inicialmente era composta por poucos e conhecidos nomes, mas nos Estados Unidos, já na década de 70, chegou a mais de um milhão de pessoas com graus técnicos e científicos.

No Brasil, entre os inúmeros periódicos existentes nos mais diferentes campos do conhecimento, a revista Ciência da Informação, do Ibict, desponta na área de ciência da informação por sua tradição, regularidade e relevância reconhecida pela comunidade deste campo.

\section{OBJETIVOS E METODOLOGIA}

O objetivo do presente artigo é analisar, quantitativa e qualitativamente, o processo evolutivo da revista Ciência da Informação, nos seus aspectos formais, editoriais, de conteúdo e autoria, a fim de retraçar a sua trajetória, tendo como pano de fundo o papel do periódico para a comunidade científica e o panorama histórico brasileiro de ciência, tecnologia e do setor de informação científica e tecnológica (ICT), enfatizando tanto a sua tradição quanto a modernidade, nos parâmetros da sociedade da informação.

Entre os objetivos específicos, destacamos os seguintes:

- levantar as características formais de um periódico, artigos e outros tipos de documentos publicados, média por fascículo, páginas e padrões adotados;

- analisar a constituição dos comitês editoriais e o processo de avaliação, normas para autores e exigências do editor;

- analisar o conteúdo dos artigos publicados no periódico, identificando temas ou disciplinas abordados, como reflexo da evolução da ciência da informação no Brasil;

- identificar os autores e o padrão de autoria (individual ou coletiva), na geração de conhecimentos na área;

- verificar, por meio de sua transformação em periódico também eletrônico e sua indexação em periódicos secundários, a sua potencialidade de disseminação e acesso universal.

Na metodologia, foi definido o período de análise (de 1972, ano de criação do periódico, a 2004, fascículo 1), por ter sido o último número lançado até o final da pesquisa, correspondendo a 32 anos, ou mais de três décadas, tempo suficiente para ser traçada a trajetória da revista.

Ci. Inf., Brasília, v. 34, n. 3, p.23-75, set./dez. 2005 
A metodologia reúne critérios adotados por diferentes autores, sobretudo Braga e Oberhofer (1982), Valério (1994), Mueller et al. (1996,2001) e Krzyzanowski e Ferreira. (1998), aos quais foram acrescentados novos parâmetros, principalmente os relativos à universalização de acesso.

A análise foi desdobrada em dois conjuntos de dados: o primeiro relativo a aspectos de forma ou extrínsecos e o segundo, aos de conteúdo ou intrínsecos. Entre os primeiros, foram analisadas seções, idiomas do título, textos, resumos, descritores (se incluídos ou não), editores, comitês editoriais, avaliadores, datas de aceitação dos trabalhos, normas editoriais, periodicidade, ISSN, dados bibliográficos, legendas, paginação, publicidade, tiragem, detalhes de capa, notas gerais e indexação.

A análise de características intrínsecas privilegiou os temas ou assuntos de caráter e estrutura científicos, originados de pesquisas, portanto, artigos ( no total de 552), além de 40 estudos, assim denominados os artigos em determinado período e um opinion paper, perfazendo 593 artigos estudados. Não foram analisadas as seções intituladas comunicações, fórum, artigos de revisão, especial, além de relatos de experiência, documentos, sistemas e serviços de informação, anexos, apresentações, cartas, editoriais, entrevistas, índices e todas as seções relativas ao mesmo, in memoriam, livros e periódicos; normas da ABNT, panoramas, recensões, resenhas e resumos de dissertações em ciência da informação, trabalhos biográficos descritivos e sem análise das idéias do biografado, além dos relativos a atividades e ações de ICT.

A análise dos temas ou da literatura da área é comumente realizada no âmbito da bibliometria, a partir de levantamento estatístico e freqüência, conforme adotado neste artigo.

Os temas foram estudados tendo por parâmetro a terminologia adotada na tese de Pinheiro (1997) que, por sua vez, foi baseada na fonte utilizada na pesquisa, o Annual Review of Information Science and Technology (Arist), com pequenas alterações ou adaptações.

No grupo de informações intrínsecas foi também incluído o estudo de autoria e de política editorial.

Os dados sobre autoria foram coletados a partir dos próprios artigos e, quando não mencionados, aparecem nas tabelas e gráficos como "não informados".

Foram considerados todos os autores que contribuíram com cada artigo da revista, e não apenas o autor principal, pois o mesmo autor pode ter produzido mais de um artigo, e nas análises aparece tanto como autor principal quanto secundário. Dessa forma, a revista, no período de 1972 a 2004, totaliza 856 ocorrências de autores. Se for considerada a contribuição de um autor apenas uma vez, a revista, em seus 32 anos de existência, contou com a colaboração de 641 autores únicos.

Para cada ocorrência de autor foram coletados os seguintes dados:

- nome: sobrenome e iniciais do nome;

- grau de formação: grau mais elevado de formação informado pelo autor: pós- doutorado, doutorado, mestrado, especialização, graduação ou nível médio;

- área de atuação: ciência da informação, informática ou outras áreas;

- instituição onde o autor desenvolve suas atividades profissionais ;

- região onde está localizada a instituição do autor;

- natureza da autoria: única ou co-autoria;

- tipo de autoria: principal ou secundária;

- país onde está localizada a instituição do autor.

As análises foram realizadas ano a ano, para maior detalhamento das informações, depois agrupadas por décadas, procedimento que visou a deixar mais claro o crescimento e evolução da revista.

\section{RELEVÂNCIA DO PERIÓDICO CIENTÍFICO}

O periódico científico, por seu relevante papel na comunicação científica, tem sido objeto de estudo, especialmente sobre metodologias de avaliação, entre os quais a dissertação de mestrado depois publicada como livro, de Valério (1994), Espelho da Ciência: avaliação do Programa Setorial de Publicações em Ciência e Tecnologia da Finep, enfocando a dinâmica interna do sistema de comunicação de ciência, estrutura editorial e funções, editores, controle de qualidade, disseminação da informação, indexação, idioma, regularidade e recursos financeiros, entre outros aspectos.

Uma das primeiras e mais conhecidas metodologias é de Braga e Oberhofer (1982), por sua vez adaptada do modelo da Unesco, para avaliação de periódicos brasileiros científicos e técnicos e direcionada sobretudo às características de forma. 
Posteriormente, outras pesquisas nessa linha e com a mesma finalidade foram realizadas, como a de Krzyzanowski e Ferreira (1998, p.166), dando continuidade e aperfeiçoando seus estudos de 1988 e 1991, e tendo por fonte a Lista de Periódicos Científicos Brasileiros Financiados pelo Conselho Nacional de Desenvolvimento Científico e Tecnológico (CNPq)/Financiadora de Estudos e Projetos (Finep) 1995/96 e o Núcleo Básico de Periódicos Científicos Brasileiros Correntes, correspondendo aos avaliados pela Fundação de Amparo à Pesquisa do Estado de São Paulo (Fapesp), em 1991, cujo objetivo foi a "atualização e refinamento crítico, no aspecto de conteúdo (mérito)", daí a sua importância.

Quanto ao fomento, instituições brasileiras do porte do CNPq e seu Programa de Apoio a Publicações Científicas, ao qual passa a integrar a Finep, a partir de 1983, com seu Programa Setorial de Publicações em Ciência e Tecnologia e, em nível estadual, a Fapesp, têm empreendido esforços para apoio sistemático de periódicos científicos brasileiros, desde que atendam e mantenham as exigências de procedimentos e critérios científicos.

A ação conjunta CNPq e Finep foi estabelecida tendo por objetivo "fazer com que, a médio prazo, o Brasil venha a ter pelo menos um periódico de prestígio internacional em cada área do conhecimento" e possibilitou o aumento do número de periódicos financiados (CNPq/SEPLAN; OLIVEIRA, apud VALÉRIO, 1994, p.23).

Editores científicos fundaram, em 1985, a Associação Brasileira de Editores Científicos (Abec) que, nos seus eventos, vem discutindo questões relativas ao periódico científico e, nas suas recomendações, tem contribuído para o padrão editorial nacional (VALÉRIO, 1994,p.26).

Outra função do periódico científico e de seus artigos é servir de fonte de informação e material de pesquisa, uma vez que, a partir de bases de dados, podem ser realizados estudos de bibliometria ou informetria (denominação estabelecida pela FID), entre os quais os de citação e fator de impacto, além de indicadores de C\&T em geral (cientometria).

No exterior, destaca-se o Institute for Scientific Information (ISI), nos Estados Unidos, responsável por indicadores dessa natureza.

No Brasil, a Scientific Eletronic Library Online (Scielo) "organiza e publica textos completos de revistas na Internet/Web, assim como produz e publica indicadores do seu uso e impacto" (PACKER et al., 1998, p.109), tendo desenvolvido metodologia com este objetivo.

\section{PERIÓDICOS CIENTÍFICOS ESTRANGEIROS E BRASILEIROS EM CIÊNCIA DA INFORMAÇÃO}

A existência, sobrevivência e consolidação de um periódico depende da produção científica no campo do conhecimento que cobre, portanto, de pesquisas e de cursos de pós-graduação, geradores do conhecimento, dos quais se originam os artigos científicos, matéria essencial de um periódico e sua característica principal.

Considerando-se que as revistas brasileiras em ciência da informação surgiram no início da década de 70, qual seria a produção anterior da área? Neves e Melo (1980) levantaram um interessante dado a respeito, indicando que na Bibliografia Brasileira de Documentação do Ibict, nos três volumes existentes no momento de sua pesquisa, abrangendo trabalhos publicados no período de 1811 a 1977, foram incluídos 5.850 documentos, dos quais " ... 2.047 (34\%) são extraídos de periódicos diversos ...”. A análise desses trabalhos oriundos de periódicos mostra que $40 \%$ correspondiam a "... levantamentos bibliográficos ou noticiários de associações e entidades ligadas à área”; portanto, não eram artigos propriamente ditos.

Reconhecendo que os Estados Unidos são o berço da ciência da informação e país no qual a área apresenta maiores avanços, além da Inglaterra, saber da situação dos periódicos estrangeiros nesses países e no exterior, em geral, contribui para melhor compreensão do ciclo de vida do periódico brasileiro estudado.

Nesse contexto, não pode deixar de ser abordada a pesquisa de Cunha (1985), na qual é feita uma análise bibliométrica dos periódicos de ciência da informação, recorrendo ao método de avaliação pelo volume de citações em publicações secundárias, adotado por diversos especialistas. Ainda que reconheçamos as limitações de análises quantitativas e que a própria autora alerte para o "grau de arbitrariedade" de pesquisa dessa natureza, além da dificuldade das fronteiras de um campo interdisciplinar, sobretudo há 20 anos, esta pesquisa tem sua importância nessa abordagem.

Há , ainda, a defasagem de tempo desse estudo, utilizando fontes de 1980: Library Literature, Library and Information Science Abstracts e Bulletin Signalétique 101: Sciences de l'Information, Documentation, mas, ainda assim, os resultados permitem uma visão do conjunto de periódicos na área e afins, naquele momento. Foram identificados 292 periódicos, devendo ser ressaltado que nem todos são científicos e especializados, uma vez que esta lista inclui, além do periódico científico propriamente dito, “ o boletim de biblioteca, a revista profissional". 
A autora (CUNHA, 1985, p.40) lista as 20 revistas mais citadas e por ela denominadas "essenciais", identificandose aqui somente as dez primeiras: Library Journal (USA), Publisher's Weekly (USA), American Libraries, Wilson Library Bulletin (USA), A B Bookman's Weekly (USA), Buch und Bibliothek (Alemanha) College and Research Libraries News (USA), Library Association Record (Inglaterra) Bulletin of the American Society for Information Science (USA) e Special Libraries (USA). Como podemos constatar, alguns não correspondem a um periódico científico, e a maioria é mais voltada à biblioteconomia, o que é confirmado por Vieira (p.42), quando lista os assuntos tratados, com maiores índices de citação: biblioteconomia (44,1\%), bibliotecas especializadas $(14,7 \%)$ e ciência da informação, apenas com 13\%.

São identificados 219 periódicos não-especializados, que transitam em vasto conjunto de áreas, disciplinas e assuntos, desde a educação, administração, comunicação / jornalismo, engenharia/energia, tecnologia, lingüística, telecomunicações, arquitetura, ciências médicas, até direitos autorais.

As características gerais desses periódicos são periodicidade trimestral, edição em língua inglesa, origem nos Estados Unidos, publicação por associações, interesse em prática profissional e ter a biblioteconomia como objeto principal (CUNHA, 1985, p.43).

Em sua tese, Pinheiro (1997), na parte da pesquisa empírica e com o objetivo de mapear o "domínio epistemológico" desse campo, ou melhor, disciplinas ou temas que a compõem, e tomando como fonte o Arist, realizou um levantamento complementar sobre os periódicos citados nos 307 artigos de revisão analisados , no período 1966 1995. Foram identificados 136 periódicos, aparecendo entre os dez (10) mais citados, naturalmente os da própria área como o Journal of American Society of Information Science and Technology (Jasist), o Information Processing and Management, o American Documentation (USA), Collection Management e Journal of Documentation (USA), mas também de áreas interdisciplinares, como Automatic Documentation and Mathematical Linguistics e Social Studies of Science. Os periódicos norte-americanos predominam com 206 citações (70\%), o que se justifica pelos avanços deste país nesse campo e também pela fonte utilizada, da mesma origem. Dentre as interdisciplinas, destacam-se a biblioteconomia, a psicologia, a ciência da computação e a comunicação, além da sociologia da ciência. $\mathrm{O}$ único periódico brasileiro citado nesse período foi a revista Ciência da Informação, uma única vez (PINHEIRO,1997)
Esses resultados foram orientados à ciência da informação, objeto da pesquisa da qual se originou (PINHEIRO,1997), e diferem dos de Cunha (1985), que utilizou fontes sobretudo de biblioteconomia e cujo levantamento foi concentrado no ano de 1980, portanto, mais antigo.

Não analisamos os trabalhos voltados à biblioteconomia, exceto o de Neves e Melo (1980), mencionado no início deste tópico, que inclui também a ciência da informação e apresenta resultados de interesse para o presente trabalho. O próprio título do artigo dessas autoras, "Revistas brasileiras de Biblioteconomia e Documentação na década de 70", evidencia o enfoque essencialmente nessa área.

No estudo de Neves e Melo (1980), a revista Ciência da informação é reconhecida por divulgar, “... de preferência, trabalhos inéditos de pesquisadores brasileiros ou estrangeiros, nos campos teórico e prático da ciência da informação"; e dos 95 artigos publicados no período estudado, 16,8\% correspondem a dissertações de mestrado. Este dado comprova a relação e importância da pósgraduação na geração de conhecimento em qualquer área e nos leva a relembrar que o nascimento desse periódico ocorreu dois anos após a institucionalização do Mestrado em Ciência da Informação, no Ibict.

No Brasil, até 1996 existiam seis periódicos em ciência da informação e áreas afins, conforme pesquisa de Mueller, Campelo e Dias (1996), os mais antigos, o do Ibict e o da Universidade Federal de Minas Gerais (UFMG), o último atualmente denominado Perspectivas de Ciência da Informação.

Sobre a dificuldade de manutenção de periódicos científicos, é oportuno destacar que, no levantamento em que se baseou esse artigo, inicialmente foram identificados 32 periódicos em ciência da informação e também biblioteconomia, dos quais a maioria era constituída por boletins de notícias e revistas desativadas.

Posteriormente, foram lançados periódicos direcionados à ciência da informação, abrangendo áreas correlatas, sendo incluídos no quadro 1 aqueles de caráter científico, isto é, que apresentem comitês editoriais, recorram à avaliação pelos pares e sejam correntes. Estes critérios excluem os boletins informativos ou de notícias e publicações de associações profissionais, bem como os desativados. Por este motivo, não faz parte do quadro o Informare, lançado em 1995 pelo Programa de Pós-graduação em Ciência da Informação, do Ibict, na ocasião em convênio com a Universidade Federal do Rio de Janeiro (UFRJ), editado até 2000 e hoje suspenso. 
QUADRO 1

Periódicos científicos brasileiros em ciência da informação

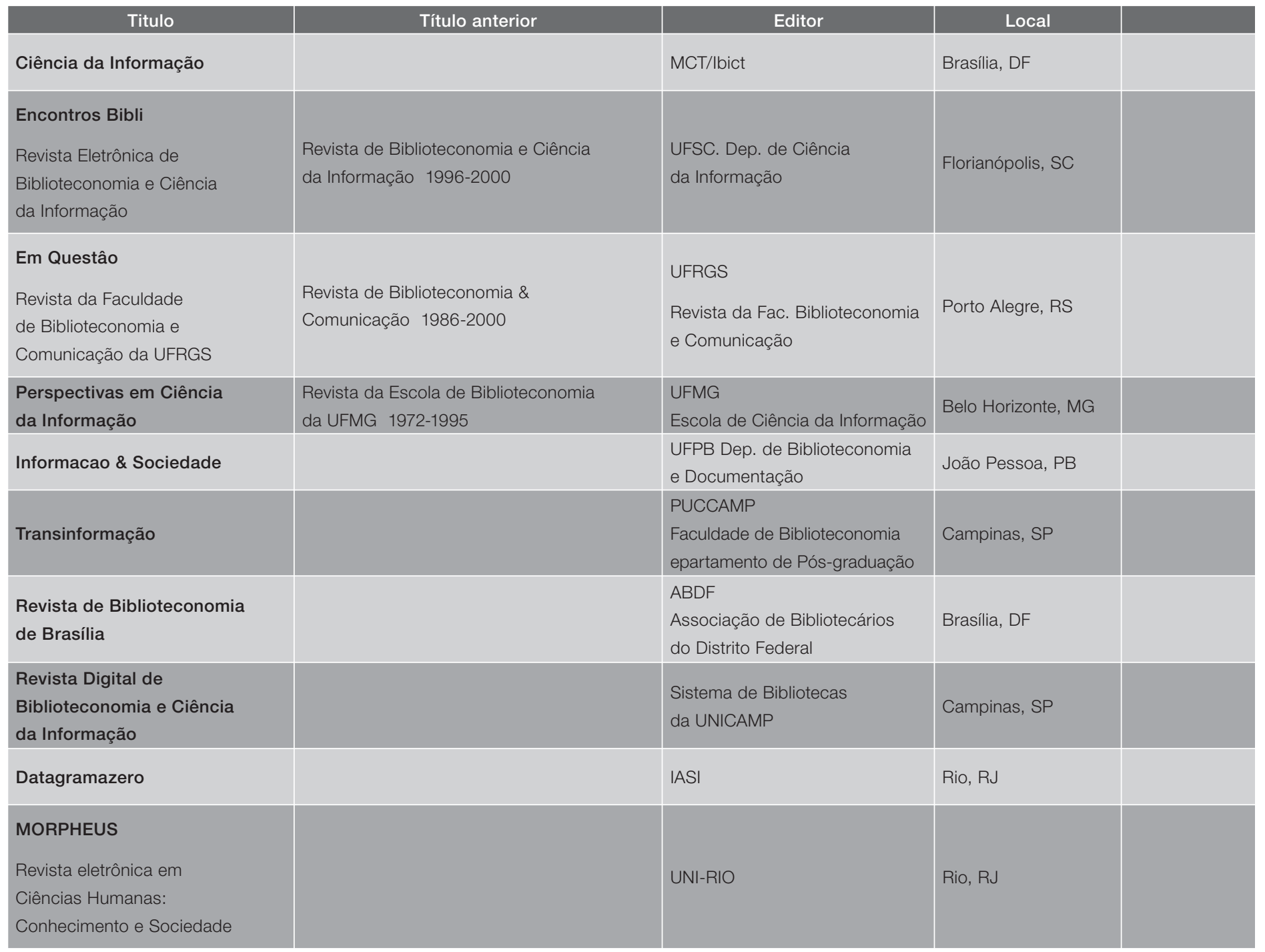

Conforme verificamos, a metade (50\%) dos periódicos é editada na região Sudeste, no Sul e Nordeste, dois (20\%) em cada região, e apenas um (10\%) periódico no Nordeste.

Se cronologicamente agrupados, esses periódicos mostram o seguinte resultado: dois foram lançados nos anos 70, um na década de 80 , quatro na seguinte, de 90 , e três a partir de 2000. Esses dados indicam a expansão da área pois, além das quatro revistas iniciadas na década de 90, em cinco anos (2000-2004) três novos periódicos surgiram.

Entre os mais recentes estão o DatagramaZero, lançado em 1999, periódico eletrônico do Instituto de Adaptação e Inserção na Sociedade da Informação (IAS), tendo à frente o professor Aldo Barreto, e a Revista Digital de Biblioteconomia e Ciência da Informação, publicada a partir de julho de 2003, pelo Sistema de Bibliotecas da Unicamp.
Esta, embora não vinculada a órgão de pesquisa ou pósgraduação, adota critérios de um periódico científico, com processo de avaliação e conselho editorial constituído por professores e pesquisadores da área.

Além destes, há ainda o periódico Morpheus, editado pela Coordenadoria de Educação a Distância da Universidade Federal do Estado do Rio de Janeiro (UNI-RIO), de natureza científica acadêmica, "optando pela interdisciplinaridade e pela multiculturalidade”.

Portanto, atualmente os pesquisadores e especialistas em ciência da informação dispõem de dez periódicos científicos dedicados à área, dos quais quatro dotam $o$ software livre Sistema Eletrônico de Editoração de Revistas (Seer), que será abordado no tópico $\mathrm{O}$ "admirável mundo novo” de um periódico brasileiro (p. 49). 
Ciência da Informação: 32 anos (1972-2004) no caminho da história e horizontes de um periódico científico brasileiro

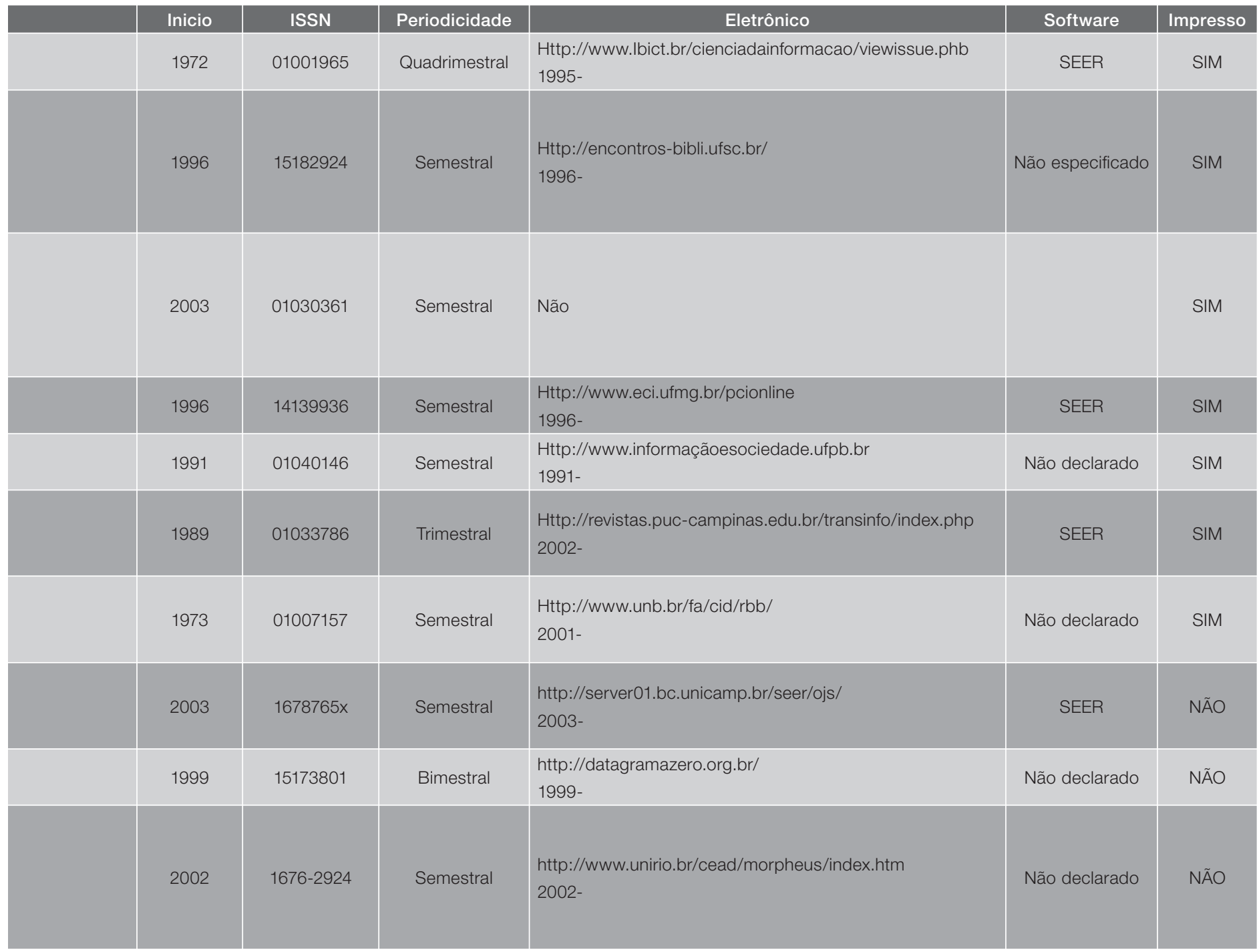

\section{PERIÓDICO CIÊNCIA DA INFORMAÇÃO}

Quais as circunstâncias históricas do Brasil, especificamente de ciência e tecnologia, que propiciaram o lançamento do periódico Ciência da informaçãa?

Nos anos 60, algumas transformações no panorama de C\&T brasileiras ocorreram e são apontadas por Araújo (1985), entre as quais a "... preocupação com o desenvolvimento da produção mediante a utilização de C\&T produzidas no Brasil", a implantação da Fundação de Amparo à Pesquisa do Estado de São Paulo (Fapesp) e a mudança do Distrito Federal para Brasília, no Centro-Oeste, com "nova separação espacial das estruturas de produção e de poder".

Segundo levantamento do próprio Ibict (apud ARAÚJO, 1986), na década de 70 (ano de 1978) foram identificadas as instituições de informação científica e tecnológica (ICT), concentradas na região Sudeste (67\%), sendo $35,3 \%$ no Rio de Janeiro e 21\% em São Paulo, enquanto no Centro-Oeste 23,2\% estavam no Distrito Federal, o que pode ser explicado pela transferência, para Brasília, de inúmeras instituições e mesmo de acervos. Portanto, o nascimento da revista no Rio de Janeiro ocorreu na cidade onde estava localizado o IBBD/Ibict e a maioria das entidades de ICT nacionais, e depois de $80 \mathrm{em}$ Brasília, com a transferência do instituto para a nova capital do país.

É oportuno mencionar, nesse panorama, a concentração de instituições executoras de pesquisa também no Sudeste, no total de 213 , correspondendo a $49,2 \%$, das quais 89 situavam-se no Rio de Janeiro e 87 em São Paulo (CNPq/ SELAP,1984, apud ARAÚJO, 1985). 
A década de 70, com todos os impasses e restrições decorrentes do golpe militar de 64, ao mesmo tempo e de forma contraditória "...gerou espaço para o desenvolvimento dos sistemas de informação científica e tecnológica e para a criação de novos cursos de pós-graduação em biblioteconomia, dentro da ideologia de 'informação para o desenvolvimento nacional', professada, então, pela elite governamental" (VIEIRA, 1995).

De acordo com resultados da dissertação de Oliveira (1989) sobre as revistas apoiadas pelo CNPq e Finep, no período de 1980-1985, a maioria surgiu na década de 70, e os editores são sobretudo instituições de pesquisa ou ensino.

A fundação do Instituto Brasileiro de Bibliografia e Documentação (IBBD), em 1954, e suas iniciativas de vanguarda, entre as quais a pós-graduação da área, representam marcos da história da informação científica e tecnológica (ICT), no Brasil, e são reconhecidas por diversos autores, inclusive Vieira (1995).

Não podemos esquecer que o movimento que conduziu à criação do IBBD teve inspiração na Unesco e intermediação da Fundação Getúlio Vargas. Sua transformação em Ibict foi influenciada pelo Unisist e os Centros Nacionais de informação Científica (Natis), diretrizes introduzidas pela Unesco nos países em desenvolvimento na América Latina.

A inclusão da informação científica e tecnológica nas políticas públicas nacionais ocorre de forma gradativa e tem início nos anos 70, com os Planos Básicos de Desenvolvimento Científico e Tecnológico (PBDCTs) e Planos Nacionais de Desenvolvimento (PNDs). O período é caracterizado por ações de planejamento governamental (MIRANDA, 1977), fase em que o Instituto Brasileiro de Bibliografia e Documentação (IBBD) passou a se denominar Instituto Brasileiro de Informação em Ciência e Tecnologia (Ibict), em 1976, assumindo papel político e de coordenação, e não somente de gerador de produtos e serviços de ICT, como no início.

Na década seguinte, as funções do Ibict foram expandidas, inclusive atribuído importante papel de órgão nacional de informação, coordenador das atividades de ICT em território brasileiro.

A revista Ciência da Informação foi lançada em 1972, pelo então IBBD, dois anos depois do início do Mestrado em Ciência da Informação do Ibict, iniciativa pioneira na América Latina e no Ano Internacional do Livro, o que mereceu chamada de capa.

Hagar Espanha Gomes (1996), em entrevista registrada no fascículo comemorativo dos 25 anos da revista do Ibict, descreve as circunstâncias de sua criação, afirmando que "a idéia estava no ar", o IBBD em "momento de efervescência", com o mestrado em ciência da informação e primeiros projetos de pesquisa na área. Ela atribui à Célia Zaher, presidente do instituto naquela ocasião, a "fonte de energia", e ao computador, a "mola propulsora" da criação da revista. Desde o primeiro fascículo, atuou uma comissão editorial, da qual participavam a própria Hagar, Laura Maria de Figueiredo, Gilda Braga e Maria Beatriz Pontes de Carvalho. Sobre o assunto, a entrevistada explica que foram os conhecimentos de sociologia da ciência que orientaram a constituição da revista, mais tarde incorporados à disciplina comunicação científica, por ela introduzida no mestrado, e na qual são estudados os periódicos, suas funções, estrutura, processo de avaliação, entre outros aspectos. $\mathrm{O}$ mestrado do Ibict foi decisivo, segundo Hagar E. Gomes, pelo contato com pesquisadores estrangeiros que se tornaram professores da pós-graduação do Ibict, na década de 70, identificados em tópico posterior deste artigo (Natureza da utoria e perfil dos autores, p.38), e pela relação entre pós-graduação, pesquisa e produção do conhecimento, conforme já ressaltado.

A revista Ciência da Informação participa do Programa de Apoio à Publicação Científica (SCT/PR, CNPq, Finep, MCT) desde 1991, quando foi instituído, até hoje, embora nos anos 2000 a informação sobre esse apoio não apareça registrada na revista, o que volta a ocorrer a partir de 2004.

Este periódico é um dos produtos do Ibict consolidados, tendo superado as diferentes crises político-institucionais do instituto, que ocasionaram descontinuidade e desativação de atividades.

\section{CORPO E ALMA DO PERIÓDICO CIÊNCIA DA INFORMAÇÃO OU QUALIDADES INTRÍNSECAS E EXTRÍNSECAS}

Neste tópico, de acordo com os objetivos geral e específicos já descritos, o periódico Ciência da Iinformação será analisado em dois conjuntos de características, as primeiras, extrínsecas, relativas à forma, e as demais correspondendo aos aspectos intrínsecos ou de conteúdo.

\section{AsPeCtOS EXTRÍNSECOS OU DE FORMA}

Foram analisados os 32 anos da revista Ciência da Informaçãa, nos seus 33 volumes, com total de 75 fascículos e 593 artigos, em uma trajetória de crescimento ininterrupto, o que demonstra o comprometimento do Ibict com a área da ciência da informação (quadro 2). 
Ciência da Informação: 32 anos (1972-2004) no caminho da história e horizontes de um periódico científico brasileiro

QUADRO 2

Distribuição de volumes, fascículos e artigos por período

\begin{tabular}{|l|c|c|c|}
\hline Período & Volumes & Fascículos & Artigos \\
\hline $1972-1979$ & 8 & 15 & 86 \\
\hline $1980-1989$ & 10 & 19 & 109 \\
\hline $1990-1999$ & 10 & 28 & 250 \\
\hline 2000-2004 (1) & 5 & 13 & 148 \\
\hline TOTAL & 33 & 75 & 593 \\
\hline
\end{tabular}

Nos aspectos extrínsecos, foram levantados 20 itens de informação dentro dos tradicionalmente selecionados para avaliação de um periódico científico e suas variações conceituais ou terminológicas. Os itens estão explicitados na metodologia e aqui serão analisados por conjuntos de informação, reunidos por suas características comuns.

Neste grupo, destacam-se as seções do periódico, mostradas no quadro 3.

Conforme o quadro 3, levantou-se o total de 972 documentos incluídos nas diversas seções da revista, que vão desde os artigos, que representam a essência do periódico e seu caráter científico, aos índices, revisões, entre outros, totalizando 22 tipos de seções. Observando essa diversidade, que se acentua nos anos 90 e, em menor escala, na década de 80 , verificamos a falta de padronização na estrutura da revista e na terminologia, como, por exemplo, resenhas e recensões que abrigam o mesmo tipo de conteúdo, portanto, são semelhantes, bem como apresentação e editorial, que têm a mesma função e para a qual deveria ser adotado o termo editorial, enquanto apresentação é própria de livros. Isso não significa que o periódico não passe por nenhuma modificação, ao longo dos anos, nem possa ser criada uma nova seção, mas o desejável é que mantenha um padrão estrutural e terminológico que, inclusive, identifique-o.

O caso mais sério é a substituição, durante certo período da década de 80 , de artigos por estudos, equívoco depois corrigido. Assim, aos artigos (552) devem ser somados os estudos (40), além de um opinion paper, totalizando 593 artigos (61\%). No entanto, observou-se um crescimento acentuado de relatos de experiências na década de 90 , em um total de 69 (27,6\%), o que pode comprometer um

\section{QUADRO 3}

\section{Distribuição de seções no periódico Ciência da Informação}

\begin{tabular}{|c|c|c|c|c|c|}
\hline Seções & $1972-1979$ & 1980-1989 & 1990-1999 & $2000-2003$ & Total \\
\hline 01. Anexo & & & 01 & & 01 \\
\hline 02. Apresentação & & 01 & & & 01 \\
\hline 03. Artigos * & $86^{\star}$ & $69^{*}$ & $249^{*}$ & $148^{*}$ & $552^{*}$ \\
\hline 04. Cartas & & 04 & 02 & & 06 \\
\hline 05. Charter of book & 01 & & & & 01 \\
\hline 06. Comunicação & 09 & 07 & 35 & 04 & 55 \\
\hline 07. Documento & & 05 & 27 & 01 & 33 \\
\hline 08. Editorial & 01 & 02 & 27 & 07 & 37 \\
\hline 09. Entrevista & & & 04 & 01 & 05 \\
\hline 10. Especial & & & 03 & & 03 \\
\hline 11. Estudos & & $40^{*}$ & & & $40^{*}$ \\
\hline 12. Fórum & & 08 & & & 08 \\
\hline 13. Índice & & & 01 & & 01 \\
\hline 14. Livros e periódicos & & 02 & & & 02 \\
\hline 15. Panorama & 13 & 11 & & & 24 \\
\hline 16. Ponto de vista & & & $01^{*}$ & & $01^{*}$ \\
\hline 17. Recensões & & 25 & 45 & 08 & 78 \\
\hline 18. Relato experiência & & 14 & 69 & 07 & 90 \\
\hline 19. Resenhas & 23 & & & & 23 \\
\hline 20. Resumos de teses/dissertações & 02 & & & & 02 \\
\hline 21. Revisões & & 03 & & & 03 \\
\hline 22. Sistemas e serviços & & 06 & & & 06 \\
\hline Total de indexados * & $86^{*}$ & $\begin{array}{c}109^{*} \\
69+40=109\end{array}$ & $\begin{array}{c}250^{*} \\
249+1=250\end{array}$ & $148^{*}$ & $593^{*}$ \\
\hline Total & 135 & 197 & 464 & 176 & 972 \\
\hline
\end{tabular}


periódico científico, no qual o núcleo são os artigos e as demais seções têm função complementar.

Uma das seções tem denominação muito genérica (documento), embora explicitado pelas normas da revista:"compreende textos inéditos ou não, que se referem a aspectos históricos, documentos não convencionais de circulação limitada, resultados de análise e levantamento sobre o setor de informação, elaborados por iniciativa de diferentes instituições, relatórios de consultoria etc." Ainda assim, é difícil o enquadramento de trabalhos nessa categoria, tanto por autores quanto editores, e, em geral, poderiam ser inseridos em outras seções existentes na revista, principalmente relatos de experiência. Afinal, todas as seções contêm documentos e, por todos os motivos explicitados, esta categoria poderia ser excluída.

Algumas seções resultaram de decisões institucionais. Em 1981, o então diretor do Ibict, Afrânio Aguiar, em editorial, para tornar mais atraente e diversificada a revista, anuncia mudanças em sua estrutura, entre as quais a criação de novas seções, como Fórum. Este deveria abrigar "temas de interesse geral", que deveriam ser discutidos por profissionais de informação, tendo praticamente a mesma função do ponto de vista (opinion paper).

Podemos constatar, a partir de 2000 , menor quantidade de seções, agora numericamente equilibradas: documento, comunicação, relato de experiência recensão, editorial e entrevista.

Estas seções devem ser definidas pelo editor e comissão editorial e constar das normas da revista, de forma a orientar, claramente, autores e editores.

Quanto às normas e padrões editoriais, a ciência da informação, desde o seu primeiro número, inclui sumário, informações sobre a periodicidade, ficha catalográfica, legenda bibliográfica, instituição editora e créditos institucionais. Consta o local de edição que, conforme já mencionado, inicialmente era o Rio de Janeiro (19721979) e posteriormente Brasília, até hoje.

A data de recebimento do artigo é um dado que aparece, irregularmente, nos fascículos de 1972-1973 (1),19871988 (1), 1991-1994 (1), 1995 (2-3)-1996(1-2), 2000 (3), 2001(3),2002 e 2003(2). A revista deveria manter regularidade na indicação dessa data, para assegurar a prioridade intelectual do autor.

Uma alteração importante, que traduz a evolução da revista e também o crescimento da produção científica da área, é a passagem de periodicidade semestral, seguida até 1991, para quadrimestral, a partir de 1992.
É oportuno destacar que a Ciência da Informação tem mantido a regularidade de sua publicação e apenas duas vezes foram lançados fascículos cumulativos: no ano de 1976, com o v. 5, números 1 e 2 e, em 1980, quando foi editado o v. 9 , números 1 e 2 .

No entanto, ocasionalmente houve atrasos, o que é apontado por Mueller e colaboradores (1996, p.343)

O Número Internacional Normalizado para Publicações Seriadas (ISSN), em inglês "International Standard Serials Number”, foi atribuído à revista Ciência da Informação em 1976. Sua função é assegurar o registro único de cada publicação seriada ( jornais, revistas, anuários, relatórios, monografias seriadas etc.) em circulação, futuras (prépublicações) e encerradas, em qualquer idioma ou suporte físico utilizado (impresso, on-line, CD-ROM etc.), em base de dados internacional, identificando-a internacionalmente e possibilitando o intercâmbio bibliográfico ( http://www. ibic.br/secao.php?cat=ISSN ).

O uso do ISSN é definido pela norma técnica da International Standards Organization - ISO 3297, operacionalizado por uma rede, cujo centro internacional fica em Paris, sendo no Brasil representado pelo Ibict, membro único em nosso país, que atua, desde 1975, como centro nacional dessa rede.

A média de artigos por fascículo é de 8,2. A revista anteriormente não estabelecia o número mínimo ou máximo de páginas por artigo, mas, nas normas dos fascículos atuais, limita a 20 laudas.

Mueller e colaboradores (1996), em artigo já citado, levantaram a média de páginas entre 20 e 30, nos periódicos brasileiros de ciência da informação e biblioteconomia. Nesse mesmo estudo, o número médio de artigos por fascículo na revista do Ibict é de 12, sendo recebidos por ano cerca de 50, dos quais são aprovados anualmente 36 e rejeitados 15 (30\%).

Com base na distribuição de volumes, fascículos e artigos mostrados no quadro 2 deste artigo, verificamos o crescimento de número de artigos por fascículo, a saber: nas décadas de 70 e 80, 5,7 artigos, nos anos 90, 8.9, e de 2000 a 2004 ( até o fascículo 1), a média de 11,3 artigos por fascículo. Este resultado pode indicar que a produção científica da área cresceu, fato também constatado pela passagem da periodicidade do periódico Ciência da Informação de semestral para quadrimestral, em 1992, e comentada neste tópico.

A taxa de rejeição da revista do Ibict é baixa, se comparada à identificada por Miranda e Pereira (1996, p.379), nas 
ciências sociais e comportamentais, que alcança 80\%, o que as autoras pensam ocorrer também por falta de espaço nos periódicos, por sua vez decorrente de ausência de apoio financeiro governamental para publicações periódicas nessas áreas, ressaltando que artigos em economia e sociologia são 30\% mais longos do que em outras áreas. Estas observações são pertinentes e oportunas, uma vez que a ciência da informação faz parte das ciências sociais aplicadas.

Quanto a idiomas, os títulos dos artigos sempre foram publicados na língua original e, a partir do volume 14, número 1, de 1985, passou a ser incluído o título em inglês, assim aparecendo também no sumário. Já o texto é publicado apenas no idioma original, enquanto os resumos foram editados sempre em português e em inglês.

Sobre o idioma dos descritores, a partir de 1977 (número 2) eles são apresentados em português, procedimento que perdura até 1985 (volume 14, número2), quando os descritores são suprimidos, até 1990 ( v.19, número 2). De 1991 (volume 20, número 1) em diante, os descritores passam a ser em português e inglês.

Ressaltamos que o resumo em inglês facilita a disseminação e visibilidade dos artigos, bem como a sua indexação em publicações secundárias, assunto tratado, nesta pesquisa, no tópico Potencial de disseminação e universalização do acesso (p.47). A publicidade merece ser abordada, porque, em determinado período, dos anos 70 aos 90, havia divulgação dos próprios serviços e produtos do Ibict, além dos de outras instituições. Esta função certamente orientava instituições de ICT, o que está em consonância com o papel do instituto, de órgão nacional de ICT, que tanto desenvolve pesquisa quanto dissemina serviços e produtos de informação como apoio ao desenvolvimento da ciência e tecnologia nacionais.

Esta importância dada aos serviços de informação estava refletida no fornecimento de fichas analíticas dos artigos publicados (de 1972 a 1985), inseridas no final da revista e prontas para serem recortadas e armazenadas e assim integrarem os catálogos. Naturalmente, com os processos de automação e a produção de bases de dados, esta função passou a ser das bibliotecas que adquirem a revista. No entanto, poderia ser oferecido o mesmo serviço em uma forma adaptada e atualizada, adotando recursos da moderna tecnologia. Por exemplo, estando a revista disponível na rede, no momento de download poderia haver a opção para o fornecimento da referência bibliográfica do artigo para ser incluído em qualquer bibliografia ou para importação de dados, em formatos variados.

Sobre aspectos econômicos, como tiragem, este dado não estava disponível na revista até 2001, quando passou a ser divulgado. Esta informação seria básica para estudos de custo - benefício, principalmente considerando que a revista tem versões impressa e eletrônica.

A capa da revista foi padronizada durante muitos anos, até 1990, tendo de 1972 a 1976 um determinado padrão estético e, de 1977 a 1990 (v.19,n.1), uma capa listrada representado a compactação de solo que corresponderia à sedimentação da ciência da informação. A partir de 1990, no v.19, n.2, a capa deixou de ser padronizada e passou a ser ilustrada com imagens relacionadas à temática do fascículo (ver anexo 1).

Algumas revistas científicas mantêm a capa padronizada, como forma de identificação, como, por exemplo, a Scientific American, a Lancet e o American Journal of Medicine, entre muitas outras.

Um resumo das principais características extrínsecas da revista Ciência da Informação pode ser observado no quadro. 4

\section{Política editorial E PRocesso de AVAliação}

A política editorial de um periódico científico é, basicamente, determinada pela instituição editora, pelo editor científico e o comitê editorial e, entre diferentes aspectos, devem ser levados em conta os avanços da área e questões emergentes.

O papel dos participantes do comitê editorial é central, e entre os seus requisitos constam a titulação de doutor, o conhecimento da área e a experiência em pesquisa. No processo de avaliação, são assessorados por pares, que desempenham a função de avaliadores (referees).

Miranda e Pereira (1996) resumem a escolha do comitê editorial à sua excelência acadêmica.

Na Ciência da Informação, cada trabalho passa pela avaliação de dois especialistas e, no caso de pareceres discordantes, um terceiro avaliador é convocado. Para cada fascículo, os membros do comitê editorial fazem a seleção final de trabalhos que o comporão e, para tal decisão, podem consultar os pareceres de avaliadores. Em nenhuma fase desse processo, os autores dos artigos são identificados, da mesma forma que os nomes dos avaliadores são omitidos ao serem enviados os pareceres aos autores.

A política editorial se manifesta de diferentes maneiras, inclusive na definição de números especiais, temáticos ou comemorativos, a seguir descritos. 
Números especiais:

- 1973, v.2, n.1, dedicado ao 7ํㅡㄹ Congresso Brasileiro de Biblioteconomia e Documentação, realizado em Belém, no ano de 1973;

- edição comemorativa dos 20 anos do mestrado em ciência da informação (1990, v.19, n.32);

- 40 anos do Ibict e índice da Ciência da Informação, 1972-1993, (1994,v.23,n.1);

- 25 anos da Pós-graduação do Ibict (1995, v.24, n.1);
- 25 anos da revista Ciência da Informação (1996, v.25, n.3);

- 45 anos do Ibict (1999, v.28, n.1).

Dos números temáticos, iniciados em 1991, o primeiro foi sobre informação tecnológica (1991, v.20, n.1), seguido de universidade/empresa (1991, v.20, n.2), meio ambiente (1992, v.21, n.1), Mercosul (1993, v.22, n.1), saúde - Aids (1993, v.22, n.3), terminologia (1995, v.24, n.3, com apoio da União Latina), informação tecnológica (1996, v.25, .1), biblioteca virtual (1997, v.26, n.2, tendo a colaboração do Grupo de Trabalho sobre Bibliotecas Virtuais, do Comitê Gestor da Internet) e rumo à publicação eletrônica ( 1998, v.27, n.2).

QUADRO 5

Comissão Editorial da revista Ciência da Informação (1995/1998)

\begin{tabular}{|c|c|c|c|c|c|}
\hline Profissional & Instituição & 1995 & 1996 & 1997 & 1998 \\
\hline Abel Laerte Parker & BIREME & & & & $x$ \\
\hline Afranio Carvalho Aguiar & FAPEMIG & $x$ & & & \\
\hline Aldo de Albuquerque Barreto & IBICT/DEP & & $x$ & & \\
\hline Ana Beatriz Zoss & ASTROLAB & & $x$ & & \\
\hline Antonio Carvalho de Miranda & UNB & & & $x$ & $x$ \\
\hline Cavan Michael McCarthy & UFPB & & & $x$ & $x$ \\
\hline Dinah Poblacion & USP & & & $x$ & $x$ \\
\hline Edson Nery da Fonseca & UNB & $x$ & & & \\
\hline Enilde Falstick & UNB & $x$ & & & \\
\hline Flavio Petersen & S/vínculo & & $x$ & & \\
\hline Helena Maria Lastres & IBICT/DEP & $x$ & & & \\
\hline Ilce Gonçalves Milet Cavalcanti & IBICT/DEP & $x$ & & & \\
\hline Irati Antonio & UFPB & & & & $x$ \\
\hline Jose Teixeira Coelho Netto & USP/ECA & $x$ & & & \\
\hline Kira Tarapanoff & UNB & $x$ & & & \\
\hline Lena Vania Ribeiro Pinheiro & IBICT/DEP & & $x$ & $x$ & $x$ \\
\hline Luiz Antonio Gonçalves & $\mathrm{IBICT}$ & & & $x$ & \\
\hline Maria de Nazaré Freitas Pereira & IBICT/DEP & $x$ & & & \\
\hline Monina Rapp & UFRJ & & $x$ & & \\
\hline Neusa Dias de Macedo & USP/ECA & $x$ & & & \\
\hline Regina Marteleto & IBICT/DEP & $x$ & & & \\
\hline Rosali Fernandez de Souza & IBICT/DEP & & $x$ & & \\
\hline Ruth Steinberg & S/vínculo & & $x$ & & \\
\hline Solange Puntel Mostafa & PUCCAMP & & & & $x$ \\
\hline Vanda Paranhos & UFPR & & & $x$ & $x$ \\
\hline Vania Maria Rodrigues Hermes de Araújo & SENAI/CIET & & & $x$ & $x$ \\
\hline Vera Sílvia Marão Beraquet & PUCCAMP & & & & $x$ \\
\hline
\end{tabular}

Fonte: IBICT. GT 15 - Serviços de informação e publicações para especialistas em ICT. Relatório final. Rio de Janeiro, Brasília, maio de 2001 
A partir de 2000, foi lançado apenas um número especial sobre a sociedade da informação $(2000, v .29$, n.2), o que deixou a revista mais aberta às diferentes questões da ciência da informação. Fascículos dedicados a determinado tema, desde que não seja um procedimento freqüente, permitem abordar assuntos emergentes e de importância para a área, como, por exemplo, bibliotecas virtuais e publicações eletrônicas.

Conforme constatamos, esses números temáticos e especiais estão também relacionados às comemorações de eventos da história do Ibict, à sua política, programas e projetos. Este é o caso de informação tecnológica e universidade/empresa, durante a administração de José Rincon Ferreira, fortemente voltada à informação tecnológica e industrial.

Os componentes do comitê editorial nem sempre são identificados institucionalmente, na página de créditos da ciência da informação, dado que seria importante analisar. Esta ausência foi apontada por Mueller e Pecegueiro (2001), que, baseadas nos dados disponíveis e informações obtidas, identificaram três instituições predominantes ( Ibict-UFRJ, USP e UnB), além da UFMG, em números mais antigos. Observamos que estas instituições são as que oferecem cursos de pós-graduação há mais tempo e dispõem de programas, portanto, incluem doutorado.

Relatório de um grupo de trabalho do Ibict (2001) também identificou os membros do comitê editorial, no período de 1995 a 1998, mostrados no quadro 5.

Do total de 27 especialistas do comitê, 20 (74\%) são oriundos de universidades ou institutos de pesquisa. Destes, 8 (29,6\%) estão vinculados ao Ibict.

O editor científico de uma revista, conforme tradição em C\&T, deve ser um pesquisador de excelência acadêmica, reconhecido nacionalmente por seus pares, tanto que esta função é considerada uma honra. $\mathrm{O}$ editor institucional da Ciência da Informação, como bem sabemos, é o Ibict, e aparece na revista apenas um editor responsável pela publicação, não havendo identificação de editor científico. Esta omissão pode ter ocorrido pela não-distinção entre “editor", responsável intelectual, e o "publisher", que cuida da editoração, papéis diferenciados em língua inglesa, enquanto no Brasil esses termos são compreendidos como sinônimos.

A revista Ciência da Informação, no âmbito de sua política editorial, inclui, em todos os seus fascículos, impressos e eletrônicos, instrução ou normas editoriais aos autores, desde o seu primeiro fascículo, até 1979, em português e inglês, somente em português nas décadas de 80 e 90 e, a partir de 2000, volta a adotar os idiomas português e inglês nessas informações.

Por ser uma revista aberta a autores estrangeiros, inclusive publicando na sua língua original, o que será analisado em tópico específico, este deveria ser um procedimento mantido. Especificamente sobre o inglês, não pode deixar de ser destacado que a produção científica em ciência da informação ocorre majoritariamente nesse idioma, uma vez que os países de maior avanço da área são os Estados Unidos e a Inglaterra.

Reconhecendo-se que o idioma da ciência é o inglês e a importância de contribuições de pesquisadores de outros países, a ausência de normas para autores nessa língua é uma limitação à sua participação e à internacionalidade da revista.

\section{Aspectos INTRínsecos OU DE CONTEÚdo}

Este tópico reúne a análise e discussão de resultados, desdobradas em dois conjuntos: dos temas de artigos e de autoria. O primeiro corresponde ao conteúdo dos artigos da revista, identificando temas ou questões da ciência da informação pesquisados em nosso país e publicados no periódico. Estes resultados serão comparados com os de Pinheiro (1997, 2002), sobre a ciência da informação no exterior, no que a autora denominou domínio epistemológico e delimitações internas da área, adotando o Arist como fonte, permitindo refletir o estágio de desenvolvimento e atualidade da área, no Brasil, e sua inserção na sociedade da informação.

A análise dos resultados sobre autoria indicará os padrões de produção do conhecimento e características dos especialistas e pesquisadores da área.

\section{QUESTÕES OU TEMAS ABORDADOS NOS ARTIGOS}

Na geração de conhecimentos em ciência da informação, a temática dos artigos do periódico estudado é reflexo do estágio e evolução desta área, com indicadores de suas tendências e até novas disciplinas que possam surgir, daî a importância do seu estudo.

Ziman (1979, p. 118) afirmava que "o carimbo de aprovação de uma nova disciplina é o aparecimento de uma revista especialmente dedicada aos interesses de seus expoentes. Ela representa um ato de solidariedade e confraternidade e polariza o assunto".

O mapeamento dos temas, no período estudado, é apresentado no quadro 6 , a seguir, e o seu detalhamento pode ser visto nos anexos 2 a 11 . 


\section{QUADRO 6}

Freqüência de temas de artigos da Ciência da Informação distribuídos por décadas

\begin{tabular}{|c|c|c|c|c|c|c|c|c|c|c|}
\hline Temas & \multicolumn{2}{|c|}{$1972-79(\%)$} & \multicolumn{2}{|c|}{$1980-89(\%)$} & \multicolumn{2}{|c|}{$1990-99 \%(\%)$} & \multicolumn{2}{|c|}{ 2000-04 (\%) } & \multicolumn{2}{|c|}{ Total (\%) } \\
\hline 1. Teoria da ciência da informação & 4 & 4,65 & 8 & 7,33 & 23 & 9,2 & 14 & 9,45 & 49 & 8,26 \\
\hline 2. Bibliometria & 18 & 20,93 & 11 & 10,09 & 14 & 5,6 & 5 & 3,37 & 48 & 8,09 \\
\hline 3. Representação da informação & 8 & 9,3 & 9 & 8,25 & 15 & 6 & 14 & 9,45 & 46 & 7,75 \\
\hline 4. Políticas de informação & 3 & 3,48 & 11 & 10,09 & 12 & 4,8 & 17 & 11,48 & 43 & 7,25 \\
\hline 5.Necessidades e usos de informação & 6 & 6,97 & 9 & 8,25 & 16 & 6,4 & 11 & 7,43 & 42 & 7,08 \\
\hline 6. Gestão da informação & 2 & 2,32 & 7 & 6,42 & 25 & 10 & 7 & 4,72 & 41 & 6,91 \\
\hline 7. Comunicação científica & 7 & 8,13 & 10 & 9,17 & 12 & 4,8 & 10 & 6,75 & 39 & 6,57 \\
\hline 8.Tecnologias da informação & - & & 1 & 0,91 & 18 & 7,2 & 18 & 12,16 & 37 & 6,23 \\
\hline 9. Formação e aspectos profissionais & 6 & 6,97 & 9 & 8,25 & 15 & 6 & 4 & 2,7 & 34 & 5,73 \\
\hline 10. Sistemas e redes de informação & 6 & 6,97 & 6 & 5,5 & 17 & 6,8 & 3 & 2,02 & 32 & 5,39 \\
\hline 11. Disseminação da informação & 4 & 4,65 & 7 & 6,42 & 16 & 6,4 & 4 & 2,7 & 31 & 5,22 \\
\hline 12. Sistema de recuperação da informação & 4 & 4,65 & 2 & 1,83 & 6 & 2,4 & 9 & 6,08 & 21 & 3,54 \\
\hline 13. Bibliotecas virtuais / digitais & - & & - & & 6 & 2,4 & 11 & 7,43 & 17 & 2,86 \\
\hline 14. Inteligência competitiva & - & & - & & 8 & 3,2 & 5 & 3,37 & 13 & 2,19 \\
\hline 15. Política de ciência e tecnologia & - & & 3 & 2,75 & 7 & 2,8 & 2 & 1,35 & 12 & 2,02 \\
\hline 16. Bases de dados & 3 & 3,48 & 4 & 3,66 & 2 & 0,8 & 2 & 1,35 & 11 & 1,85 \\
\hline 17. Organização e processamento da informação & 6 & 6,97 & 1 & 0,91 & 1 & 0,4 & 2 & 1,35 & 10 & 1,68 \\
\hline 18. Economia da informação & - & & 2 & 1,83 & 5 & 2 & 2 & 1,35 & 09 & 1,51 \\
\hline 19. Biblioteconomia/bibliotecas/livros & 2 & 2,32 & 3 & 2,75 & - & & 2 & 1,35 & 07 & 1,18 \\
\hline 20. Arquivologia & - & & - & & 6 & 2,4 & - & & 06 & 1,01 \\
\hline 21. Processamento automático da linguagem & 1 & 1,16 & 1 & 0,91 & 4 & 1,6 & - & & 06 & 1,01 \\
\hline 22. Automação de biblioteca & 2 & 2,32 & 1 & 0,91 & 2 & 0,8 & 1 & 0,67 & 06 & 1,01 \\
\hline 23. Divulgação científica & - & & 1 & 0,91 & 2 & 0,8 & 1 & 0,67 & 04 & 0,67 \\
\hline 24. Ciência e tecnologia & - & & - & & 3 & 1,2 & - & & 03 & 0,5 \\
\hline 25. Gestão do conhecimento & - & & - & & - & & 3 & 2,02 & 03 & 0,5 \\
\hline 26. Política editorial & 2 & 2,32 & 1 & 0,91 & - & & - & & 03 & 0,5 \\
\hline 27. Sistemas especialistas & - & & - & & 2 & 0,8 & & & 02 & 0,33 \\
\hline 28. Comunicação social & & & & & 2 & 0,8 & & & 02 & 0,33 \\
\hline 29. Imprensa & & & & & 2 & 0,8 & & & 02 & 0,33 \\
\hline 30. Lingüística & & & & & 2 & 0,8 & & & 02 & 0,33 \\
\hline 31. Tecnologias & & & & & 2 & 0,8 & & & 02 & 0,33 \\
\hline Temas com freqüência 1 no somatório geral & 2 & 2,32 & 2 & 1,83 & 5 & 2 & 1 & 0,67 & 10 & 1,68 \\
\hline Total & 86 & 100 & 109 & 100 & 250 & 100 & 148 & 100 & 593 & 100 \\
\hline
\end{tabular}

Desde o seu início, a temática da revista Ciência da Informação reflete bem as questões da área e, de um modo geral, as pesquisas desenvolvidas no Brasil estão direcionadas aos mesmos temas estudados no exterior, aparecendo diferenças de ênfase, por circunstâncias históricas, sociais e científicas nacionais. Além disso, não podemos deixar de mencionar a preocupação com a própria área, refletida na maior incidência de artigos teóricos sobre a ciência da informação, em um total de 49.

Os temas de maior freqüência, nos artigos da revista brasileira, também estão presentes nas pesquisas de Pinheiro $(1997,2002)$ sobre a área no exterior, variando apenas a ordem de freqüência: sistemas de informação, tecnologia da informação, sistemas de recuperação da informação, políticas de informação, necessidades e usos de informação, representação da informação, teoria da ciência da informação. Assim, os resultados nos permitem afirmar que, no exterior, os temas com enfoque tecnológico predominam, enquanto no Brasil têm maior incidência os de caráter teórico, de gestão da informação, político e de transferência da informação, conforme podemos constatar no quadro 6.

Na análise por décadas, ficam mais evidentes as influências locais. No caso da década de 70, o predomínio da bibliometria pode ser explicado pela atuação do Mestrado em Ciência da Informação do Ibict, no qual um de seus professores estrangeiros e autoridade das mais respeitadas 
internacionalmente até hoje, Tefko Saracevic, introduz a bibliometria. Conseqüentemente, são iniciadas pesquisas nesse tema, aparecem as primeiras dissertações, professores brasileiros tornam-se especialistas em bibliometria, entre os quais se destaca Gilda Braga, que dará continuidade às pesquisas nessa linha no Brasil e, por sua vez, formará novas gerações de estudiosos em bibliometria. (URBIZAGÁTEGUI ALVARADO, 1983).

Chama atenção, já nessa década, a identificação de assuntos de ponta, como processamento automático de linguagem e segurança da informação, além de comunicação científica, outro tema de grande incidência de artigos.

Se compararmos estes resultados com os de Neves e Melo (1980), referentes a revistas brasileiras na década de 70, incluindo a revista Ciência da Informação, verificaremos que, ainda com enfoques e metodologia diferentes e guardando terminologias distintas, há algumas coincidências entre os temas mais freqüentes: sistemas de informação (freqüência 34), bibliometria (31), disseminação seletiva da informação (18), ciência da informação (11). Estudos de usuários, que no presente artigo são incluídos em necessidades e usos de informação, alcançaram freqüência 14; classificação, indexação e catalogação, na atual pesquisa reunidas em representação da informação, aparecem com freqüências altas, a primeira com 16, a segunda com 10, e catalogação, com 7 .

Na década de 80 , os principais temas se mantêm, embora com variações de freqüência, e aparecem novos, entre os quais gestão da informação. Ao mesmo tempo, assuntos relativos ao contexto de $C \& T$, como políticas de ciência e tecnologia são objeto de artigos, fato explicável pela ênfase em informação científica e tecnológica (ICT).

Outra comparação pode ser feita com os resultados de Foresti (1986), ainda que as categorias tenham sido estabelecidas com parâmetros diferentes e a terminologia tenha se modificado nesses quase 20 anos que separam as duas pesquisas. Sistemas de informação, bibliometria, política de ICT e teoria da própria área, por exemplo, que estão entre os temas de maior incidência no estudo de Foresti, também aparecem com alta freqüência nos resultados do presente artigo.

Na década de 80 , os temas de maior freqüência, no total de 11, são bibliometria e política de informação, seguidos de comunicação científica (freqüência 10) e representação da informação e formação e aspectos profissionais, ambos com freqüência 9. Portanto, a bibliometria continua a ser foco de pesquisa, bem como a comunicação científica, que apresenta regularidade em todas as décadas e recentemente tem sido estudada à luz das novas tecnologias.
Na década de 90, a gestão da informação assume o índice mais alto (25), seguida de teoria da ciência da informação (23), ganhando espaço maior as tecnologias da informação (freqüência 18) e sistemas e redes de informação (freqüência 17). A gestão da informação e estes dois últimos temas são decorrência da nova era da sociedade da informação e, particularmente no Brasil, da implantação da Rede Nacional de Pesquisas (RNP), que proporcionou a infraestrutura tecnológica necessária para a operacionalização da Internet/Web em território nacional. Não poderia deixar de ser mencionada a emergência de novos temas, como inteligência competitiva e bibliotecas digitais / virtuais.

Em análise da temática de artigos da revista Ciência da Informação, na década de 90, já citada, Mueller e Pecegueiro (2001), baseadas em tabela produzida em dissertação de mestrado de Teixeira (1997), adaptada, chegaram a dois grandes temas predominantes: entrada, armazenamento, recuperação e disseminação da informação $(30,70 \%)$ e estudos de usuários, transferência e usos de informação e uso de bibliotecas $(29,87 \%)$. As autoras utilizaram os cabeçalhos mais amplos da tabela e reconhecem a abrangência desses temas, o que pode explicar a incidência maior de artigos em ambos.

A análise comparativa com resultados do Library and Information Science Abstracts (Lisa), publicação secundária e fonte de caráter distinto ao da nossa pesquisa, apresenta terminologia (descritores) diferente e, como as próprias autoras apontam, motivam dúvidas sobre a sua compatibilidade e, conseqüentemente, validade (MUELLER; PECEGUEIRO,2001). Ainda assim, é possível perceber a convergência de resultados, mostrada nos temas mais pesquisados, apresentados em ordem decrescente de freqüência, aos quais introduzimos, entre parênteses, a terminologia correspondente à adotada no presente artigo: entrada, tratamento e armazenamento (representação da informação e organização e processamento da informação) ; estudo de usuários, transferência e uso (necessidades e usos de informação); estudo da literatura e do documento (bibliometria); organização e gerência de atividades de informação (gestão da informação); ciência da informação e biblioteconomia (teoria da ciência da informação).

Observamos, ainda, que a terminologia do Lisa algumas vezes está mais próxima da biblioteconomia do que da ciência da informação, e este é o caso de processos técnicos e prédios de bibliotecas, assuntos não muito freqüentes, mesmo na biblioteconomia brasileira. Pode ser citado, como exemplo raro, o Seminário Nacional de Bibliotecas Universitárias (SNBU), de 1989, que dedicou uma sessão especialmente à arquitetura de bibliotecas. 
Na década de 90, constatamos, ainda, dispersão maior de assuntos do que em outras décadas, reunidos nas freqüências 2 e 1, a maioria relativa ao setor, como bibliotecas, livros, literatura e imprensa, além de áreas interdisciplinares entre as quais biblioteconomia, ciência cognitiva, administração, comunicação social e arquivística, esta com freqüência maior, 6, além de disciplinas emergentes, neste caso, mineração de dados.

Para compreender melhor a dispersão da revista, apresentamos os temas que apareceram uma única vez no período estudado, não identificados no quadro, no total de 10 , por ordem alfabética e respectivas décadas em que foram publicados: administração $(90 / 00)$, ciência cognitiva (90/00), design (90/00), educação (90/00), literatura infantil (80/00), mineração de dados $(90 / 00)$, pós-modernismo (80/00), saúde pública $(90)$, segurança da informação (70) e sociologia da ciência (90).

Assim, a dispersão na revista Ciência da Informação não teria exatamente o sentido da Lei de Bradford adotado para produtividade de periódicos, mas refletiria aspectos de contexto e do setor de ICT e de interdisciplinaridade, relativos à natureza epistemológica da área de ciência da informação.

Finalmente, reforçando a atualidade da revista Ciência da Informação, podemos concluir com o mapeamento de artigos referentes ao período de 1998 a 2000 (Ibict, 2000): inteligência competitiva e gestão do conhecimento foram o tema predominante, juntamente com sistemas serviços de informação e bases de dados, ambos com freqüência 15, seguidos de bibliotecas virtuais / digitais (14) e bibliometria / cientometria e indicadores, com freqüência 12 (anexo 12).

O procedimento metodológico desse mapeamento foi semelhante ao adotado neste artigo, com a diferença de identificar temas mais específicos ( ver anexo 12), enquanto na presente pesquisa correspondem a disciplinas, portanto, mais amplos (quadro 6).Um exemplo que pode clarificar esta explicação é o resultado referente a periódicos científicos e eletrônicos ( anexo 12), que na pesquisa atual estão englobados em comunicação científica. É oportuno ressaltar a incidência de estudos sobre periódicos, atualmente englobando os eletrônicos, inclusive sobre a própria revista Ciência da Informação, comentário ao qual retornaremos.

\section{NATUREZA DA AUTORIA E PERFIL DOS AUTORES}

$\mathrm{Na}$ análise de tipo de autoria, isto é, se o artigo foi produzido por um único autor (autoria individual ou autoria única) ou em co-autoria (em colaboração com outros autores), constatamos, no quadro 5 e gráfico 1 , que a autoria única predominou nas três primeiras décadas da revista, com um número mais elevado nas décadas de 70 e $80,77,2 \%$ e $79,3 \%$, respectivamente. Na década de 90, há equilíbrio entre autores individuais, 199 (56,4\%), e coletivos, 154 (46,6\%). Nos primeiros anos de 2000, a tendência é de produção em co-autoria, com 192 (68,3\%), havendo decréscimo na autoria única (31,7\%).

Mueller e Pecegueiro (2001) identificaram, em artigo mencionado anteriormente, a predominância da autoria individual ou única $(78,23 \%)$, nos anos 90 , enquanto a co-autoria correspondeu a $21,77 \%$, sendo a maioria de dois autores. Esta proporção, segundo as autoras, coincide com os resultados dos encontros da Associação Nacional de Pesquisa e Pós-Graduação (Ancib)/ Encontro Nacional de Pesquisa em Ciência da Informação (Enancib): em 1994 (50\% de autores escrevendo sozinhos, e 50\% em colaboração); em 1995, 77,19\% de autores individuais e $22,81 \%$ coletivos; no ano de $1997,70,15 \%$ de autoria individual e 29,85\% de co-autoria; 2000, 75,20\% de autores individuais, e coletivos, $24,80 \%$.

Esta análise comparativa mostra resultados distintos, sobretudo em relação aos trabalhos da Ancib, pois a tendência na presente pesquisa é de aumento de autoria coletiva, conforme previu Solla Price, em estudos analisados no gráfico 2.

\section{QUADRO 7}

Tipo de autoria por década - 1972 a 2004

\begin{tabular}{|l|c|c|c|c|c|c|c|c|c|c|}
\hline Natureza & $1972-1979$ & $\%$ & $1980-1989$ & $\%$ & $1990-1999$ & $\%$ & $2000-2004$ & $\%$ & Total geral & $\%$ \\
\hline Autoria única & 78 & 77,2 & 96 & 79,3 & 199 & 56,4 & 89 & 31,7 & 462 \\
\hline Co-autoria & 23 & 22,8 & 25 & 20,7 & 154 & 43,6 & 192 & 68,3 & 394 & 46 \\
\hline Total geral & 101 & 100 & 121 & 100 & 353 & 100 & 281 & 100 & 856 & 100 \\
\hline
\end{tabular}

* Os números dizem respeito a autores /autorias, e não a artigos. 


\section{GRÁFICO 2}

Tipo de autoria por década - 1972 a 2004

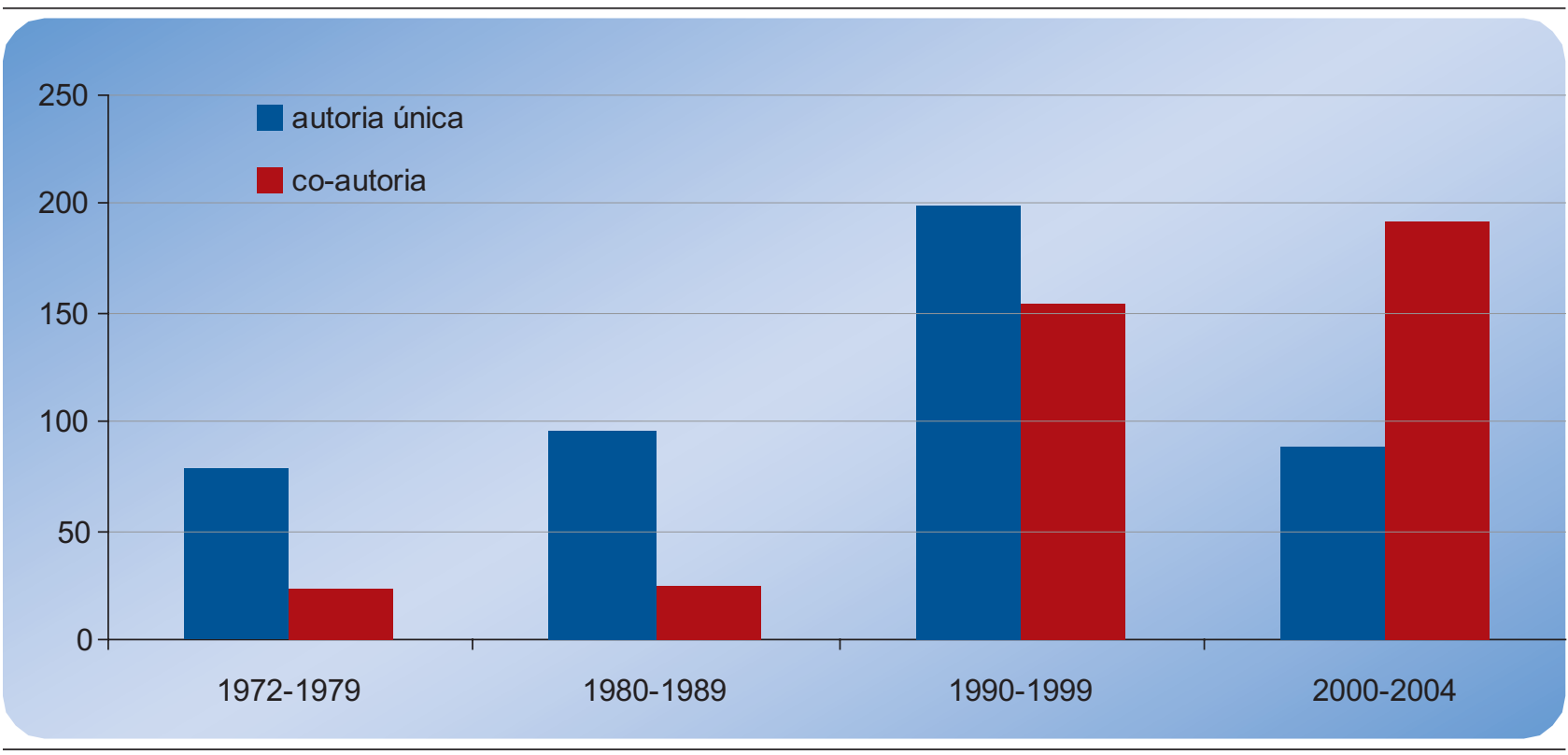

Já na década de 60 do século passado, Solla Price ( 1976, p.55) constatara que "a incidência do trabalho científico em colaboração "(...) tem aumentado continuamente e de modo cada vez mais rápido", de forma "vertiginosa" a partir do início desse século, a tal ponto que ele chega a prever que, "se for mantido o presente ritmo, ao redor de 1980 desaparecerão os artigos de autoria única”. Suas observações têm como base o Chemical Abstracts, e uma das constatações foi de que a maioria desses trabalhos em colaboração tinha como autores professores e seus doutorandos.
Solla Price (1976, p.55) destaca exemplo inusitado na matemática: de um grupo de 10 a 20 eminentes matemáticos, a maioria franceses, que produziram uma coleção de tratados sobre matemática superior, sem indicação de seus respectivos nomes e todos identificados pelo "maior pseudônimo matemático do mundo, Nicolas Bourbaki" ou, como ele chama, "policéfalo".

Miranda e Pereira (1996, p.377), em artigo mencionado antes, citam um estudo bibliométrico de Gupta (1986) sobre autores no campo da Aids, no qual $75 \%$ de autoria são

\section{QUADRO 8}

\section{Doze (12) autores mais produtivos}

\begin{tabular}{|l|c|c|c|}
\hline Autor & Autoria única (individual) & Co-autoria (em colaboração) & Total geral \\
\hline Araujo,V.M.R.H. de & 8 & 1 & 9 \\
\hline Figueiredo,N.M. de & 8 & 1 & 9 \\
\hline Gómez,M.N.G. de & 8 & & 8 \\
\hline Cunha,M.B.da & 5 & 2 & 7 \\
\hline Freire,I.M. & 5 & 2 & 7 \\
\hline Barreto,A. de A. & 6 & 2 & 6 \\
\hline Mueller,S.P.M. & 4 & 5 & 6 \\
\hline Borges,M.E.N. & 1 & & 5 \\
\hline Dusoulier,N. & 5 & & 5 \\
\hline Fonseca,E.N.da & 5 & & 5 \\
\hline Vieira,A.daS. & 5 & 1 & 5 \\
\hline Tarapanoff,K. & 4 & 380 & 778 \\
\hline Outros (1) & 398 & 394 & 856 \\
\hline Total (2) & 462 & & 5 \\
\hline
\end{tabular}

Obs: (1) Outros: correspondem ao total de autores que produziram menos de cinco artigos, isto é, os de freqüências 4, 3, 2 e 1.

(2) Total: corresponde ao conjunto de autorias de todos os autores no período observado. 
coletivas, o que é atribuído ao interesse de pesquisadores e aumento do financiamento para pesquisa nessa área por parte dos governos.

Não podemos deixar de chamar a atenção sobre as diferenças e especificidades de padrões de comunicação científica, nos diversos campos do conhecimento.

Considerando as autorias únicas (individuais) e coautorias (trabalhos em colaboração), são identificados os autores mais produtivos (quadro 8), mostrados no anexo 13 em termos percentuais, bem como a relação completa de todos os autores que contribuíram com artigos para a revista Ciência da Informação, até a freqüência 1, constantes do anexo 14. Nesta relação, diferentemente do quadro 8, estão incluídas as autorias principais e secundárias. Estes autores que escreveram uma única vez (freqüência 1) na revista, durante o período analisado, não devem ser confundidos com os de autoria única, ou melhor, individual.

Nesta pesquisa, foram identificados, nas autorias coletivas ou co-autorias, também os autores principais (primeiro autor) e os colaboradores (segundo, terceiro, quarto autores, e assim em diante), não analisados no presente artigo.

Entre os autores mais produtivos predomina a autoria única, exceto no caso de Borges, M. E. N. , com uma autoria individual e cinco co-autorias e, no grupo, entre os doze, cinco autores sempre escreveram como autores individuais. Portanto, nesse conjunto de autores mais produtivos, não se observa a tendência apontada por Solla Price, de artigos em colaboração, embora o gráfico 1 , de análise geral de autorias, mostre o crescimento de co-autorias e, nos anos 2000-2004, o predomínio de artigos em colaboração, de acordo com os estudos de Solla Price.

Nos resultados em percentuais, fica patente a inexistência de um autor ou autores que concentrem grande volume de artigos, e a dispersão, ou melhor, a multiplicidade de autorias, é bastante acentuada, conforme pode ser constatado na mencionada listagem completa de produtividade de autores, identificando autorias principais e secundárias, mostradas no anexo 14 .

A síntese da freqüência de produtividade de autores é apresentada no quadro 9.

O número acentuado de autores que escreveram uma vez apenas ( freqüência 1), durante os 32 anos da revista analisados, mostra a diversidade de autorias e a abertura da revista à comunidade de ciência da informação em geral, sem traços endogênicos.
QUADRO 9

Síntese de produtividade de autores / autorias*

\begin{tabular}{|c|c|}
\hline Número de autores & Número de autorias \\
\hline 2 & 9 \\
\hline 1 & 8 \\
\hline 2 & 7 \\
\hline 3 & 6 \\
\hline 5 & 5 \\
\hline 10 & 4 \\
\hline 25 & 3 \\
\hline 82 & 2 \\
\hline 494 & 1 \\
\hline
\end{tabular}

*Os números não se referem a artigos, e sim a autorias.

Sobre a formação dos autores, no periódico Ciência da Informação este dado não foi identificado na primeira década da revista (100\% não informados), bem como continuou ausente em vários artigos de décadas posteriores, apresentando um total de 364 (42,52\%) autores cuja formação não foi registrada.

Na segunda década, de 80 , apenas 17,35\% dos autores trazem informações sobre a sua titulação. Já na década de 90 e nos primeiros anos de 2000, constatamos maior preocupação com a qualificação de autores, que passa a ser registrada com maior freqüência na revista, ficando apenas 30,87\% (década de 90) e 19,21\% (a partir de 2000) de autores sem este tipo de dado. Portanto, embora o problema persista, vem gradativamente sendo superado, e a revista deve solicitar aos autores esta importante informação e mantê-la como norma.

A análise de nível de formação, como demonstra o gráfico 3, revela que o maior percentual, $21,03 \%$, é de autores com mestrado, seguido de $19,86 \%$ dos que são doutores, $1,52 \%$ que se especializaram e 14,14\% com graduação. Apenas 0,47\% dos autores realizaram pós-doutoramento. Pelo cruzamento dos dados, foi possível identificar que, dos 0,47\% de autores com nível médio, todos são de autoria secundária.

A contribuição de autores que obtiveram título de pósgraduação stricto sensu totaliza 41,36\% em relação ao total, o que indica que a revista, como os periódicos científicos em geral, é um importante veículo de disseminação das atividades de pesquisa, no caso do periódico estudado, desenvolvidas no campo da ciência da informação.

Não por acaso, a revista Ciência da Informação, conforme já enfatizamos, surge dois anos após a criação do primeiro mestrado nessa área no Brasil e na América Latina, em 1970, implantado pelo Ibict e com mandato acadêmico da UFRJ, justamente na década em que a pós-graduação brasileira teve grande crescimento. 
Ciência da Informação: 32 anos (1972-2004) no caminho da história e horizontes de um periódico científico brasileiro

GRÁFICO 3

Formação de autores de artigos no período 1972-2004

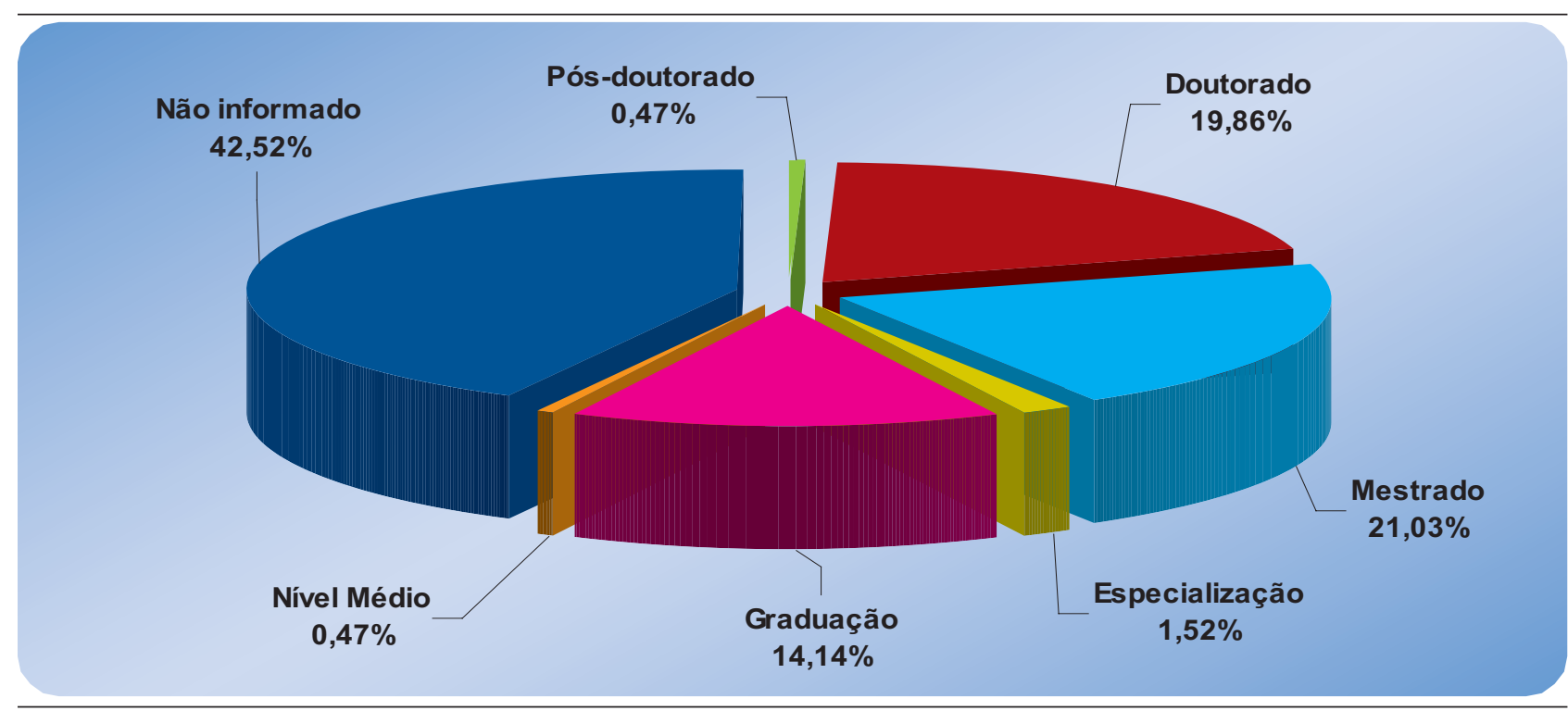

Em 1985, Hagar Espanha Gomes, ex-diretora do IBBD e antiga editora da revista, afirmava que, entre os seus objetivos, estavam a divulgação de resultados de projetos do instituto, a maioria em automação, e trabalhos de interesse para o mestrado, ressaltando que os meios de comunicação existentes até então eram anais de congressos (apud FORESTI, 1986).

A formação acadêmica dos autores, importante dado para análise da revista, inicialmente não era informada e foi um dado que gradativamente mereceu registro, conforme é mostrado no quadro 10, no qual pode ser constatado o predomínio de mestres, seguidos de doutores.
Quanto aos autores por área de atuação, identificada com base em suas vinculações institucionais e mostrada no quadro 11 , verifica-se que a maioria provém da ciência da informação e áreas correlatas, em um total de 564 (65,88\%). A contribuição de autores de outras áreas totaliza 154 $(17,99 \%)$, sendo $41(4,7)$ de informática. Não foi possível identificar a área de atuação de 97 autores (11,33\%).

Em estudo de caso relativo à revista da UFMG, no artigo de Mueller et al. (1996) citado antes, foram identificados $62 \%$ de professores das áreas de ciência da informação e biblioteconomia, entre os autores dos artigos de periódicos por eles estudados.

QUADRO 10

Autores com formação em Biblioteconomia ou titulação em Ciência da Informação

\begin{tabular}{|c|c|c|c|c|c|c|c|c|c|c|}
\hline Década & 1972-1979 & $\%$ & 1980-1989 & $\%$ & 1990-1999 & $\%$ & $2000-2004$ & $\%$ & Total geral & $\%$ \\
\hline Pós-doutorado & & $0,0 \%$ & & $0,0 \%$ & 2 & $0,8 \%$ & & $0,0 \%$ & 2 & 0,4 \\
\hline Doutorado & & $0,0 \%$ & 2 & $2,4 \%$ & 60 & $25,1 \%$ & 56 & $33,7 \%$ & 118 & 20,9 \\
\hline Mestrado & & $0,0 \%$ & 14 & $16,9 \%$ & 77 & $32,2 \%$ & 41 & $24,7 \%$ & 132 & 23,4 \\
\hline Especialização & & $0,0 \%$ & & $0,0 \%$ & 1 & $0,4 \%$ & 5 & $3,0 \%$ & 6 & 1,1 \\
\hline Graduação & & $0,0 \%$ & 3 & $3,6 \%$ & 33 & $13,8 \%$ & 44 & $26,5 \%$ & 80 & 14,2 \\
\hline Nível Médio & & $0,0 \%$ & & $0,0 \%$ & & $0,0 \%$ & 2 & $1,2 \%$ & 2 & 0,4 \\
\hline Não informado & 76 & $100,0 \%$ & 64 & $77,1 \%$ & 66 & $27,6 \%$ & 18 & $10,8 \%$ & 224 & 39,7 \\
\hline Informação Total & 76 & $100,0 \%$ & 83 & $100,0 \%$ & 239 & $100,0 \%$ & 166 & $100,0 \%$ & 564 & $100,0 \%$ \\
\hline
\end{tabular}

QUADRO 11

Produção de autores por área de atuação

\begin{tabular}{|l|c|c|c|c|c|}
\hline Década & Ciência da Informação Total & Informática Total & Outras Total & Não informado Total & Total Período \\
\hline $1972-1979$ & 76 & 1 & 6 & 18 & 101 \\
\hline $1980-1989$ & 83 & 3 & 15 & 20 & 121 \\
\hline $1990-1999$ & 239 & 9 & 69 & 36 & 353 \\
\hline $2000-2004$ & 166 & 28 & 64 & 23 & 281
\end{tabular}


Analisando-se a contribuição das áreas por período, no gráfico 3, observa-se que, de 2000 a 2004, muito naturalmente a contribuição da ciência da informação predomina, mas há aumento de autores de outros campos, inclusive informática. Este fato pode ser explicado pela própria interdisciplinaridade da ciência da informação, qualidade reconhecida desde o seu surgimento e sobre a qual há consenso por parte de especialistas e pesquisadores. De acordo com Saracevic (1992, 1999), entre os campos do conhecimento de relação interdisciplinar com a ciência da informação, a ciência da computação se destaca, juntamente com a biblioteconomia, comunicação e ciência cognitiva, que inclui inteligência artificial. este eminente teórico ressalta também a "complementaridade" entre ciência da informação e ciência da computação, representada por aplicações de computadores e computação na recuperação da informação, além de produtos, serviços e redes.

A forte interdisciplinaridade entre essas duas áreas é também evidenciada nos resultados desta pesquisa, nos quais aparecem com índices de freqüência significativos os temas tecnologias da informação, sistemas e redes de informação, sistemas de recuperação da informação e bibliotecas virtuais / digitais, entre outros de índice menor, como bases de dados, processamento automático de linguagem e automação de bibliotecas (item Questões ou temas abordados nos artigos, p.35, e quadro 6)

Não podemos deixar de considerar que, sob a égide da sociedade da informação, caracterizada pela globalização e novas tecnologias de informação e comunicação, sobretudo a Internet/Web, disciplinas de cunho tecnológico ganharam ainda mais relevância.
Para a análise da contribuição à revista, por parte dos cursos de pós-graduação de ciência da informação, que corresponde a $26,7 \%$ do total de autores, foram considerados apenas os cursos reconhecidos pela Capes em 2004, à exceção da ECA/USP, uma vez que este curso, em área dentro do programa de comunicação, tem seus professores entre os autores de artigos.

Este Programa, não credenciado na última avaliação, foi novamente reconhecido pela Capes, agora especificamente em ciência da informação. Entretanto, ainda não está incluída a UFF, porque o convênio com o Ibict foi assinado no final de 2003, e por enquanto não gerou produção acadêmica na pós-graduação. A autoria só foi considerada como oriunda da pós-graduação quando o autor informou ser professor ou aluno do curso.

No gráfico 5, observamos que a pós-graduação que apresenta maior número de artigos na revista é a do Ibict/UFRJ, com 82 autores (9,6\% do total), seguida pela da UnB, com 53 autores (6,2\%), da UFMG, 46 autores (5,4\%), da USP, 24 autores (2,8\%), da Puccamp, 11 autores $(1,3 \%)$, da UFSC, 8 (0,9\%), UFBA, com $3(0,4 \%)$ e Unesp com $1(0,1 \%)$ autor.

Nestes resultados deve ser considerado o tempo de existência dos programas e cursos de pós-graduação, o que também interfere. Assim, programas mais antigos, como do Ibict/UFRJ (1970), USP/ECA (1972), UFMG (1976), Puccamp (1977) e UnB (1978), contribuíram por um período mais longo do que os cursos mais novos, exceto o da UFPB, implantado em 1977 e hoje não credenciado.

GRÁFICO 4

Produção de autores - 1972 a 2004, por área de atuação

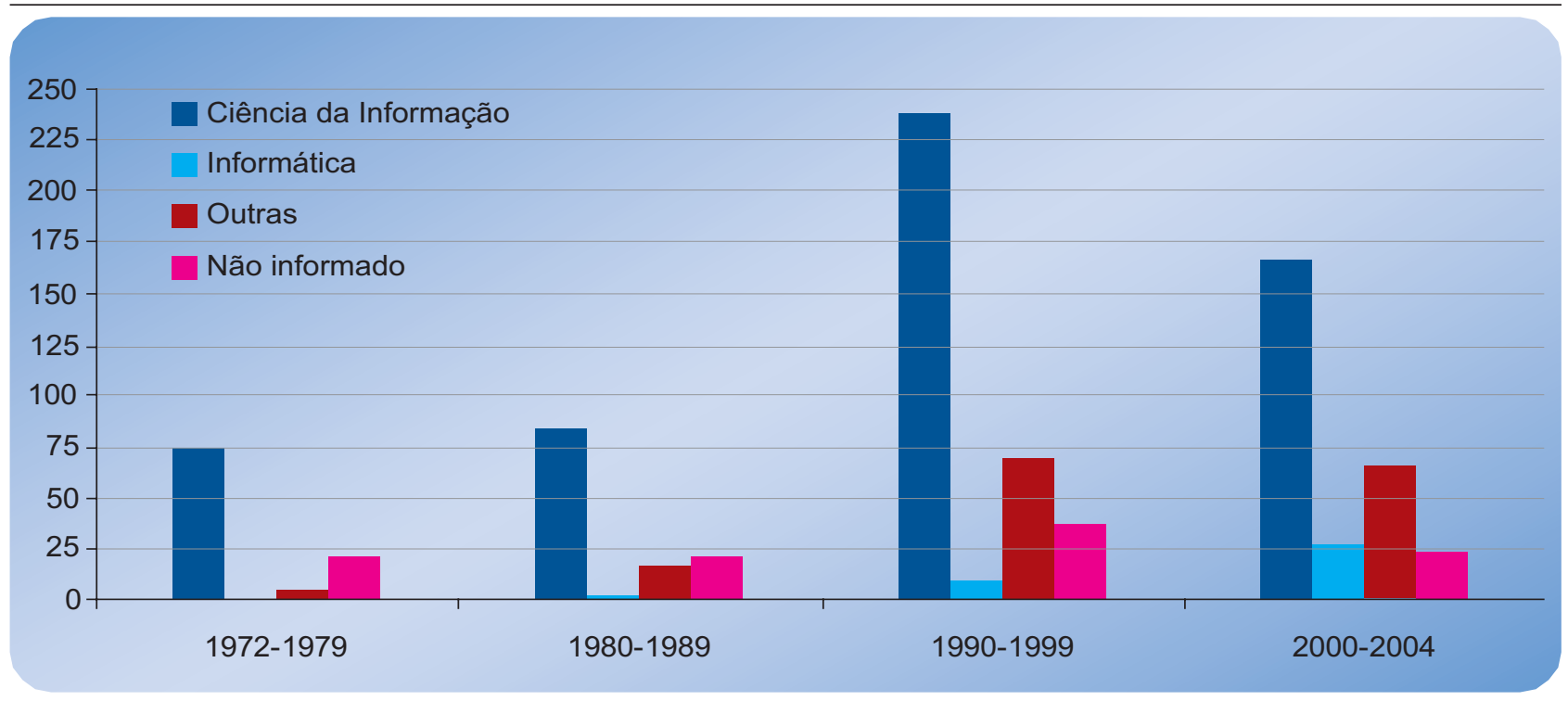




\section{GRÁFICO 5}

Contribuição dos cursos de pós-graduação - 1972 a 2004

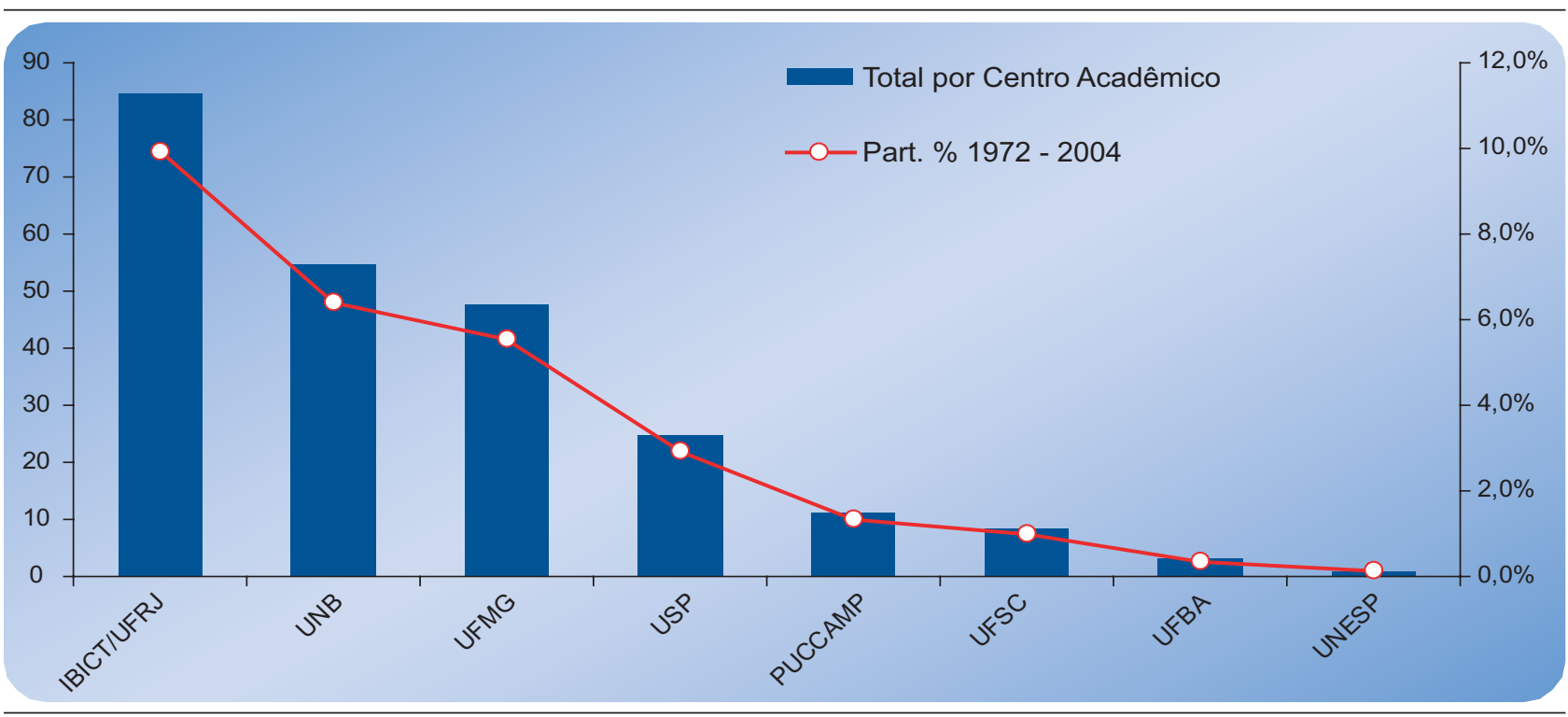

O percentual maior, do Ibict/UFRJ, não chega a caracterizar endogenia, pois não atinge $10 \%$.

Dos três cursos mais recentes, dois foram criados no final dos anos 90, na UFBA e na Unesp, ambos em 1998, e na UFSC, em 2003, daí serem exatamente estes os que apresentam menor produtividade na revista.

Em levantamento realizado pelo Ibict (2001) sobre afiliação de autores da revista Ciência da Informação, no período de 1998-2000 (anexo15), podemos verificar não somente a predominância de instituições que oferecem pós-graduação na área (UFMG, USP, Ibict e UnB), mas também a forte presença de outras universidades, por exemplo, PUC/ PR e UFRS, além de institutos de pesquisa e órgãos de fomento. No anexo 15 , estão identificadas também as instituições estrangeiras, nesse período a maioria iberoamericana, embora constem, ainda, as européias e norteamericanas. Mais uma vez a ausência de dados, neste caso a identificação das instituições dos autores, no total de nove, prejudica a análise e nos leva a enfatizar a necessidade de a revista Ciência da Informação tornar esta informação (vinculação institucional do autor) obrigatória.

Deve ser explicado que o Ibict aparece no anexo 15 sem a UFRJ, porque os autores pertencem ao quadro funcional do Ibict, embora sejam professores do Programa de PósGraduação em Ciência da Informação, então sob convênio com a UFRJ.

A expansão dos cursos de pós-graduação na área e o conseqüente aumento de pesquisas e geração do conhecimento são decisivos para a consolidação dos periódicos científicos, o que é ressaltado por Miranda e Pereira (1996), ao apontarem fatores que interferem no seu maior ou menor desenvolvimento : "do estágio de desenvolvimento da área científica cujas idéias eles veiculam; de uma comunidade engajada na atividade de pesquisa e da afluência de artigos para publicação; da existência de grupos e instituições que desempenham funções típicas de edição, avaliação, publicação, disseminação e recuperação; da existência de mercado representado por uma comunidade de usuários que o legitimem; de infra-estrutura para distribuição, recuperação e acesso à informação".

Esta distribuição também pode ser observada por décadas, o que permite verificar o surgimento de novos cursos e programas, bem como a evolução e crescimento da pósgraduação no Brasil.

A produtividade de autores oriundos de programas e cursos de pós-graduação, por tipo de autoria, única (individual) e co-autoria (coletiva), aparece no anexo 16.

A distribuição de autores por regiões brasileiras e exterior pode ser observada nos quadros 13 e 14 e gráficos 6,7 e 8 , destacando-se alguns dados.

A região Sudeste, durante todo o período de existência da revista, é a que mais contribui, mantendo sempre um percentual próximo a 50\% de autores. Um fator a ser considerado é a presença de cursos de pós-graduação de ciência da informação (Ibict/UFRJ,USP,UFMG, Puccamp e Unesp) na região. 
Lena Vania Ribeiro Pinheiro / Marisa Bräscher / Sonia Burnier

QUADRO 12

Produção de autores de cursos /programas de pós-graduação e sua formação, por décadas

\begin{tabular}{|c|c|c|c|c|c|c|c|c|c|c|c|}
\hline Produção PG & Formação & 1972-1979 & $\%$ & 1980-1989 & $\%$ & 1990-1999 & $\%$ & 2000-2004 & $\%$ & Total geral & $\%$ \\
\hline \multirow{4}{*}{ IBICT/UFRJ } & Doutorado & & - & 1 & $3,6 \%$ & 16 & $48,5 \%$ & 9 & $100,0 \%$ & 26 & $31,7 \%$ \\
\hline & Mestrado & & - & 4 & $14,3 \%$ & 4 & $12,1 \%$ & & - & 8 & $9,8 \%$ \\
\hline & Graduação & & - & 1 & $3,6 \%$ & & - & & - & 1 & $1,2 \%$ \\
\hline & Não informado & 12 & 100 & 22 & $78,6 \%$ & 13 & $39,4 \%$ & & - & 47 & $57,3 \%$ \\
\hline \multicolumn{2}{|c|}{ IBICT/UFRJ Total } & 12 & 100 & 28 & 100,0 & 33 & 100,0 & 9 & 100,0 & 82 & 100,0 \\
\hline \multirow{4}{*}{ PUCCAMP } & Doutorado & & - & & - & 4 & $57,1 \%$ & & - & 4 & $36,4 \%$ \\
\hline & Mestrado & & - & 1 & $33,3 \%$ & & - & & - & 1 & $9,1 \%$ \\
\hline & Graduação & & - & & - & & - & 1 & $100,0 \%$ & 1 & $9,1 \%$ \\
\hline & Não informado & & - & 2 & $66,7 \%$ & 3 & $42,9 \%$ & & - & 5 & $45,5 \%$ \\
\hline \multicolumn{2}{|c|}{ PUCCAMP Total } & & - & 3 & 100,0 & 7 & 100,0 & 1 & 100,0 & 11 & 100,0 \\
\hline \multirow{3}{*}{ UFBA } & Doutorado & & - & & - & & - & 1 & $50,0 \%$ & 1 & $33,3 \%$ \\
\hline & Graduação & & - & & - & & - & 1 & $50,0 \%$ & 1 & $33,3 \%$ \\
\hline & Não informado & & - & 1 & 100 & & - & & - & 1 & $33,3 \%$ \\
\hline \multicolumn{2}{|l|}{ UFBA Total } & & - & 1 & $100,0 \%$ & & - & 2 & $100,0 \%$ & 3 & 100,0 \\
\hline \multirow{5}{*}{ UFMG } & Pós-doutorado & & - & & - & 1 & $4,0 \%$ & & - & 1 & $2,2 \%$ \\
\hline & Doutorado & & - & 1 & $50,0 \%$ & 5 & $20,0 \%$ & 7 & $46,7 \%$ & 13 & $28,3 \%$ \\
\hline & Mestrado & & - & & - & 11 & $44,0 \%$ & 4 & $26,7 \%$ & 15 & $32,6 \%$ \\
\hline & Graduação & & - & & - & 2 & $8,0 \%$ & 1 & $6,7 \%$ & 3 & $6,5 \%$ \\
\hline & Não informado & 4 & $100,0 \%$ & 1 & $50,0 \%$ & 6 & $24,0 \%$ & 3 & $20,0 \%$ & 14 & $30,4 \%$ \\
\hline \multicolumn{2}{|l|}{ UFMG Total } & 4 & $100,0 \%$ & 2 & $100,0 \%$ & 25 & $100,0 \%$ & 15 & $100,0 \%$ & 46 & $100,0 \%$ \\
\hline \multirow{2}{*}{ UFSC } & Doutorado & & - & & - & 1 & $33,3 \%$ & 3 & $100,0 \%$ & 4 & $50,0 \%$ \\
\hline & Não informado & & - & 2 & $100,0 \%$ & 2 & $66,7 \%$ & & - & 4 & $50,0 \%$ \\
\hline \multicolumn{2}{|l|}{ UFSC Total } & & - & 2 & $100,0 \%$ & 3 & $100,0 \%$ & 3 & $100,0 \%$ & 8 & $100,0 \%$ \\
\hline \multirow{5}{*}{ UNB } & Doutorado & & - & & - & 15 & $65,2 \%$ & 8 & $47,1 \%$ & 23 & $43,4 \%$ \\
\hline & Mestrado & & - & 1 & $12,5 \%$ & 4 & $17,4 \%$ & 7 & $41,2 \%$ & 12 & $22,6 \%$ \\
\hline & Especialização & & - & & - & & - & 1 & $5,9 \%$ & 1 & $1,9 \%$ \\
\hline & Graduação & & - & 1 & $12,5 \%$ & 1 & $4,3 \%$ & 1 & $5,9 \%$ & 3 & $5,7 \%$ \\
\hline & Não informado & 5 & $100,0 \%$ & 6 & $75,0 \%$ & 3 & $13,0 \%$ & & - & 14 & $26,4 \%$ \\
\hline \multicolumn{2}{|l|}{ UNB Total } & 5 & $100,0 \%$ & 8 & $100,0 \%$ & 23 & $100,0 \%$ & 17 & $100,0 \%$ & 53 & $100,0 \%$ \\
\hline UNESP & Não informado & & - & 1 & $100,0 \%$ & & - & & - & 1 & $100,0 \%$ \\
\hline \multicolumn{2}{|l|}{ UNESP Total } & & - & 1 & $100,0 \%$ & & - & & - & 1 & $100,0 \%$ \\
\hline \multirow{4}{*}{ USP } & Doutorado & & - & & - & 6 & $40,0 \%$ & 2 & $50,0 \%$ & 8 & $33,3 \%$ \\
\hline & Mestrado & & - & & - & 6 & $40,0 \%$ & 2 & $50,0 \%$ & 8 & $33,3 \%$ \\
\hline & Graduação & & - & & - & 1 & $6,7 \%$ & & - & 1 & $4,2 \%$ \\
\hline & Não informado & & - & 5 & $100,0 \%$ & 2 & $13,3 \%$ & & - & 7 & $29,2 \%$ \\
\hline \multicolumn{2}{|l|}{ USP Total } & & - & 5 & $100,0 \%$ & 15 & $100,0 \%$ & 4 & $100,0 \%$ & 24 & $100,0 \%$ \\
\hline \multirow{7}{*}{$\begin{array}{l}\text { Sem } \\
\text { informação }\end{array}$} & Pós-doutorado & & - & & - & 3 & $1,2 \%$ & & - & 3 & $0,5 \%$ \\
\hline & Doutorado & & - & & - & 36 & $14,9 \%$ & 49 & $21,8 \%$ & 85 & $13,8 \%$ \\
\hline & Mestrado & & - & 9 & $12,7 \%$ & 76 & $31,4 \%$ & 50 & $22,2 \%$ & 135 & $22,0 \%$ \\
\hline & Especialização & & - & & - & 3 & $1,2 \%$ & 9 & $4,0 \%$ & 12 & $2,0 \%$ \\
\hline & Graduação & & - & 2 & $2,8 \%$ & 44 & $18,2 \%$ & 65 & $28,9 \%$ & 111 & $18,1 \%$ \\
\hline & Nível Médio & & - & & - & 2 & $0,8 \%$ & 2 & $0,9 \%$ & 4 & $0,7 \%$ \\
\hline & Não informado & 76 & $100,0 \%$ & 60 & $84,5 \%$ & 78 & $32,2 \%$ & 50 & $22,2 \%$ & 264 & $43,0 \%$ \\
\hline \multicolumn{2}{|c|}{ Sem informação Total } & 76 & $100,0 \%$ & 71 & $100,0 \%$ & 242 & $100,0 \%$ & 225 & $100,0 \%$ & 614 & $100,0 \%$ \\
\hline \multicolumn{2}{|c|}{ Total geral } & 101 & $100,0 \%$ & 121 & $100,0 \%$ & 353 & $100,0 \%$ & 281 & $100,0 \%$ & 856 & $100,0 \%$ \\
\hline
\end{tabular}


Ciência da Informação: 32 anos (1972-2004) no caminho da história e horizontes de um periódico científico brasileiro

QUADRO 13

Produção de autores por região

\begin{tabular}{|c|c|c|c|c|c|c|c|c|c|c|}
\hline \multirow{2}{*}{ Região Período } & \multicolumn{2}{|c|}{$1972-1979$} & \multicolumn{2}{|c|}{ 1980-1989 } & \multicolumn{2}{|c|}{ 1990-1999 } & \multicolumn{2}{|c|}{$2000-2004$} & \multicolumn{2}{|c|}{ Total por Região } \\
\hline & Qtde & $\%$ & Qtde & $\%$ & Qtde & $\%$ & Qtde & $\%$ & Qtde & $\%$ \\
\hline Sudeste & 53 & $52,5 \%$ & 64 & $52,9 \%$ & 177 & $50,1 \%$ & 121 & $43,1 \%$ & 415 & $48,5 \%$ \\
\hline Centro-Oeste & 8 & $7,9 \%$ & 24 & $19,8 \%$ & 63 & $17,8 \%$ & 51 & $18,1 \%$ & 146 & $17,1 \%$ \\
\hline Exterior & 30 & $29,7 \%$ & 5 & $4,1 \%$ & 37 & $10,5 \%$ & 44 & $15,7 \%$ & 116 & $13,6 \%$ \\
\hline Sul & 3 & $3,0 \%$ & 8 & $6,6 \%$ & 32 & $9,1 \%$ & 42 & $14,9 \%$ & 85 & $9,9 \%$ \\
\hline Nordeste & 2 & $2,0 \%$ & 11 & $9,1 \%$ & 16 & $4,5 \%$ & 13 & $4,6 \%$ & 42 & $4,9 \%$ \\
\hline Norte & & - & 1 & $0,8 \%$ & 1 & $0,3 \%$ & 3 & $1,1 \%$ & 5 & $0,6 \%$ \\
\hline Não identificado & 5 & $5,0 \%$ & 8 & $6,6 \%$ & 27 & $7,6 \%$ & 7 & $2,5 \%$ & 47 & $5,5 \%$ \\
\hline Total por período & 101 & $100,0 \%$ & 121 & $100,0 \%$ & 353 & $100,0 \%$ & 281 & $100,0 \%$ & 856 & $100,0 \%$ \\
\hline
\end{tabular}

Em levantamento da informação científica e tecnológica, no Brasil, Garcia (1980) identificou 82 "sistemas /serviços/ centros de informação/ documentação em diversos estágios de implementação, áreas /especialidades, localização geográfica", a maioria concentrada na região Sudeste, principalmente no Rio de Janeiro.

A segunda maior contribuição, na década de 70 , é de autores do exterior $(29,70 \%)$, resultado que se explica sobretudo pela participação no curso de pós-graduação do Ibict de professores estrangeiros de renome internacional que publicaram no Brasil, inclusive na revista:Tefko Saracevic, Frederick W. Lancaster, LaVahn M. Overmemyer, Bert Boyce, Jack Mills, John Eyre, Ingetraut Dahlberg e Suman Datta. Deve ser considerada, ainda, a presença de consultores estrangeiros do Ibict, em diferentes fases, como Michel Menou, Stephen Parker e Julio Cubillo, entre outros autores de artigos.

\section{GRÁFICO 6}

\section{Produção de autores por região}

A participação de autores estrangeiros (13,55\%), no total de contribuições, é maior do que a participação de autores das regiões Sul $(9,93)$, Nordeste $(4,91 \%)$ e Norte $(0,58 \%)$.

A contribuição da região Sudeste - a mais produtiva é, aproximadamente, três vezes maior em relação à da região Centro-Oeste, a segunda mais produtiva, e 80 vezes maior se comparada à da região Norte, a menos produtiva.

Em termos de pesquisa e ensino, esta situação se repete no Diretório de Grupos de Pesquisa do CNPq, no qual, com base em dados de 1995, no total de 33.273 pesquisadores, $22.741(68,34 \%)$ estão na região Sudeste. www.cnpq.br/ gpesq2/tab1/total/1_tot.htm

Analisando-se, comparativamente, a contribuição de autores estrangeiros e nacionais na revista, observa-se,

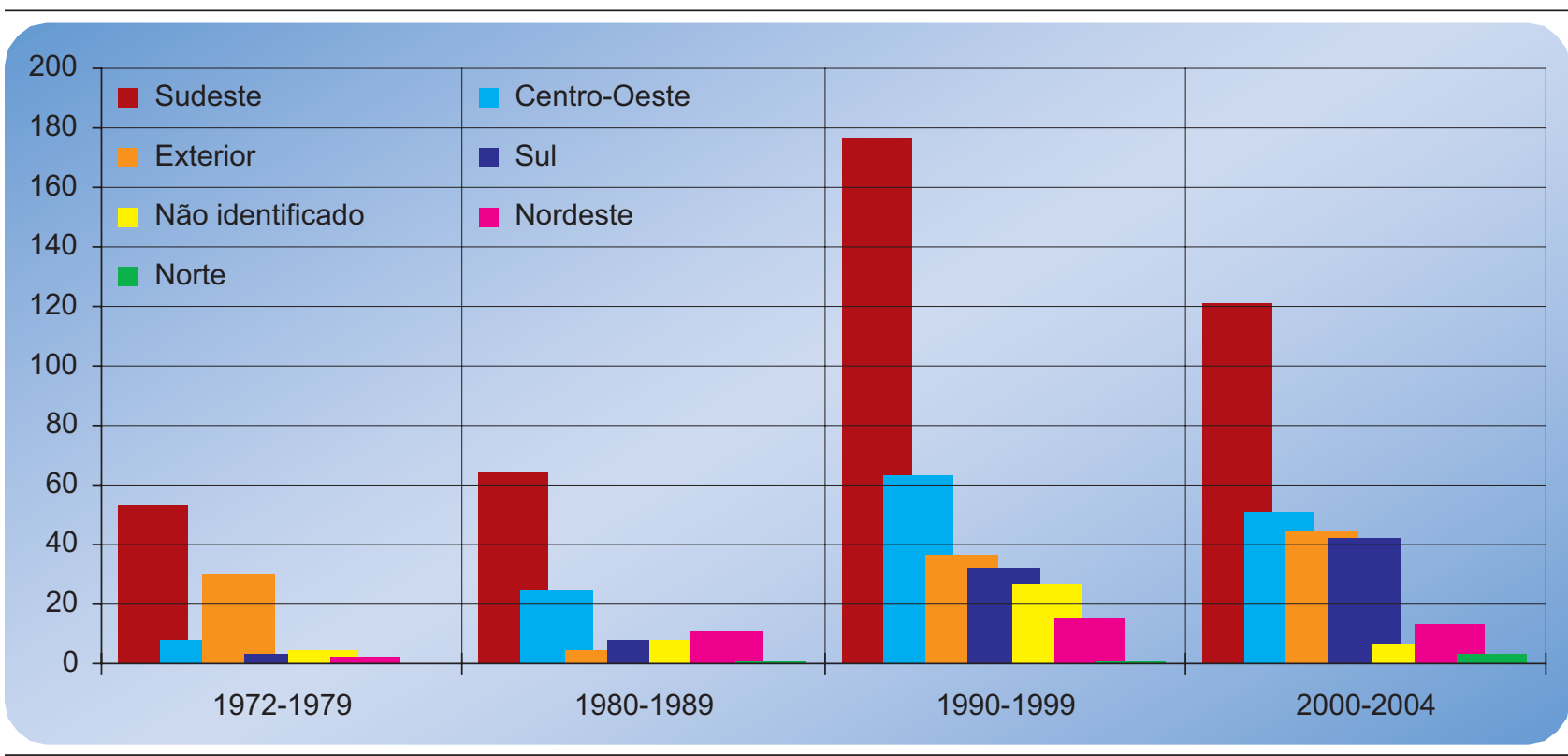

Ci. Inf., Brasília, v. 34, n. 3, p.23-75, set./dez. 2005 
QUADRO 14

Produção de autores de 1972 a 2004, no Brasil e exterior

\begin{tabular}{|l|c|c|c|c|c|c|c|c|c|c|}
\hline País & $1972-1979$ & $\%$ & $1980-1989$ & $\%$ & $1990-1999$ & $\%$ & $\mathbf{2 0 0 0 - 2 0 0 4}$ & $\%$ & Total geral & $\%$ \\
\hline Brasil & 69 & $68,3 \%$ & 116 & $95,9 \%$ & 308 & $87,3 \%$ & 238 & $84,7 \%$ & 731 & $85,4 \%$ \\
\hline Exterior & 32 & $31,7 \%$ & 5 & $4,1 \%$ & 45 & $12,7 \%$ & 43 & $15,3 \%$ & 125 & $14,6 \%$ \\
\hline Total geral & 101 & $100,0 \%$ & 121 & $100,0 \%$ & 353 & $100,0 \%$ & 281 & $\mathbf{1 0 0 , 0} \%$ & $\mathbf{8 5 6}$ & $\mathbf{1 0 0}, \mathbf{0} \%$ \\
\hline
\end{tabular}

no quadro 14, que 125 ocorrências (14,6\%) referem-se a autores do exterior e $731(85,4 \%)$ aos brasileiros.

Com exceção da década de 80 , sempre houve significativa participação de autores estrangeiros na publicação de artigos na revista, mantendo-se uma média de 30 a 40 autores por década. No entanto, em termos percentuais, comparando- se com o número de autores brasileiros, o maior índice de participação ocorre na primeira década da revista (31,7\% de autores estrangeiros e 68,3\% de brasileiros), quando os professores do exterior participaram no início do mestrado, e o menor índice ocorre na década de 80, com apenas $4,1 \%$ de autores estrangeiros e 95,9\% de brasileiros. A década de 90 e os primeiros anos de 2000 apresentam,

GRÁFICO 7

Produção de autores - 1972 a 2004, no Brasil e exterior

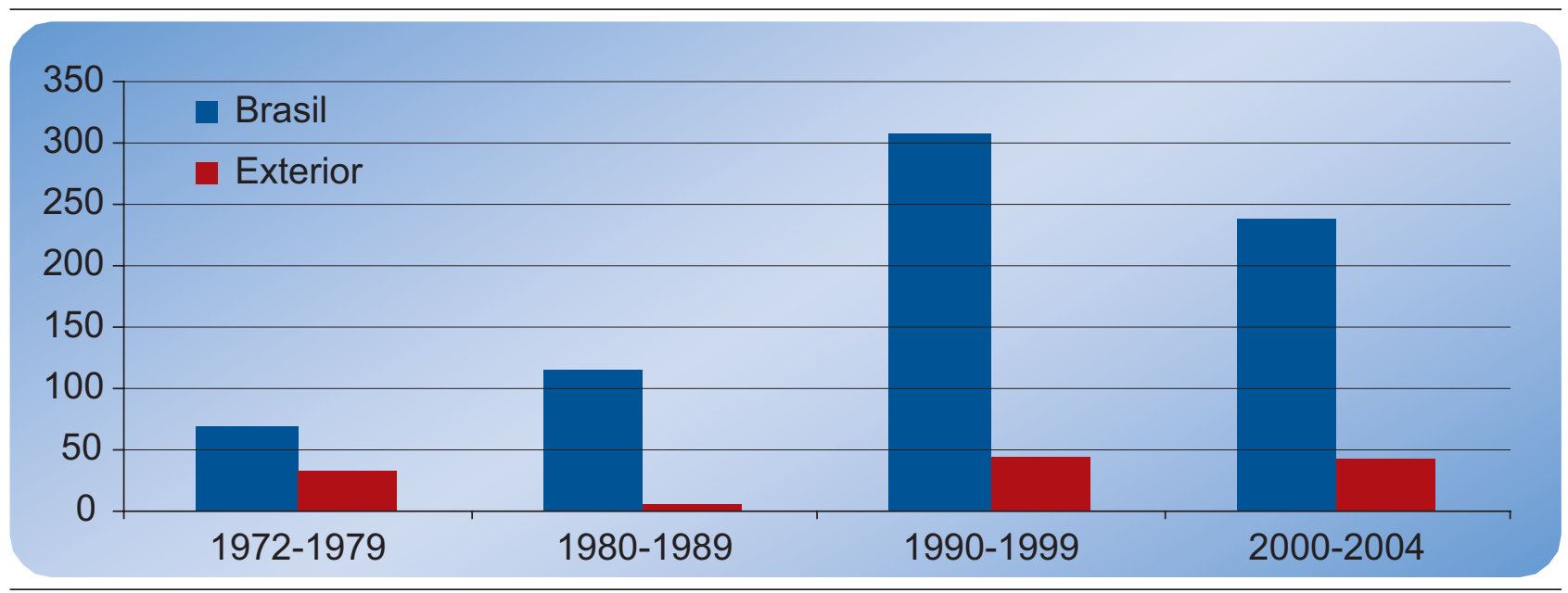

GRÁFICO 8

Produção de autores - 1972 a 2004, por países, exceto Brasil

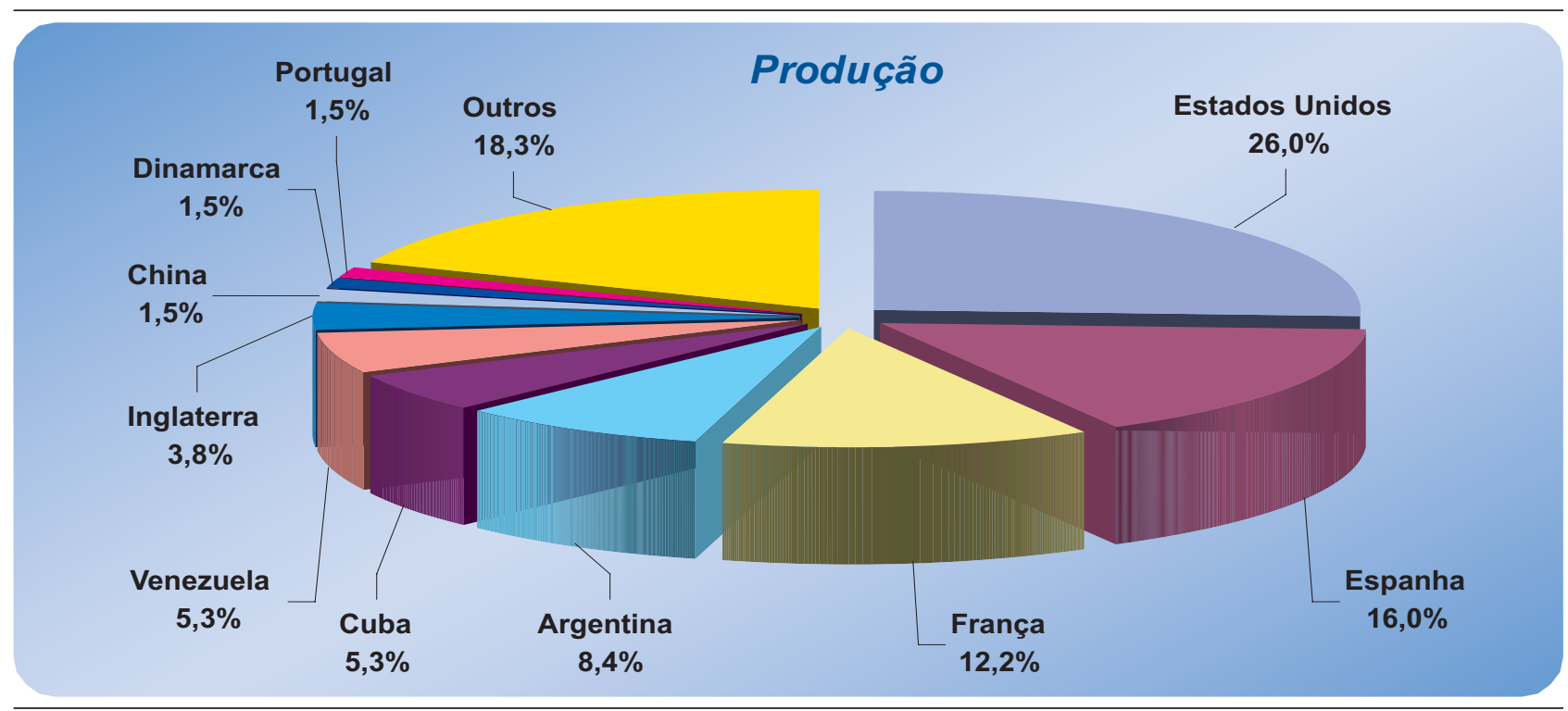


respectivamente, $12,7 \%$ e $15,3 \%$ de autores estrangeiros, e $87,3 \%$ e $84,7 \%$ de brasileiros ( ver anexo 17 )

No gráfico 7, pode-se visualizar esta comparação entre o volume de autores nacionais e de outros países.

Nas contribuições estrangeiras, distribuídas por países e mostradas no gráfico 8 , destacam-se, com maior número de autores, os Estados Unidos (34 - 4\%), Espanha (21 2,5\%), França (16-1,9\%) e Argentina (11 - 1,3\%).

É oportuno retomar o resultado sobre afiliação de autores ( anexo 15), que, por abranger um período curto, de apenas três anos (1998-2000), traz resultados diferentes, com a predominância de autores ibero-americanos.

O resultado, com maior concentração de autores estrangeiros dos Estados Unidos, reforça o que é reconhecido na área, a expressiva produtividade científica nesse país, por seus avanços científicos e tecnológicos, bem como a atuação de professores norte-americanos no Programa de Pós- Graduação em Ciência da Informação do Ibict, fato destacado em tópicos anteriores deste artigo.

A Europa apresenta, por ordem decrescente de produtividade, autores da Espanha, França, Inglaterra, Portugal e Dinamarca, totalizando um percentual de $35 \%$, enquanto a América Latina atinge 19\% e a China surge com $1,5 \%$.

A incidência de países europeus pode ser atribuída a acordos internacionais do instituto, à colaboração de consultores europeus ou, ainda, à participação de brasileiros em programas de pós-graduação europeus, principalmente na Espanha.

A América Latina está representada por três países - Cuba, Argentina e Venezuela -, e o seu expressivo percentual se explica não somente por o Brasil integrar o mesmo continente, mas também pela proximidade lingüística e atuação significativa do Ibict na região, por meio de programas, convênios e projetos.

Os resultados do Grupo de Trabalho do Ibict (2002) que identificou a afiliação de autores do periódico Ciência da Informação, durante três anos (1998-2000), citados anteriormente, clarifica a questão: da Universidade Carlos III, de Madrid, são três autores, seguidos de dois da Universidade do México, além de institutos semelhantes ao Ibict, como o Conycit, do Chile, e o IDICT, de Cuba.

Os autores estrangeiros, norte-americanos e europeus são oriundos das seguintes instituições, cada qual com freqüência 1: Universidade da Bélgica, ISI- Institute for
Scientific Information, Escola Real de Biblioteconomia, de Copenhague, Universidade de Paris, Universidade de Stanford e Universidade de Tenessee.

A produtividade de autores estrangeiros na revista pode ser observada por décadas no anexo 17, no qual os anos 70 apresentam números significativos, o que já foi comentado em tópico anterior e está relacionado ao Programa de Pós-Graduação do Ibict e a professores estrangeiros que dele participaram. A década de 90 também se destaca mas, neste caso, pode ser pela consolidação da revista e sua visibilidade e reconhecimento, inclusive no exterior. Estes mesmos resultados são mostrados em ordem de produtividade no anexo seguinte, o 18.

Ao finalizarmos a análise dos dados sobre autoria, fica evidente a amplitude nacional e internacional do periódico Ciência da Informação, do Ibict, no qual escrevem autores das mais importantes instituições da área e de diferentes países do mundo. Portanto, há necessidade de padronização e detalhamento desse tipo de informação, de forma a possibilitar estudos dessa natureza e também a elaboração de séries históricas que permitam a sua continuidade e aprofundamento.

\section{POTENCIAL DE DISSEMINAÇÃO E UNIVERSALIZAÇÃO DE ACESSO}

Quanto ao aspecto da disseminação e potencial de acesso, desde o ano de 1982 os serviços de indexação começaram a incluir a revista, que já nessa época aparecia em seis destes (quadro 15), sendo dois nacionais e quatro estrangeiros, entre os quais o Library and Information Science Abstracts (Lisa), um dos mais importantes serviços de indexação da área. Acompanhando-se as décadas, pode-se perceber a inclusão crescente em outros serviços, bases de dados e diretórios, como também a vida curta de alguns serviços nacionais, como o ABCD, encerrado. A Literatura em Ciência da Informação (Lici), do Ibict não tem sido alimentada regularmente, e a atualização é feita no catálogo on-line da Biblioteca do Ibict.

Além disso, os avanços tecnológicos a serviço da disseminação e principalmente da disponibilização na Internet / Web ampliaram o acesso à revista em repertórios e diretórios eletrônicos, bibliotecas digitais e virtuais, portais etc.

É importante destacar a presença da revista Ciência da Informação no Catálogo Coletivo Nacional de Publicações Seriadas (CCN), no qual aparece disponível em 191 bibliotecas brasileiras, a maioria com assinatura até o ano de 1994, já que a partir de 1995 seus fascículos passam a estar disponíveis também via Web, no site http://www. Ibict.br/cienciadainformacao. 
QUADRO 15

Indexação da Ciência da Informação em publicações secundárias

\begin{tabular}{|c|c|c|c|}
\hline Publicações secundárias & $1982-1989$ & $1990-1999$ & $2000-2004$ \\
\hline 1 - ABCD - Resumos \& Sumários & $x$ & & \\
\hline 2 - Bibliografia Brasileira de Ciência da Informação / LICI & $x$ & & \\
\hline 3 - Bulletin Signaletique & $x$ & & \\
\hline 4 - Ciências de la Información & $x$ & $x$ & $x$ \\
\hline 7 - Documentation & $x$ & $x$ & $\mathrm{x}$ \\
\hline 8 - Educaccíon: Noticias de Educación, Ciência y Cultura Iberoamericana & $x$ & $x$ & $x$ \\
\hline 9 - Information Science Abstracts (0020-0239) & $x$ & $x$ & $x$ \\
\hline \multicolumn{4}{|l|}{10 - IREBI: Índices de Revistas de Bibliotecologia } \\
\hline 11 - Library and Information Science Abstracts & $x$ & $x$ & $x$ \\
\hline 12 - Library and Literature & & $x$ & $x$ \\
\hline 13 - New Serials Titles & $x$ & & \\
\hline 14 - Páginas de Contenido & $x$ & $x$ & $x$ \\
\hline 15 - PAIS Foreign Language Index (0896-792-X) & $x$ & $x$ & $x$ \\
\hline 16 - Pascal: Science de l'Information & $x$ & $x$ & $x$ \\
\hline 17 - Referativnyi Zhurnal: Inormatika & $x$ & $x$ & $x$ \\
\hline 18 - Resumos de Informação & $x$ & & \\
\hline 19 - Sumários Correntes Brasileiros: Ciências Sociais e Humanas & $x$ & $x$ & \\
\hline Total & 15 & 11 & 10 \\
\hline
\end{tabular}

Mesmo assim, a revista impressa integra as grandes coleções brasileiras e de bibliotecas especializadas. Destaca-se, aqui, a busca realizada no WorldCat, da OnLine Computer Library Center (OCLC), mostrando a presença deste periódico em 17 bibliotecas do sistema.

O WorldCat é um catálogo coletivo mundial, criado e mantido coletivamente por mais de 9 mil instituiçõesmembro, com 56 milhões de registros bibliográficos referentes a informações bibliográficas de acervos das bibliotecas que contribuem, constituindo-se na maior base de dados deste tipo existente no mundo. Berço da maioria dos serviços oferecidos pela OCLC, o WorldCat possibilita que as bibliotecas processem, administrem e façam intercâmbio de informações e oferece serviço de busca aos usuários. http://www.oclc.org/worldcat/about/ default.htm

Um pequeno exercício nessa base mostra, no quadro 16, os resultados da inclusão da revista Ciência da Informação nas coleções estrangeiras, adotando a seguinte estratégia de busca : Database: WorldCat - november 2004 Query: ti: ciencia and ti: informação All Libraries that Own Item: "Ciência da informação."*

Conforme mostra o quadro 16 , nem sempre as bibliotecas da rede OCLC indicam os fascículos da revista Ciência da Informação contidos nos seus respectivos acervos.

* Na base World Cat, o símbolo "ti" equivale à busca realizada no campo de título.
$\mathrm{Na}$ análise em outros catálogos coletivos, verificamos que o periódico do Ibict também faz parte de coleções da Argentina, México, Portugal, Chile e de bases de dados internacionais como Library of Congress, WorldCat, já mencionado, Latindex, Scielo e nos "browsers", o que leva o conteúdo da revista aos pesquisadores, desde a sua primeira busca. No Latindex, são indicadas a Clase (Citas Latinoamericanas em Ciências Sociales y Humanidades), o Compendex e a Infobila ( Información y Bibliotecologia Latinoamericanas).

Esta facilidade é conseguida em razão de a revista hoje disseminar o seu conteúdo de acordo com padrões internacionais, o que possibilita a interoperabilidade entre sistemas, redes e, conseqüentemente, a disponibilidade de seus artigos por um grande número de sites na grande rede.

Neste tópico, não poderiam deixar de ser mencionadas duas iniciativas da maior relevância: o Scientific Eletronic Library Online (Scielo) e o Portal da Capes. O primeiro, iniciado em 1997, é uma biblioteca virtual de revistas científicas brasileiras em formato eletrônico, fruto de parceria entre Bireme, Fapesp e editores científicos brasileiros. Entre os seus produtos, devem ser ressaltados o próprio site e a metodologia para elaboração, armazenamento, disseminação e avaliação de publicações periódicas em formato eletrônico ( PACKER et al., 1998).

Uma importante iniciativa para o acesso a textos completos de artigos de periódicos foi o Portal da Capes, repositório da produção científica mundial que reúne, em cerca de 
Ciência da Informação: 32 anos (1972-2004) no caminho da história e horizontes de um periódico científico brasileiro

QUADRO 16

Inclusão da Ciência da Informação em coleções estrangeiras

\begin{tabular}{|l|l|l|}
\hline Country/State & Library & Issues/coleção \\
\hline OH & Wilson Select Plus & \\
\hline CA & Univ of California, Berkeley & \\
\hline CA & Univ of Califórnia, Los Angeles & \\
\hline CA & Univ of Califórnia, UL & \\
\hline CT & Yale Univ Library & \\
\hline DC & Library of Congress & \\
\hline IL & Univ of Illinois & v.1- 1972- \\
\hline MN & MULS & v.1-v16, v.19-v20 - 1972- \\
\hline NY & Columbia Univ & \\
\hline NY & New York Pub Libra Res Libr & \\
\hline TX & Univ of Texas at Austin & \\
\hline WI & Univ of Wisconsin, Madison Gen Libr Sys & \\
\hline AS & Univ of Queensland & \\
\hline EU & British Library & Univ of Leeds \\
\hline EU & Univ of Wales, Aberystwyth, Thomas Parry & \\
\hline EU & Univ of Puerto Rico, Rio Piedras CAM & \\
\hline PP & DIBAM Biblioteca Nacional de Chile & Total 18 bibliotecas \\
\hline ZZ & & \\
\hline
\end{tabular}

Fonte: OCLC /nov.2004

90 bases de dados, mais de 9 mil títulos de periódicos, em todos os campos do conhecimento. Podem acessar gratuitamente este serviço da Capes universidades federais de ensino superior e universidades privadas, estas com pelo menos um doutorado com nota 5 ou superior, instituições de pesquisa que ofereçam pós-graduação, além dos Cefet e da Embrapa. A revista Ciência da Informação do Ibict faz parte do Portal da Capes, disseminada por dois editores e distribuidores, o Scielo e Wilson.

Outra iniciativa da Capes é o Programa Qualis que, baseado em determinados critérios, classifica os periódicos científicos brasileiros que disseminam a produção de programas de pós- graduação nacionais. Neste programa, a Ciência da Informação foi classificada na categoria de qualidade alta (A), embora quanto ao âmbito esteja enquadrada entre as de circulação nacional. No entanto, os dados referentes à sua circulação, constantes nesta pesquisa (item Potencial de disseminação e universalização de acesso, p.47) comprovam a presença da revista Ciência da Informação em várias coleções estrangeiras, bem como a sua inclusão em diversas fontes de informação internacionais.

\section{O "ADMIRÁVEL MUNDO NOVO” DE UM PERIÓDICO BRASILEIRO}

Alguns autores, entre os quais brasileiros como Stumpf (1996, p.386), têm manifestado a sua preocupação com o futuro das revistas eletrônicas, especificamente o arquivo para sua preservação e a duração de sua disponibilidade na rede, além da recuperação da informação.

No presente artigo, mesmo reconhecendo a relevância de estudos já considerando características do formato eletrônico, como o fizeram Simeão e Miranda (2004), baseados no modelo comunicacional extensivo, não incluímos a análise de aspectos como interatividade, hipertextualidade e hipermidiação. Ainda assim, é pertinente mencionarmos um dos resultados gerais do artigo citado, o de interatividade, no qual as ciências sociais aplicadas e letras e artes, área em que se inscreve a ciência da informação, apresentaram o menor índice.

Assim, este tópico está concentrado na descrição dos recursos eletrônicos de comunicação e de informação utilizados pela revista Ciência da Informação, com breves comentários sobre a situação dos periódicos eletrônicos da área de ciência da informação, no exterior e no Brasil.

No Directory of Eletronic Journals de 1996, foi identificado apenas um periódico eletrônico da área de ciência da informação, o Information Research e, em busca no Yahoo, quatro títulos: Ariadne - Library and Information Science Journal, da Inglaterra, Provenance, do Canadá, Journal or Internet Cataloging e The Library Quaterly, ambos dos Estados Unidos. 
No Brasil, o primeiro projeto de periódicos eletrônicos foi do Grupo de Publicações Eletrônicas em Medicina e Biologia, responsável pela editoração eletrônica de 14 periódicos. Desde a década de 80 , estavam sendo pensados projetos de periódicos eletrônicos e, na década seguinte, anos 90, principalmente a partir de 1993, o número de periódicos eletrônicos cresceu muito, após a expansão da Internet e o surgimento da Web (SILVA et al., 1996).

Hoje, conforme destacado no início deste artigo, os pesquisadores e profissionais de ciência da informação dispõem de dez (10) periódicos devotados à área, entre os quais seis (6) são apresentados em formato impresso e eletrônico (Ciência da Informação, Encontros Bibli, Informação e Sociedade, Perspectiva de Ciência da Informação, Revista de Biblioteconomia de Brasília e Transinformação), três (3) apenas em formato eletrônico, o DatagramaZero, Morpheus e Revista Digital de Biblioteconomia e Ciência da Informação, e apenas um (1) somente em versão impressa, Em Questão.

O planejamento da revista Ciência da Informação eletrônica começou em abril de 1996, contando com uma equipe multidisciplinar. Diferentemente de outros periódicos que somente disponibilizam sumários, a revista Ciência da Informação, na sua versão eletrônica, reproduz todo o conteúdo da edição impressa, conforme descrito por Silva e colaboradores (1996).

Atualmente, também o processo de editoração é todo eletrônico, utilizando o Sistema Eletrônico de Editoração de Revistas (Seer), tradução e adaptação do Ibict do software livre Open Journal Systems, desenvolvido pelo Public Knowledge Project, da University of British Columbia (http://www.pkp.ubc.ca/ojs/), tendo por objetivo a produção e gestão de publicação periódica eletrônica e suas funções editoriais.

Este é um avanço que facilita e traz maior rapidez ao processo editorial, da mesma forma que permite o acompanhamento, pelos autores, do andamento da avaliação de seu trabalho junto à revista.

Um periódico eletrônico não prescinde de avaliação, pois, para ser reconhecido pela comunidade científica a que se dirige, deve apresentar as mesmas características do impresso: "revisão crítica, controle de qualidade editorial, acesso universal e arquivo permanente de matérias". (CLEMENT, apud SILVA et al., 1996)

A Ciência da Informação mantém a avaliação pelos pares, para assegurar a qualidade dos trabalhos publicados na revista e, com a aplicação do Seer, foi acrescentada ao processo a avaliação final pelos membros do Comitê Editorial, que consolida a avaliação dos consultores ad hoc, conforme descrito em tópico anterior.

O Ibict, cumprindo o seu papel de órgão nacional de ICT, tanto repassa o pacote do software do Seer aos editores de periódicos eletrônicos, quanto promove workshops e treinamentos para o seu uso. Dos nove periódicos que apresentam versão eletrônica ( quadro 1), além de Ciência da Informação, do Ibict, mais três adotam o Seer (Perspectivas da Ciência da Informação, Transinfomação e Revista Digital de Biblioteconomia e Ciência da Informação, dados que comprovam essa atuação do instituto. Assim, o Ibict, ao mesmo tempo que elevou o seu padrão editorial, contribui para que os editores de periódicos científicos disponham dos mesmos recursos, compartilhando modernas tecnologias.

\section{DESBRAVANDO CAMINHOS...}

O tema deste artigo, periódico científico, está presente nas pesquisas e estudos da área e é recorrente na literatura publicada pela revista Ciência da Informação, do Ibict, ora estudada.

Trabalho de Menezes e Couzinet (1999) sobre o assunto, especialmente em formato eletrônico, partiu de seleção feita no Lisa, fonte na qual aparecem indexados quatro periódicos brasileiros da área: Revista de Biblioteconomia de Brasília, da Associação dos Bibliotecários do Distrito Federal (ABDF), Revista Brasileira de Biblioteconomia e Documentação, da Febab, Perspectivas em Ciência da Informação, da UFMG, e o periódico do Ibict, Ciência da Informação. No período de 1990 a 1999, as duas primeiras não publicaram nenhum trabalho sobre periódicos científicos, a terceira apenas um e a revista do Ibict se destaca com 28 artigos, em alguns dos quais é o tema, conforme pode ser constatado na bibliografia da presente pesquisa. Estes artigos estão concentrados sobretudo no fascículo comemorativo dos 25 anos da revista (1996) e no especialmente dedicado ao periódico eletrônico, publicado em 1998.

Este resultado pode indicar tanto a importância deste periódico, quanto a perspectiva de olhar para si mesmo e, certamente, ser aperfeiçoado.

Além disso, as autoras também verificaram a incidência de produção científica nacional da área em periódicos científicos e comprovaram que os pesquisadores brasileiros de ciência da informação têm preferência também pela comunicação em artigos (MENEZES; COUZINET,1999), resultado semelhante a outros campos da ciência, confirmando o periódico como o canal de comunicação formal por excelência, em C\&T. 
Há mais de 20 anos e antes da Internet, Ziman (1979, p.118, p.129) afirmava:

É extraordinário pensar que em linhas gerais uma publicação científica tenha mudado menos em quase trezentos anos, do que qualquer outro tipo de literatura..." e reconhecia que "as únicas instituições da comunidade científica que têm força e uma base sólida são as suas revistas científicas.

Ao mesmo tempo que a importância do periódico é enfatizada, as transformações ocasionadas pelas tecnologias, principalmente a Internet/Web, são uma realidade, e o estudo da trajetória da revista Ciência da Informação as torna evidentes. No entanto, a primeira afirmativa de Ziman ainda tem sua força, mesmo no mundo contemporâneo. $\mathrm{Na}$ sua essência, o periódico mantém práticas seculares, como a avaliação pelos pares, e os artigos continuam reproduzindo a estrutura de uma pesquisa, em resultados parciais ou finais.

Autores e editores têm à disposição recursos eletrônicos de comunicação e informação que agilizam o processo de avaliação e, conseqüentemente, a disseminação e transferência de informação, socializando o conhecimento.

Além disso, a revista Ciência da Informação ganha visibilidade e universalidade no seu acesso.

Por ocasião do aniversário de 25 anos deste periódico, Pinheiro (1996) indaga no editorial: "Qual o significado da permanência de uma revista científica brasileira de área emergente, por tanto tempo, em um país de freqüentes mudanças e mesmo rupturas político-institucionais? E acentua a "acidentada e difícil trajetória das revistas científicas, mesmo no exterior...", o que valoriza ainda mais a publicação ora estudada.

Este artigo pretendeu responder a algumas das questões que podem refletir esse significado.

A revista Ciência da Informação, "arauto da ciência da informação no Brasil" (PINHEIRO,1996), pela análise de todos os resultados apresentados neste artigo, nas suas qualidades intrínsecas e extrínsecas, está antenada com os avanços da área, os quais tem usufruído, sendo uma revista compatível com a sociedade da informação. E sua repercussão atinge a comunidade científica brasileira de ciência da informação e a de C\&T, em geral, com experiência e tecnologias repassadas a periódicos científicos nacionais em todos os campos do conhecimento.

O periódico Ciência da Informação, do Ibict, desempenha função primordial no desenvolvimento, consolidação e expansão da área de ciência da informação no Brasil.

Agradecimentos especiais, pela valiosa colaboração, a Geovane Eugênio F. de Oliveira, especialista em inteligência organizacional e competitiva, pela UnB, responsável pela geração das tabelas e gráficos em Excel.

\section{REFERÊNCIAS}

AGUIAR, Afrânio Carvalho. Editorial. Ciência da Informação, Brasília, v. 10, n. 1, p. 3, 1981.

ARAUjO, Vânia Maria R. Hermes de. A organização espacial da informação científica e tecnológica no Brasil. Ciência da Informação, v. 14, n. 1, p. 17-24, jan.jun. 1985.

BRAGA, G. M.; OBHERHOFER, Cecília A. Diretrizes para a avaliação de periódicos científicos e técnicos brasileiros. Revista Latina de Documentação, n. 1, p. 27-31, jan./jun. 1982.

CIÊNCIA DA INFORMAÇÃO, Brasília: Instituto Brasileiro de Informação em Ciência e Tecnologia, v. 25, n. 3, p. 283-472, set./dez.1996. Número especial comemorativo dos 25 anos da revista Ciência da Informação.

Disponível em: <http://www.Ibict.br/cienciadainformacao/viewissue. php?id=30>. Acesso em: 2006.

, Brasília: Instituto Brasileiro de Informação em Ciência e Tecnologia, Brasília, v. 27, n. 2, p. 103-238, maio/ago. 1998.

Disponível em: <http://www.Ibict.br/cienciadainformacao/viewissue. php?id=25>. Acesso em: 2006.

COORDENAÇÃO DE APERFEIÇOAMENTO DE PESSOAL DE NÍVEL SUPERIOR - CAPES. Portal Brasileiro da Informação Científica. Disponível em: <http://www.periodicos.capes.gov.br/>. Acesso em: 2006.

CUNHA, Miriam Vieira da. Os periódicos em ciência da informação: uma análise bibliométrica. Ciência da Informação, Brasília, v. 14, n. 1, p. 37-45, jan./jun. 1985.

DIRETÓRIO de grupos de pesquisa do CNPq. Disponível em: <www. cnpq.br/gpesq2/tab1/total/1_tot.htm>. Acesso em: 2006.

FORESTI, Noris Almeida B. A revista Ciência da Informação no contexto de sua Instituição: algumas considerações. Ciência da Informação, Brasília, v. 15, n. 2, p. 143-150, jul./dez. 1986.

GARCIA, Maria Lúcia A. A informação científica e tecnológica no Brasil. Ciência da Informação, Brasília, v. 9, n. 1/2, p. 41-81, 1980.

GOMES, Hagar E. Entrevista a Lena Vania R. Pinheiro. Ciência da Informação, Brasília, v. 25, n. 3, p. 292-295, set./dez.1996. Disponível em: <http://www.Ibict.br/cienciadainformacao/viewissue.php?id=30>. Acesso em: 2006.

INSTITUTO BRASILEIRO DE INFORMAÇÃO EM CIÊNCIA E TECNOLOGIA - Ibict. Identificação das linhas de atuação do Ibict (19971999) e visão de futuro: sumário executivo com anexos. Brasília, 2000. $96 \mathrm{p}$.

. GT-15 - serviços de informação e publicações para especialistas em ICT: relatório final. Brasília, 2001.

. ISSN - Número Internacional Normalizado para Publicações Seriadas ("International Standard Serials Number"). Disponível em: <http:// www.ibic.br/secao.php?cat=ISSN>. Acesso em: 2006.

KRZYZANOWSKI, Rosaly F.; FERREIRA, Maria Cecília G. Avaliação de periódicos científicos e técnicos brasileiros. Ciência da informação, v. 27, n. 2, p. 165-175, maio/ago. 1998. Disponível em: <http://www.Ibict. br/cienciadainformacao/viewissue.php?id=25>. Acesso em: 2006.

LATINDEX. Disponível em: <http://www.latindex.org/busquedas/ directoriotitulo.html>. Acesso em: 01 out. 2004. 
LEMOS, Antonio A Briquet de. A nova fase de ciência da informação. Ciência da Informação, v. 10, n. 1, p. 69-70, 1981.

MENEZES, Estera M.; COUZINET, Viviane. O interesse das revistas brasileiras e francesas de biblioteconomia e ciências da informação pela revista eletrônica no período 1990-1999. Ciência da Informação, Brasília, v. 28, n. 3, p. 278-285, set./dez. 1999. Disponível em: <http://www.Ibict.

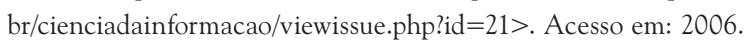

MIRANDA, Antonio. Planejamento bibliotecário no Brasil: a informação para o desenvolvimento. Rio de Janeiro: Livros Técnicos e Científicos Editora S. A; Brasília: Editora da Universidade de Brasília, 1977. 135 p.

MIRANDA, Dely Bezerra de; PEREIRA, Maria de Nazaré Freitas. O periódico científico como veículo de comunicação: uma revisão de literatura. Ciência da Informação, Brasília, DF, v. 25, n. 3, p. 375-382, set./dez. 1996.

MUELLER, Suzana P. M.; CAMPELLO, Bernadette S.; DIAS, Eduardo José W. Disseminação da pesquisa em ciência da informação e biblioteconomia no Brasil. Ciência da Informação, v. 25, n. 3, p. 337-351, set./dez. 1996 Disponível em: <http://www.Ibict.br/cienciadainformacao/viewissue. php?id=30>. Acesso em: 2006.

; PECEGUEIRO, Claudia M. P. de A. O periódico Ciência da Informação na década de 90: um retrato da área refletido em seus artigos. Ciência da Informação, v. 30, n. 2, p. 47-63, 2001. Disponível em: <http://www.Ibict.br/cienciadainformacao/viewissue.php?id=16>. Acesso em: 2006.

NEVES, Fernanda Ivo; MELO, Maria das Graças de L. Revistas brasileiras de Biblioteconomia e documentação na década de 70. In: CONGRESSO LATINO-AMERICANODEBIBLIOTECONOMIAEDOCUMENTAÇÃO, Salvador, 1980. Anais... Salvador: [s.n.], 1980. p. 419-433.

OLIVEIRA, Eloísa da C. Príncipe. O apoio governamental às publicações periódicas científicas: o programa de apoio a revistas científicas do CNPq e da FINEP. Orientadores: Antonio A. Briquet de Lemos e Hagar Espanha Gomes. 1989. Dissertação (Mestrado em Ciência da Informação)Universidade Federal do Rio de Janeiro, Escola de Comunicação, Conselho Nacional de Desenvolvimento Científico e Tecnológico/Instituto Brasileiro de Informação em Ciência e Tecnologia, Rio de Janeiro, 1989.

ONLINE COMPUTER LIBRARY CENTER - OCLC. FirstSearch. Disponível em: <http://www.oclc.org/firstsearch/periodicals/index_title.asp $>$.

Acesso em: 20 out. 2004.

. WorldCat. Disponível em: <http://www.oclc.org/worldcat/ about/default.htm>. Acesso em: 2006. Acesso somente por assinatura.

PACKER, Abel L. et al. SciELO: uma metodologia para publicação eletrônica. Ciência da Informação, v. 27, n. 2, p. 109-121, maio/ago. 1998. Disponível em: <http://www.Ibict.br/cienciadainformacao/viewissue. php?id=25>. Acesso em: 2006.

PINHEIRO, Lena Vania Ribeiro. A ciência da informação entre sombra e luz: domínio epistemológico e campo interdisciplinar. Orientador: Gilda Maria Braga. 1997. 278 f. Tese (Doutorado em Comunicação)Universidade Federal do Rio de Janeiro, Rio de Janeiro, 1997. Disponível em: $\quad<$ http://bibliotecalbict.br/ph18/anexos/lenavaniapinheiro1997. pdf $>$. Acesso em: 2006.

Ciência da Informação: páginas de uma revista em 25 anos. Ciência da Informação, v. 25, n. 3, p. 290-291, set.dez. 1996. Disponível em: <http://www.Ibict.br/cienciadainformacao/viewissue.php?id=30>.
Acesso em: 2006.

. Ciência da Informação: questões sobre formação, ensino e pesquisa. DatagramaZero, Rio de Janeiro, v. 3, n. 5, out. 2002. Disponível em: <www.dgzero.org/out02/F_I_com.htm>. Acesso em: 2006.

PRICE, Derek de Solla. A ciência desde a Babilônia. Belo Horizonte: Itatiaia; São Paulo: EDUSP, 1976. 189 p. (Coleção O homem e a ciência, 2).

O desenvolvimento da ciência. Rio de Janeiro: Livros Técnicos e Científicos, 1976.96 p.

SAMPAIO, Maria Imaculada et al. PAQ: Programa de avaliação da qualidade de produtos e serviços de informação: uma experiência no SIBI/USP. Ciência da Informação, v. 33, n. 1 p. 142-148, 2004. Disponível em: <http://www. Ibict.br/cienciadainformacao/viewissue.php?id=5>. Acesso em: 2006.

SARACEVIC, Tefko. Information science. Journal of the American Society for Information Science, v. 50, n. 12, p. 1051-1063, 1999.

Information science: origin, evolution and relations. In: VAKKARI, Pertti, CRONIN, Blaise, (Ed.). Conceptions of library and information science: historical, empirical and theoretical perspectives. Los Angeles: Taylor Graham, 1992. p. 5-27.

SCIENTIFIC ELECTRONIC LIBRARY ONLINE. Disponível em: <http:// www.scielo.br>. Acesso em: 2006.

SILVA, Luiz A. G. da; ALMEIDA, Robson L.; PARANHOS, Bruno S. A. Buscando soluções para se publicar na Internet a experiência do Ibict com a Ciência da Informação on-line. Ciência da Informação, Brasília, v. 25, n. 3, p. 454-460, set./dez. 1996. Disponível em: <http://www.Ibict.br/ cienciadainformacao/viewissue.php?id=30>. Acesso: 2006 .

SIMEÃO, Elmira. L. M.; MIRANDA, Antonio L. C. de. Comunicação extensiva e o formato do periódico científico eletrônico. In: INTERNATIONAL COUNCIL FOR COMPUTER COMMUNICATION 8., 2004, Brasília. Proceedings... Brasília: UnB, 2004.

STUMPF, Ida R. Chitto. Passado e futuro das revistas científicas. Ciência da Informação, Brasília, v. 25, n. 3, p. 383-386, set./dez.1996. Disponível em: <http://www.Ibict.br/cienciadainformacao/viewissue.php?id=30>. Acesso em: 2006.

UNIVERSITY OF BRITISH COLUMBIA. Open Journal Systems, Public Knowledge Project. Disponível em: <http://www.pkp.ubc.ca/ojs/>. Acesso em: 2006.

. Public Knowledge Project. Disponível em: <http://www.pkp. ubc.ca>. Acesso em: 2006.

URBIZAGÁSTEGUI ALVARADO, Rubén. A bibliometria no Brasil. Ciência da Informação, v. 13, n. 2, p. 91-105, jul./dez. 1984.

VALÉRIO, Palmira M. Espelho da ciência: avaliação do Programa Setorial de Publicações em ciência e tecnologia da FINEP. Rio de Janeiro: FINEP; Brasília: Ibict, 1994. 145 p.

VIEIRA, Anna da Soledade. Na janela do tempo com o IBBD e Drummond: passagens, transformações e novos desafios em educação. Ciência da Informação, v. 24, n. 1, 1995. Disponível em: <http://www.Ibict.br/ cienciadainformacao/viewissue.php?id=37>. Acesso em: 2006.

WIEERS, L. A vision on the library of the future. In: GELEIJNSE, H; GROOTAERS, C. (Ed.). Developing the library of the future: the Tilburg experience. 5. ed. Tilburg: Tilburg University Press; 1994. p. 1-11.

YAMAMOTO, O H. et al. Avaliação de periódicos científicos brasileiros 
Ciência da Informação: 32 anos (1972-2004) no caminho da história e horizontes de um periódico científico brasileiro da área da psicologia. Ciência da Informação, v. 31, n. 2, p. 163-177, 2002. Disponível em: <http://www.Ibict.br/cionline/>. Acesso em: 2006. ZIMAN, John. Conhecimento público. Belo Horizonte: Itatiaia; São Paulo: EDUSP, 1979. 164 p. (Coleção O homem e a ciência, 8)

ANEXOS

ANEXo 1 - CAPAS
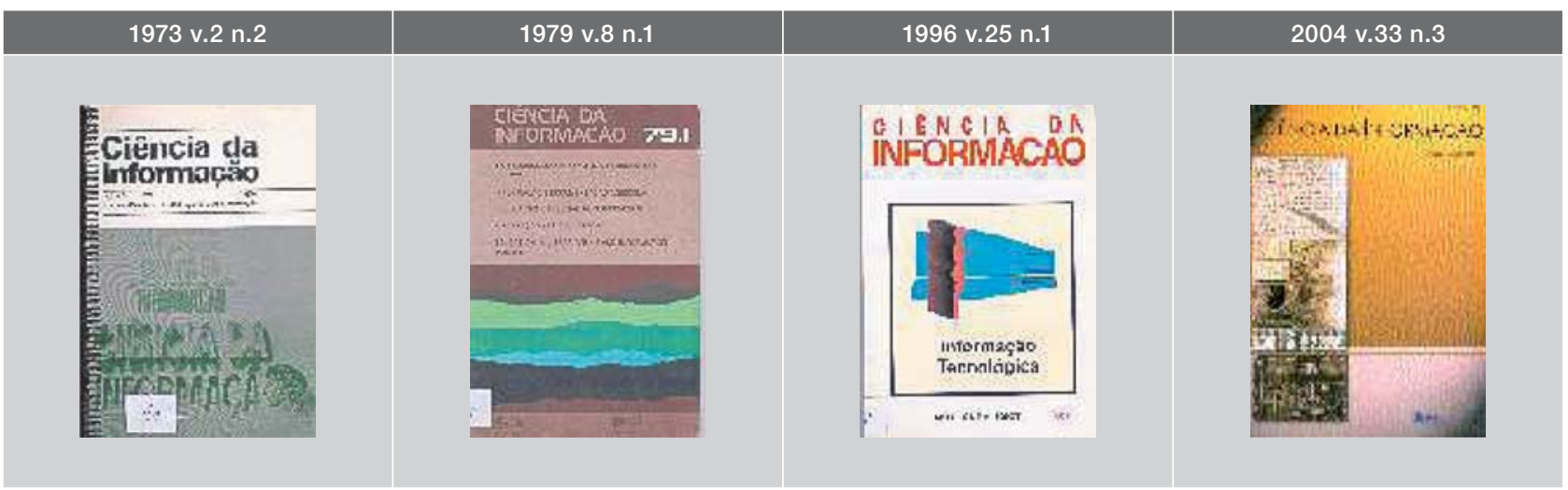

Anexo 2 - Total de ARTigos POR fascículo (1972 - 1979)

\begin{tabular}{|c|c|c|c|}
\hline Ano & Volume & Número & Total de artigos \\
\hline 1972 & 1 & 1 & 5 \\
\hline 1972 & 1 & 2 & 5 \\
\hline 1973 & 2 & 1 & 6 \\
\hline 1973 & 2 & 2 & 5 \\
\hline 1974 & 3 & 1 & 6 \\
\hline 1974 & 3 & 2 & 5 \\
\hline 1975 & 4 & 1 & 5 \\
\hline 1975 & 4 & 2 & 6 \\
\hline 1976 & 5 & $1 / 2$ & 8 \\
\hline 1977 & 6 & 1 & 7 \\
\hline 1977 & 6 & 2 & 7 \\
\hline 1978 & 7 & 1 & 6 \\
\hline 1978 & 7 & 2 & 5 \\
\hline 1979 & 8 & 1 & 5 \\
\hline 1979 & 8 & 2 & 5 \\
\hline \multicolumn{3}{|c|}{ TOTAL } & 86 \\
\hline
\end{tabular}

ANeXo 3 - Total De ARTigos (1972-1979), POR FREQÜÊNCIA DE ASSUntos/TEMAS

\begin{tabular}{|l|c|}
\hline ASSUNTOS / TEMAS & Total \\
\hline Bibliometria & 18 \\
\hline Representação da informação & 8 \\
\hline Comunicação científica & 7 \\
\hline Formação e aspetos profissionais & 6 \\
\hline Necessidades e uso de informação & 6 \\
\hline Organização e processamento da informação & 6 \\
\hline Sistemas e redes de informação & 6 \\
\hline Disseminação da informação & 4 \\
\hline Sistemas de recuperação da informação & 4 \\
\hline Teoria da Cl & 4 \\
\hline
\end{tabular}

continua... 
...continuação (Anexo 3)

\begin{tabular}{l|c}
\hline ASSUNTOS / TEMAS & Total \\
\hline Base de dados & 3 \\
\hline Política de informação & 3 \\
\hline Automação de bibliotecas & 2 \\
\hline Biblioteconomia & 2 \\
\hline Gestão da informação & 2 \\
\hline Política editorial & 2 \\
\hline Epistemologia & 1 \\
\hline Processamento automático de linguagem & 1 \\
\hline Segurança da informação & 1 \\
\hline TOTAL & 86 \\
\hline
\end{tabular}

AneXo 4 - Total de ARTigos POR fascículo (1980-1989)

\begin{tabular}{|c|c|c|c|}
\hline Ano & Volume & Número & Total de artigos \\
\hline 1980 & 9 & $1 / 2$ & 3 \\
\hline 1981 & 10 & 1 & 4 \\
\hline 1981 & 10 & 2 & 4 \\
\hline 1982 & 11 & 1 & 4 \\
\hline 1982 & 11 & 2 & 5 \\
\hline 1983 & 12 & 1 & 5 \\
\hline 1983 & 12 & 2 & 6 \\
\hline 1984 & 13 & 1 & 5 \\
\hline 1984 & 13 & 2 & 5 \\
\hline 1985 & 14 & 1 & 6 \\
\hline 1985 & 14 & 2 & 8 \\
\hline 1986 & 15 & 1 & 5 \\
\hline 1986 & 15 & 2 & 11 \\
\hline 1987 & 16 & 1 & 8 \\
\hline 1988 & 16 & 2 & 5 \\
\hline 1988 & 17 & 1 & 4 \\
\hline 1989 & 17 & 2 & 6 \\
\hline
\end{tabular}

ANeXo 5 - Total De ARTigos (1980-1989) POR FREQÜÊNCIA DE ASSUNTOS /TEMAS

\begin{tabular}{|l|c|c|}
\hline ASSUNTOS /TEMAS & Total \\
\hline Bibliometria & 11 \\
\hline Política de informação & 11 \\
\hline Comunicação científica & 10 \\
\hline Formação e aspectos profissionais & 9 \\
\hline Necessidades e usos de informação & 9 \\
\hline Representação da informação & 9 \\
\hline Teoria da Cl & 8 \\
\hline Disseminação da informação & 7 \\
\hline Gestão da informação & 7 \\
\hline Sistemas e redes de informação & 6 \\
\hline Base de dados & 4 \\
\hline Biblioteconomia, bibliotecas e livros & 3 \\
\hline Política de c\&t & 3 \\
\hline
\end{tabular}

continua... 
Ciência da Informação: 32 anos (1972-2004) no caminho da história e horizontes de um periódico científico brasileiro

...continuação (Anexo 5)

\begin{tabular}{|c|c|}
\hline ASSUNTOS /TEMAS & Total \\
\hline Economia da informação & 2 \\
\hline Sistemas de recuperação da informação & 2 \\
\hline Automação de bibliotecas & 1 \\
\hline Divulgação científica & 1 \\
\hline Organização e processamento da informação & 1 \\
\hline Política editorial & 1 \\
\hline Pós-modernismo & 1 \\
\hline Processamento automático de linguagem & 1 \\
\hline Tecnologia da informação & 1 \\
\hline Transferência de tecnologia & 1 \\
\hline Total & 109 \\
\hline
\end{tabular}

AneXo 6 - Total de ARTigos POR FAscículo (1990 -1999)

\begin{tabular}{|c|c|c|c|}
\hline Ano & Volume & Número & Total de artigos \\
\hline 1990 & 19 & 1 & 8 \\
\hline 1990 & 19 & 2 & 6 \\
\hline 1991 & 20 & 1 & 9 \\
\hline 1991 & 20 & 2 & 15 \\
\hline 1992 & 21 & 1 & 6 \\
\hline 1992 & 21 & 2 & 6 \\
\hline 1992 & 21 & 3 & 7 \\
\hline 1993 & 22 & 1 & 7 \\
\hline 1993 & 22 & 2 & 9 \\
\hline 1993 & 22 & 3 & 9 \\
\hline 1994 & 23 & 1 & 2 \\
\hline 1994 & 23 & 2 & 14 \\
\hline 1994 & 23 & 3 & 9 \\
\hline 1995 & 24 & 1 & 15 \\
\hline 1995 & 24 & 2 & 8 \\
\hline 1995 & 24 & 3 & 8 \\
\hline 1996 & 25 & 1 & 8 \\
\hline 1996 & 25 & 2 & 12 \\
\hline 1996 & 25 & 3 & 12 \\
\hline 1997 & 26 & 1 & 9 \\
\hline 1997 & 26 & 2 & 4 \\
\hline 1997 & 26 & 3 & 9 \\
\hline 1998 & 27 & 1 & 9 \\
\hline 1998 & 27 & 2 & 11 \\
\hline 1998 & 27 & 3 & 8 \\
\hline 1999 & 28 & 1 & 10 \\
\hline 1999 & 28 & 2 & 11 \\
\hline 1999 & 28 & 3 & 9 \\
\hline TOTAL & & & 250 \\
\hline
\end{tabular}

AneXo 7 - Total de ARTigos (1990-1999) POR FREQÜÊNCIA DE ASSUntos / TEMAS

\begin{tabular}{|l|c|}
\hline ASSUNTOS/TEMAS & Total \\
\hline Gestão da informação & 25 \\
\hline Teoria da Cl & 23 \\
\hline Tecnologia da informação & 18 \\
\hline
\end{tabular}


...continuação (Anexo 7)

\section{ASSUNTOS/TEMAS}

Sistemas e redes de informação

Disseminação da informação

Necessidades e usos de informação

Formação e aspectos profissionais

Representação da informação

Bibliometria

Comunicação científica

Política de informação

Inteligência competitiva

Política de C\&T

Arquivologia

Biblioteca virtual/digital

Sistemas de recuperação da informação

Economia da informação

Processamento automático de linguagem

Ciência e tecnologia

Automação de bibliotecas

Base de dados

Comunicação social

Divulgação científica

Imprensa

Lingüística

Sistemas especialistas

Tecnologias

Administração

Ciência cognitiva

Mineração de dados

Organização e processamento da informação

Sociologia da ciência

Tipografia

TOTAL

\begin{tabular}{|c|}
\hline Total \\
\hline 17 \\
\hline 16 \\
16 \\
\hline 15 \\
\hline 15 \\
\hline 14 \\
\hline 12 \\
\hline 12 \\
\hline 8 \\
\hline 7 \\
\hline 6 \\
\hline 6 \\
\hline 6 \\
\hline 5 \\
\hline 4 \\
\hline 3 \\
\hline 2 \\
\hline 2 \\
2 \\
\hline 2 \\
\hline 2 \\
\hline 2 \\
\hline 2 \\
\hline 2 \\
\hline 1 \\
\hline 1 \\
\hline 1 \\
\hline 1 \\
\hline 1 \\
\hline 250 \\
\hline \\
\hline 12 \\
\hline
\end{tabular}

Anexo 8 - Total De ARTigos POR FAscículo (2000-2004)

\begin{tabular}{|c|c|c|c|}
\hline Ano & Volume & Número & Total de artigos \\
\hline 2000 & 29 & 1 & 12 \\
\hline 2000 & 29 & 2 & 9 \\
\hline 2000 & 29 & 3 & 9 \\
\hline 2001 & 30 & 1 & 9 \\
\hline 2001 & 30 & 2 & 9 \\
\hline 2001 & 30 & 3 & 11 \\
\hline 2002 & 31 & 1 & 6 \\
\hline 2002 & 31 & 2 & 17 \\
\hline 2002 & 31 & 3 & 10 \\
\hline 2003 & 32 & 1 & 13 \\
\hline 2003 & 32 & 2 & 12 \\
\hline 2003 & 32 & 3 & 14 \\
\hline
\end{tabular}

\section{Anexo 9 - Total De ARTigos ( 2000-2004) POR FReQÜÊNCIA De ASSUntos /TEMAS}

\section{ASSUNTOS /TEMAS}

Tecnologias da informação 
Ciência da Informação: 32 anos (1972-2004) no caminho da história e horizontes de um periódico científico brasileiro

...continuação (Anexo 9)

\begin{tabular}{|l|c|}
\hline ASSUNTOS /TEMAS & Total \\
\hline Políticas de informação & 17 \\
\hline Representação da informação & 14 \\
\hline Teoria da ciência da informação & 14 \\
\hline Bibliotecas virtuais/ digitais & 11 \\
\hline Necessidades e usos de informação & 11 \\
\hline Comunicação científica & 10 \\
\hline Sistemas de recuperação da informação & 9 \\
\hline Gestão da informação & 7 \\
\hline Bibliometria & 5 \\
\hline Inteligência competitiva & 5 \\
\hline Disseminação da Informação & 4 \\
\hline Formação e aspectos profissionais & 4 \\
\hline Gestão do conhecimento & 3 \\
\hline Sistemas e redes de informação & 3 \\
\hline Bases de dados & 2 \\
\hline Biblioteconomia, bibliotecas e livros & 2 \\
\hline Economia da Informação & 2 \\
\hline Organização e processamento de Informação & 2 \\
\hline Políticas de C\&T & 2 \\
\hline Automação de bibliotecas & 148 \\
\hline Divulgação científica & 1 \\
\hline Museologia & 1 \\
\hline TOTAL & \\
\hline
\end{tabular}

Anexo 10 - Total de artigos (1972 - 2004)

TOTAL GERAL DE ARTIGOS 1972-2004: 86+109+250+148=593

\begin{tabular}{|c|c|c|c|}
\hline Ano & Volume & Numero & Total de artigos \\
\hline 1972 & 1 & 1 & 5 \\
\hline 1972 & 1 & 2 & 6 \\
\hline 1973 & 2 & 1 & 5 \\
\hline 1973 & 2 & 2 & 6 \\
\hline 1974 & 3 & 1 & 5 \\
\hline 1974 & 3 & 2 & 5 \\
\hline 1975 & 4 & 1 & 6 \\
\hline 1975 & 4 & 2 & 8 \\
\hline 1976 & 5 & $1 / 2$ & 7 \\
\hline 1977 & 6 & 1 & 7 \\
\hline 1977 & 6 & 2 & 6 \\
\hline 1978 & 7 & 1 & 5 \\
\hline 1978 & 7 & 2 & 5 \\
\hline 1979 & 8 & 1 & 5 \\
\hline 1980 & 8 & 2 & 3 \\
\hline 1981 & 9 & $1 / 2$ & 5 \\
\hline 1981 & 10 & 1 & 4 \\
\hline 1982 & 10 & 2 & 4 \\
\hline 1983 & 11 & 1 & 4 \\
\hline
\end{tabular}




\section{Lena Vania Ribeiro Pinheiro / Marisa Bräscher / Sonia Burnier}

...continuação (Anexo 10)

\begin{tabular}{|c|c|c|c|}
\hline Ano & Volume & Numero & Total de artigos \\
\hline 1984 & 13 & 1 & 6 \\
\hline 1984 & 13 & 2 & 5 \\
\hline 1985 & 14 & 1 & 5 \\
\hline 1985 & 14 & 2 & 6 \\
\hline 1986 & 15 & 1 & 8 \\
\hline 1986 & 15 & 2 & 5 \\
\hline 1987 & 16 & 1 & 11 \\
\hline 1987 & 16 & 2 & 8 \\
\hline 1988 & 17 & 1 & 5 \\
\hline 1988 & 17 & 2 & 4 \\
\hline 1989 & 18 & 1 & 6 \\
\hline 1989 & 18 & 2 & 10 \\
\hline 1990 & 19 & 1 & 8 \\
\hline 1990 & 19 & 2 & 6 \\
\hline 1991 & 20 & 1 & 9 \\
\hline 1991 & 20 & 2 & 15 \\
\hline 1992 & 21 & 1 & 6 \\
\hline 1992 & 21 & 2 & 6 \\
\hline 1992 & 21 & 3 & 7 \\
\hline 1993 & 22 & 1 & 7 \\
\hline 1993 & 22 & 2 & 9 \\
\hline 1993 & 22 & 3 & 9 \\
\hline 1994 & 23 & 1 & 2 \\
\hline 1994 & 23 & 2 & 14 \\
\hline 1994 & 23 & 3 & 9 \\
\hline 1995 & 24 & 1 & 15 \\
\hline 1995 & 24 & 2 & 8 \\
\hline 1995 & 24 & 3 & 8 \\
\hline 1996 & 25 & 1 & 8 \\
\hline 1996 & 25 & 2 & 12 \\
\hline 1996 & 25 & 3 & 12 \\
\hline 1997 & 26 & 1 & 9 \\
\hline 1997 & 26 & 2 & 4 \\
\hline 1997 & 26 & 3 & 9 \\
\hline 1998 & 27 & 1 & 9 \\
\hline 1998 & 27 & 2 & 11 \\
\hline 1998 & 27 & 3 & 8 \\
\hline 1999 & 28 & 1 & 10 \\
\hline 1999 & 28 & 2 & 11 \\
\hline 1999 & 28 & 3 & 9 \\
\hline 2000 & 29 & 1 & 12 \\
\hline 2000 & 29 & 2 & 9 \\
\hline 2000 & 29 & 3 & 9 \\
\hline 2001 & 30 & 1 & 9 \\
\hline 2001 & 30 & 2 & 9 \\
\hline 2001 & 30 & 3 & 11 \\
\hline 2002 & 31 & 1 & 6 \\
\hline 2002 & 31 & 2 & 17 \\
\hline 2002 & 31 & 3 & 10 \\
\hline
\end{tabular}

continua... 
Ciência da Informação: 32 anos (1972-2004) no caminho da história e horizontes de um periódico científico brasileiro

...continuação (Anexo 10)

\begin{tabular}{|c|c|c|c|}
\hline Ano & Volume & Numero & Total de artigos \\
\hline 2003 & 32 & 1 & 13 \\
\hline 2003 & 32 & 2 & 12 \\
\hline 2003 & 32 & 3 & 14 \\
\hline 2004 & 33 & 1 & 17 \\
\hline
\end{tabular}

\section{AneXo 11 - Total de ARTigos ( 1972 - 2004) POR ORdem Alfabética DE Assuntos/TemAs}

\begin{tabular}{|c|c|}
\hline Assuntos/ Temas & Total \\
\hline Administração & 01 \\
\hline Arquivologia & 06 \\
\hline Automação de bibliotecas & 06 \\
\hline Base de dados & 11 \\
\hline Bibliometria & 48 \\
\hline Biblioteca virtual/digital & 17 \\
\hline Biblioteconomia & 02 \\
\hline Biblioteconomia, bibliotecas e livros & 05 \\
\hline Ciência cognitiva & 01 \\
\hline Ciência e tecnologia & 03 \\
\hline Comunicação social & 02 \\
\hline Comunicação científica & 39 \\
\hline Divulgação científica & 04 \\
\hline Disseminação da informação & 31 \\
\hline Economia da informação & 09 \\
\hline Epistemologia & 01 \\
\hline Formação e aspectos profissionais & 34 \\
\hline Gestão do conhecimento & 03 \\
\hline Gestão da informação & 41 \\
\hline Imprensa & 02 \\
\hline Inteligência competitiva & 13 \\
\hline Lingüística & 02 \\
\hline Mineração de dados & 01 \\
\hline Museologia & 01 \\
\hline Necessidades e usos de informação & 42 \\
\hline Organização e processamento da informação & 10 \\
\hline Política de C\&T & 12 \\
\hline Política de informação & 43 \\
\hline Política editorial & 03 \\
\hline Pós-modernismo & 01 \\
\hline Processamento automático de linguagem & 06 \\
\hline Representação da informação & 46 \\
\hline Segurança da informação & 01 \\
\hline Sistemas especialistas & 02 \\
\hline Sistemas e redes de informação & 32 \\
\hline
\end{tabular}




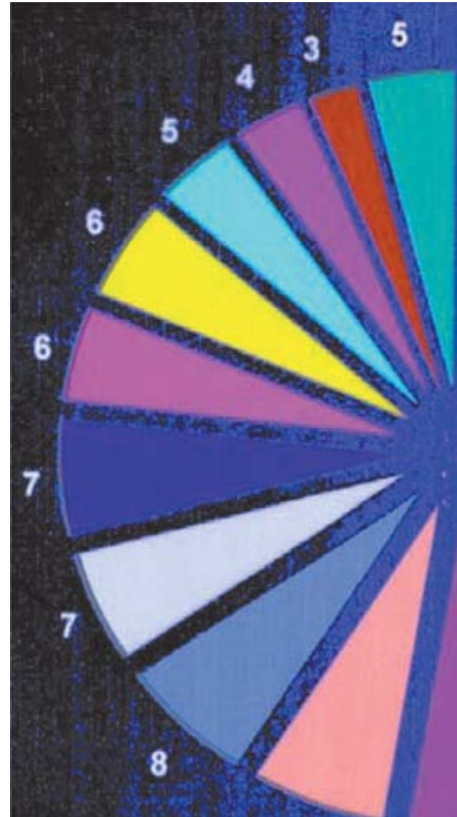

8
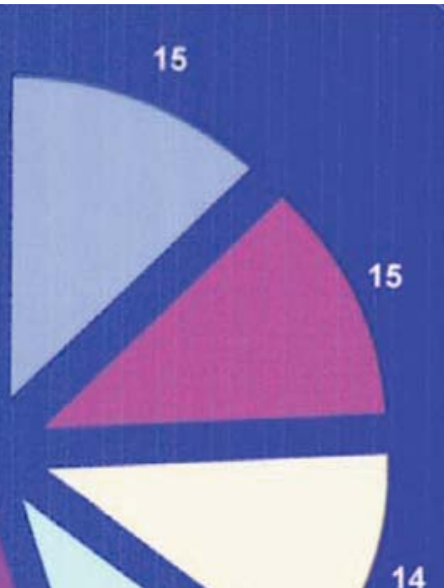

14

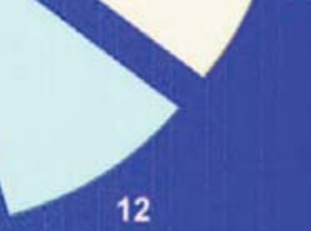

9
Inteligência Competitiva e Gestão do

Conhecimento - 15

Sistemas/serviços de informaçăo/base de dados - 15

ㅁ Biblioteca Virtuais e Digitais - 14

$\square$ Bibliometria/Cientometria e indicadores de C\&T - 12

E Informação tecnológico - industrial e para

Negócios - 9

- Periódicos cientiíficos e eletrônicos - 8

- Ciências e profissionais de informaçăo - 8

Politica de Informaçăo - 7

E Internet/rede eletrônicas e comércio eletrônico - 7

Automação e gestăo de bibliotecas - 6

- Estudos de demanda de informação/usuários e

Treinamento - 6

- Economia da informaçăo - 5

a Produçắo editorial e direito autoral - 4

- Análise/valor agregado à informaçăo e indexaçāo - 3

autros - 5

\section{Fonte: IBICT}

\begin{tabular}{|l|c|}
\hline Sociologia da ciência & 01 \\
\hline Tecnologias & 02 \\
\hline Tecnologia da informação & 37 \\
\hline Teoria da ciência da informação & 49 \\
\hline Tipografia & 01 \\
\hline Transferência de tecnologia & 01 \\
\hline TOTAL & 593 \\
\hline
\end{tabular}

ANeXo 12 - ReVISTA ClÊNCIA DA INFORMAÇão E TEMAS DE ARTIGOS, 1998-2000

Anexo 13 - Doze (12) AUtores MaIs PRODUtivos, com Resultados PeRCENTUAIS

\begin{tabular}{|l|c|c|c|c|c|c|}
\hline Autor & Autoria única & $\%$ & Co-autoria & $\%$ & Total geral & $\%$ \\
\hline Araújo,V.M.R.H. de & 8 & $1,7 \%$ & 1 & $0,3 \%$ & 9 & $1,1 \%$ \\
\hline Figueiredo,N.M. de & 8 & $1,7 \%$ & 1 & $0,3 \%$ & 9 & $1,1 \%$ \\
\hline Gómez, M.N.G. de & 8 & $1,7 \%$ & & $0,0 \%$ & 8 & $0,9 \%$ \\
\hline Cunha,M.B.da & 5 & $1,1 \%$ & 2 & $0,5 \%$ & 7 & $0,8 \%$ \\
\hline Freire,I.M. & 5 & $1,1 \%$ & 2 & $0,5 \%$ & 7 & $0,8 \%$ \\
\hline Barreto,A. de A. & 6 & $1,3 \%$ & & $0,0 \%$ & 6 & $0,7 \%$ \\
\hline Mueller,S.P.M. & 4 & $0,9 \%$ & 2 & $0,5 \%$ & 6 & $0,7 \%$ \\
\hline
\end{tabular}


Ciência da Informação: 32 anos (1972-2004) no caminho da história e horizontes de um periódico científico brasileiro

\begin{tabular}{|c|c|c|c|c|c|c|}
\hline Borges,M.E.N. & 1 & $0,2 \%$ & 5 & $1,3 \%$ & 6 & $0,7 \%$ \\
\hline \multicolumn{7}{|c|}{$\begin{array}{l}\text { Nesta relação, os nomes dos autores aparecem conforme estão registrados nos artigos. Para efeito de tratamento dos dados no Excel, foi adotada } \\
\text { entrada pelo sobrenome do autor, seguido das iniciais dos demais nomes, sem espaçamento. }\end{array}$} \\
\hline Dusoulier,N. & 5 & $1,1 \%$ & & $0,0 \%$ & 5 & $0,6 \%$ \\
\hline Fonseca,E.N.da & 5 & $1,1 \%$ & & $0,0 \%$ & 5 & $0,6 \%$ \\
\hline Vieira,A.daS. & 5 & $1,1 \%$ & & $0,0 \%$ & 5 & $0,6 \%$ \\
\hline Tarapanoff,K. & 4 & $0,9 \%$ & 1 & $0,3 \%$ & 5 & $0,6 \%$ \\
\hline Outros & 398 & $86,1 \%$ & 380 & $96,4 \%$ & 778 & $90,9 \%$ \\
\hline Total geral & 462 & $100,0 \%$ & 394 & $100,0 \%$ & 856 & $100,0 \%$ \\
\hline
\end{tabular}

\section{AneXo 14 - Total geral De PRODUtividade \\ DE AUTORES, CONSIDERANDO AUTORIA \\ PRINCIPAL E AUTORIA SECUNDÁRIA*}

\begin{tabular}{|c|c|c|c|}
\hline Autor & Autoria principal & Autoria secundária & Total geral \\
\hline Araújo,V.M.R.H.de & 9 & & 9 \\
\hline Figueiredo,N.M.de & 8 & 1 & 9 \\
\hline Gómez,M.N.G.de & 8 & & 8 \\
\hline Cunha,M.B.da & 6 & 1 & 7 \\
\hline Freire,I.M. & 5 & 2 & 7 \\
\hline Barreto,A.deA. & 6 & & 6 \\
\hline Borges,M.E.N. & 2 & 4 & 6 \\
\hline Mueller,S.P.M. & 6 & & 6 \\
\hline Dusoulier,N. & 5 & & 5 \\
\hline Fonseca,E.N.da & 5 & & 5 \\
\hline Mostafa,S.P. & 5 & & 5 \\
\hline Tarapanoff,K. & 4 & 1 & 5 \\
\hline Vieira,A.daS. & 5 & & 5 \\
\hline Braga,G.M. & 4 & & 4 \\
\hline Cianconi,R.deB. & 4 & & 4 \\
\hline Lastres,H.M.M. & 4 & & 4 \\
\hline Lima,R.C.M.de & 4 & & 4 \\
\hline Marchiori,P.Z. & 2 & 2 & 4 \\
\hline Marteleto,R.M. & 3 & 1 & 4 \\
\hline Pinheiro,L.V.R. & 4 & & 4 \\
\hline Rezende,Y. & 4 & & 4 \\
\hline Robredo,J. & 3 & 1 & 4 \\
\hline Saracevic,T. & 4 & & 4 \\
\hline Albagli,S. & 3 & & 3 \\
\hline Amaral,S.A.do & 3 & & 3 \\
\hline Caldeira,P.daT. & 1 & 2 & 3 \\
\hline Campelo,B.S. & 2 & 1 & 3 \\
\hline Campos,M.L.deA. & 3 & & 3 \\
\hline Carvalho,K.de & 3 & & 3 \\
\hline Céndón,B.V. & 3 & & 3 \\
\hline Dias,C.A. & 3 & & 3 \\
\hline
\end{tabular}


Lena Vania Ribeiro Pinheiro / Marisa Bräscher / Sonia Burnier

...continuação (Anexo 14)

\begin{tabular}{|c|c|c|c|}
\hline Autor & Autoria principal & Autoria secundária & Total geral \\
\hline Furtado,J.S. & 3 & & 3 \\
\hline Krzyzanowski,R.F. & 3 & & 3 \\
\hline Leitão,D.M. & 3 & & 3 \\
\hline Lopes,I.L. & 2 & 1 & 3 \\
\hline Marcondes,C.H. & 3 & & 3 \\
\hline McCarthy,C.M. & 3 & & 3 \\
\hline Montalli,K.M.L. & 2 & 1 & 3 \\
\hline Noronha,D.P. & 1 & 2 & 3 \\
\hline Oberhofer,C.A. & 3 & & 3 \\
\hline Packer,A.L. & 1 & 2 & 3 \\
\hline Pereira,MdeN.F. & 2 & 1 & 3 \\
\hline Pontes,C.C.C. & 2 & 1 & 3 \\
\hline Price,D.deS. & 3 & & 3 \\
\hline Sayão,L.F. & 1 & 2 & 3 \\
\hline Silva,G.O.doV. & 3 & 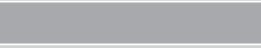 & 3 \\
\hline Targino,M.dasG. & 3 & & 3 \\
\hline Zaher,C.R. & 2 & 1 & 3 \\
\hline Aguiar,A.C. & 2 & & 2 \\
\hline Almeida,M.B. & 2 & & 2 \\
\hline Alvarado,R.U. & 2 & 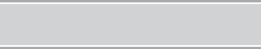 & 2 \\
\hline Alvarenga,L. & 1 & 1 & 2 \\
\hline Alves,J.B.daM. & & 2 & 2 \\
\hline Anegón,F.deM. & 1 & 1 & 2 \\
\hline AraújoJúnior,R.H.de & 1 & 1 & 2 \\
\hline Aun,M.P. & 2 & & 2 \\
\hline Baptista,D.M. & 2 & 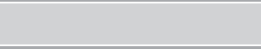 & 2 \\
\hline Bax,M.P. & 1 & 1 & 2 \\
\hline Borges,P.C.R. & 1 & 1 & 2 \\
\hline Café,L. & 1 & 1 & 2 \\
\hline Carvalho,M.M.de & 1 & 1 & 2 \\
\hline Castro,R.C.F. & 2 & & 2 \\
\hline Cintra,A.M.N. & 2 & & 2 \\
\hline Cunha,I.M.R.F. & 2 & & 2 \\
\hline Cunha,L.G.C.da & 2 & & 2 \\
\hline Cunha,M.V.da & 1 & 1 & 2 \\
\hline Dias,E.J.W. & 1 & 1 & 2 \\
\hline Dias,G.A.de & 2 & & 2 \\
\hline Ferreira,M.A.T. & & 2 & 2 \\
\hline Ferreira,M.C.G. & & 2 & 2 \\
\hline Ferreira,S.M.S.P. & 2 & & 2 \\
\hline Figueiredo,L.M.de & 2 & & 2 \\
\hline Foresti,N.A.B. & 2 & & 2 \\
\hline Freund,G.E. & 2 & & 2 \\
\hline Furnival,A.C. & 2 & & 2 \\
\hline Galvão,M.C.B. & 2 & - & 2 \\
\hline Garcez,E.M.S. & 2 & & 2 \\
\hline Garcia,J.C.R. & 1 & 1 & 2 \\
\hline Garcia,M.L.A. & 2 & & 2 \\
\hline Gürsey,S. & & 2 & 2 \\
\hline Gusmão,H.R. & 2 & & 2 \\
\hline Jardim,J.M. & 2 & & 2 \\
\hline
\end{tabular}


Ciência da Informação: 32 anos (1972-2004) no caminho da história e horizontes de um periódico científico brasileiro

...continuação (Anexo 14)

\begin{tabular}{|c|c|c|c|}
\hline Autor & Autoria principal & Autoria secundária & Total geral \\
\hline Lancaster,F.W. & 2 & & 2 \\
\hline Lara,M.L.G.de & 1 & 1 & 2 \\
\hline Lima,A.B.A.de & 1 & 1 & 2 \\
\hline Lima,C.R.Mde & 2 & & 2 \\
\hline Lima,G.A.B. & 2 & & 2 \\
\hline Lopes,L.C. & 2 & & 2 \\
\hline Loureiro,J.M.M. & 1 & 1 & 2 \\
\hline Lucas,C.R. & 2 & & 2 \\
\hline Macedo,N.D.de & 1 & 1 & 2 \\
\hline Maranon,E.I.M. & & 2 & 2 \\
\hline Mazzoni,A.A. & 1 & 1 & 2 \\
\hline Miranda,A.L.C.de & 2 & & 2 \\
\hline Monteiro,S.D. & 2 & & 2 \\
\hline Monte-Mór,J. & 2 & & 2 \\
\hline Moresi,E.A.D. & 2 & & 2 \\
\hline Oliveira,E.deA. & 2 & & 2 \\
\hline Oliveira,S.M.de & 2 & & 2 \\
\hline Ottoni,H.M. & 2 & & 2 \\
\hline Población,D.A. & 2 & & 2 \\
\hline PohlmannFilho,O. & & 2 & 2 \\
\hline Prati,S.C. & 1 & 1 & 2 \\
\hline Quonian,L. & 1 & 1 & 2 \\
\hline Rados,G.J.V. & & 2 & 2 \\
\hline Ramos,M.G. & 1 & 1 & 2 \\
\hline Rocha,M.P.C. & 2 & & 2 \\
\hline Rodrigues,M.daP.L. & 2 & & 2 \\
\hline Rodrigues,M.E.F. & 1 & 1 & 2 \\
\hline Rosetto,M. & 2 & & 2 \\
\hline Sambaquy,L.deQ. & 2 & & 2 \\
\hline Santana,P.H.deA.A. & 1 & 1 & 2 \\
\hline Santos,F.dos & 2 & & 2 \\
\hline Santos,R.N.M. & 2 & & 2 \\
\hline Sena,N.K. & 1 & 1 & 2 \\
\hline Senra,N.deC. & 2 & & 2 \\
\hline Shera,J.H. & 2 & & 2 \\
\hline Silva,E.L.da & 1 & 1 & 2 \\
\hline Silva,S.L.da & 1 & 1 & 2 \\
\hline Souza,F.daC. & 2 & & 2 \\
\hline Souza,R.F.de & & 2 & 2 \\
\hline Souza,T.deF.C.de & 2 & & 2 \\
\hline Tálamo,M.deF.G.M. & 1 & 1 & 2 \\
\hline Torres,E.F. & 1 & 1 & 2 \\
\hline Veado,J.T. & 2 & & 2 \\
\hline Veiga,E.deA. & 2 & & 2 \\
\hline Vergueiro,W.deC.S. & 2 & & 2 \\
\hline Vicentini,A.L.C. & 2 & & 2 \\
\hline Wanderley,M.A. & 2 & & 2 \\
\hline Witter,G.P. & 2 & & 2 \\
\hline Abreu,D. & 1 & & 1 \\
\hline Aguiar,S. & 1 & & 1 \\
\hline Aires,R.V.X. & 1 & & 1 \\
\hline
\end{tabular}

continua... 
Lena Vania Ribeiro Pinheiro / Marisa Bräscher / Sonia Burnier

...continuação (Anexo 14)

\begin{tabular}{|c|c|c|c|}
\hline Autor & Autoria principal & Autoria secundária & Total geral \\
\hline Albuquerque,M.E.B.C.deA. & 1 & & 1 \\
\hline Alencar,M.deC.F. & & 1 & 1 \\
\hline Allevato,S.R. & 1 & & 1 \\
\hline Almeida,I.M.de & & 1 & 1 \\
\hline Almeida,O.de & 1 & & 1 \\
\hline Aluísio,S.M. & & 1 & 1 \\
\hline Alvares,L. & & 1 & 1 \\
\hline Alves,I.M & 1 & & 1 \\
\hline Alves,M.C. & 1 & & 1 \\
\hline Alvim,P.C.R.de & 1 & & 1 \\
\hline Andrade,M.E.A. & & 1 & 1 \\
\hline Andrade,P.S.de & & 1 & 1 \\
\hline Angeloni,M.T. & 1 & & 1 \\
\hline Antonio,l. & 1 & & 1 \\
\hline Antunes,A. & & 1 & 1 \\
\hline Aquino,L.de & 1 & & 1 \\
\hline Aragão,A.C. & & 1 & 1 \\
\hline Araújo,C.A.A. & 1 & & 1 \\
\hline Araújo,E.A.de & 1 & . & 1 \\
\hline Araújo,E.de & 1 & . & 1 \\
\hline Araújo,N.M. & & 1 & 1 \\
\hline Araujo,T.B.de & & 1 & 1 \\
\hline Archuby,G.G. & 1 & & 1 \\
\hline Arellano,M.A.M. & 1 & & 1 \\
\hline Arruda,M.daC.C. & 1 & & 1 \\
\hline Assman, $\mathrm{H}$. & 1 & & 1 \\
\hline Ataíde,M.E.M. & 1 & & 1 \\
\hline Azevedo,A.D.R.P.de & 1 & 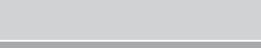 & 1 \\
\hline Baggio,R. & 1 & 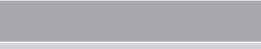 & 1 \\
\hline Baranow,U.G & 1 & & 1 \\
\hline Barbeitos,M. & & 1 & 1 \\
\hline Barbosa,A.P. & 1 & & 1 \\
\hline Barbosa,M.A. & 1 & 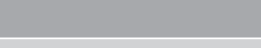 & 1 \\
\hline Barbosa,R.R. & 1 & & 1 \\
\hline Barboza,E.M.F. & 1 & 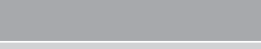 & 1 \\
\hline Barreiros,A.deA. & & 1 & 1 \\
\hline Barreto,M.Y. & & 1 & 1 \\
\hline Barros,E.deV. & & 1 & 1 \\
\hline Battaglia,B.B & & 1 & 1 \\
\hline Battaglia,M.daG.B. & 1 & & 1 \\
\hline Bauzer,R. & 1 & & 1 \\
\hline Belluzzo,R.C.B & 1 & & 1 \\
\hline Beraldi,L.C. & 1 & & 1 \\
\hline Bernardi,R. & & 1 & 1 \\
\hline Bertarello,M.B. & & 1 & 1 \\
\hline Bettiol,E.M. & 1 & & 1 \\
\hline Bevilacqua,C.R. & & 1 & 1 \\
\hline Boccato,V.R.C. & 1 & & 1 \\
\hline Bomeny,R.H.D. & 1 & & 1 \\
\hline Bomfica,J.doE. & 1 & & 1 \\
\hline Bordignon,F.R.A. & 1 & & 1 \\
\hline
\end{tabular}


Ciência da Informação: 32 anos (1972-2004) no caminho da história e horizontes de um periódico científico brasileiro

...continuação (Anexo 14)

\begin{tabular}{|c|c|c|c|}
\hline Autor & Autoria principal & Autoria secundária & Total geral \\
\hline Borges,K.S. & & 1 & 1 \\
\hline Borges,M.A.G. & 1 & & 1 \\
\hline Borschiver,S. & 1 & & 1 \\
\hline Bouché,R. & 1 & & 1 \\
\hline Boulanger,J.C. & 1 & & 1 \\
\hline Boyce,B. & 1 & & 1 \\
\hline Bremer,C.F. & & 1 & 1 \\
\hline BrescianiFilho,E. & 1 & & 1 \\
\hline Bressan,M. & & 1 & 1 \\
\hline Brito,C.J. & 1 & & 1 \\
\hline Brito,M. & 1 & & 1 \\
\hline Brittain,J.M. & 1 & & 1 \\
\hline Bueno,J.L.deO. & & 1 & 1 \\
\hline Cabré,M.T. & 1 & & 1 \\
\hline Camargo,C.C.deB. & & 1 & 1 \\
\hline CaminadaNetto,A. & & 1 & 1 \\
\hline Campello,B. & 1 & & 1 \\
\hline Campos,M.L.M. & & 1 & 1 \\
\hline Cândido,G.A. & 1 & & 1 \\
\hline Caribé,R.deC.doV. & 1 & & 1 \\
\hline Carlisie,J. & & 1 & 1 \\
\hline Carmo,V.B.do & 1 & & 1 \\
\hline Carneiro,M.V. & 1 & & 1 \\
\hline Carneiro,P. & 1 & & 1 \\
\hline Carvalho,A.deO. & 1 & & 1 \\
\hline Carvalho,C.A.de & & 1 & 1 \\
\hline Carvalho,I.C.L. & 1 & & 1 \\
\hline Carvalho,J.H.de & 1 & . & 1 \\
\hline Carvalho,M.B.P.de & & 1 & 1 \\
\hline Carvalho,M.de L.B.de & 1 & & 1 \\
\hline Carvalho,N.G.deM. & & 1 & 1 \\
\hline Cellini,J. & & 1 & 1 \\
\hline Chaparro,F. & 1 & & 1 \\
\hline Chataignier,M.C.P. & 1 & & 1 \\
\hline Chaviano, & & 1 & 1 \\
\hline Christovão,H.T. & 1 & & 1 \\
\hline Coelho,R.M.P. & 1 & & 1 \\
\hline Cohen,M.F. & 1 & & 1 \\
\hline Coletta,T.dasG. & & 1 & 1 \\
\hline Cordeiro,E.C.A. & & 1 & 1 \\
\hline Cordeiro,X.L. & 1 & & 1 \\
\hline Cormier,P.M.J. & 1 & & 1 \\
\hline Correia,E.N.S. & 1 & & 1 \\
\hline Correia,M. & 1 & & 1 \\
\hline Corte,AA.R. & 1 & & 1 \\
\hline Costa,A.F.C.da & 1 & & 1 \\
\hline Costa,I.T.M. & 1 & & 1 \\
\hline Coutinho,E. & 1 & & 1 \\
\hline Couzinet,V. & & 1 & 1 \\
\hline Crema,A. & & 1 & 1 \\
\hline Cristovão,H.T. & & 1 & 1 \\
\hline
\end{tabular}


Lena Vania Ribeiro Pinheiro / Marisa Bräscher / Sonia Burnier

...continuação (Anexo 14)

\begin{tabular}{|c|c|c|c|}
\hline Autor & Autoria principal & Autoria secundária & Total geral \\
\hline Cruz,A.A.A.C.da & 1 & & 1 \\
\hline Cruz,R. & 1 & & 1 \\
\hline Cubillo,J. & 1 & & 1 \\
\hline Cuenca,A.M.B. & 1 & & 1 \\
\hline Cunninghan,S. & & 1 & 1 \\
\hline Currás,E. & & 1 & 1 \\
\hline Curvo,P.F. & 1 & & 1 \\
\hline Cysne,F.P. & 1 & & 1 \\
\hline Dahlberg,I. & 1 & & 1 \\
\hline Datta,S. & 1 & & 1 \\
\hline Davig,A.P. & 1 & & 1 \\
\hline Demo,P. & 1 & & 1 \\
\hline Devis,J. & 1 & & 1 \\
\hline Dholakia,N. & 1 & & 1 \\
\hline Dholakia,R.R. & & 1 & 1 \\
\hline Dias,A.C. & 1 & & 1 \\
\hline Dias,M. & & 1 & 1 \\
\hline Domene,S.M.A. & & 1 & 1 \\
\hline Dona,A.M. & & 1 & 1 \\
\hline Dórea,J.G. & 1 & & 1 \\
\hline Duarte,E.N. & 1 & & 1 \\
\hline Duarte,F.A.deM. & & 1 & 1 \\
\hline Dudziak,E.A. & 1 & 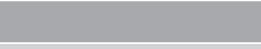 & 1 \\
\hline Dumont,L.M.M. & 1 & & 1 \\
\hline Elhaijji,M. & 1 & 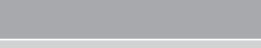 & 1 \\
\hline Ely,V.H.M.B. & & 1 & 1 \\
\hline EscrivãoFilho,E. & & 1 & 1 \\
\hline Esmeralda,M.deA. & & 1 & 1 \\
\hline Esmeraldo,M.B.P. & 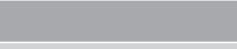 & 1 & 1 \\
\hline Estevão,S.N.deM. & & 1 & 1 \\
\hline Évora,Y.D.M. & & 1 & 1 \\
\hline Eyre,J. & 1 & & 1 \\
\hline Fachin,G.R.B. & & 1 & 1 \\
\hline Falcão,S.D. & & 1 & 1 \\
\hline Fausltich,E. & 1 & & 1 \\
\hline Fernandes,L.R.R.M.V. & 1 & & 1 \\
\hline Fernandes,P.O. & 1 & 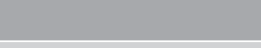 & 1 \\
\hline Fernandez-Molina,J.C. & 1 & & 1 \\
\hline Ferreira,D.T. & 1 & & 1 \\
\hline Ferreira,D.V. & 1 & & 1 \\
\hline Ferreira,J.R. & 1 & & 1 \\
\hline Ferreira,M.daS. & 1 & & 1 \\
\hline Ferreira,R.daS. & 1 & & 1 \\
\hline Ferreira,R.deC.S. & & 1 & 1 \\
\hline Ferreira,R.R.M.C. & & 1 & 1 \\
\hline Figueiredo,R.O & 1 & & 1 \\
\hline FilhoCunha,P.C. & & 1 & 1 \\
\hline Finatto,M.J.B. & & 1 & 1 \\
\hline Fioresi,V. & & 1 & 1 \\
\hline Fonseca,M.O. & 1 & & 1 \\
\hline Fontes,C.deA. & & 1 & 1 \\
\hline
\end{tabular}


Ciência da Informação: 32 anos (1972-2004) no caminho da história e horizontes de um periódico científico brasileiro

...continuação (Anexo 14)

\begin{tabular}{|c|c|c|c|}
\hline Autor & Autoria principal & Autoria secundária & Total geral \\
\hline Fox,E.A. & & 1 & 1 \\
\hline Francelin,M.M. & 1 & & 1 \\
\hline Freitas,H.M.R.de & & 1 & 1 \\
\hline Frota,M.G.daC. & 1 & & 1 \\
\hline Frota,M.N. & 1 & & 1 \\
\hline Fujita,M.S.L. & 1 & & 1 \\
\hline Funaro,V.M.B.deO. & & 1 & 1 \\
\hline Furquim,T.A. & 1 & & 1 \\
\hline Gabriel,M.A. & & 1 & 1 \\
\hline Galvão,A.P. & 1 & & 1 \\
\hline Garcia,M.J.deO. & & 1 & 1 \\
\hline Gasque,K.C.G.D. & 1 & & 1 \\
\hline Gattoni,R.L.C. & 1 & & 1 \\
\hline Gava,M. & & 1 & 1 \\
\hline Giacometti,M.M. & 1 & & 1 \\
\hline Gigante,M.C. & 1 & & 1 \\
\hline Giunti,G.M. & & 1 & 1 \\
\hline Goffman,W. & 1 & & 1 \\
\hline Gomes,E.G. & & 1 & 1 \\
\hline Gomes,H.E. & & 1 & 1 \\
\hline Gomes,H.F. & 1 & & 1 \\
\hline Gomes,S.H. & & 1 & 1 \\
\hline Gomes,S.P. & 1 & & 1 \\
\hline Gomes,T.F. & 1 & & 1 \\
\hline Gomez,M.Y.F.S.deF. & 1 & & 1 \\
\hline Gonçalves,M.A. & 1 & & 1 \\
\hline Gontow,R. & & 1 & 1 \\
\hline Gonzales,C.M. & & 1 & 1 \\
\hline Gonzáles,J.A.M. & 1 & & 1 \\
\hline Gonzales,M. & 1 & & 1 \\
\hline Gonzáles,S.C. & 1 & & 1 \\
\hline Gracioso,L.deS. & 1 & & 1 \\
\hline Gregolin,J.A.R. & & 1 & 1 \\
\hline Guedes,M.doC. & & 1 & 1 \\
\hline Guedes,V.L.daS. & 1 & & 1 \\
\hline Guimarães,A.C.F. & 1 & & 1 \\
\hline Guimarães,E.M.P. & 1 & & 1 \\
\hline Guimarães,S.D. & 1 & & 1 \\
\hline Guimarães,T.B.N. & & 1 & 1 \\
\hline Hagen,A.M.M. & 1 & & 1 \\
\hline Herañdez,G.C. & & 1 & 1 \\
\hline Hernandes,C.A.M. & 1 & & 1 \\
\hline Herrera,M.V. & & 1 & 1 \\
\hline Herrero-Solana,V. & & 1 & 1 \\
\hline Hutz,C.S. & & 1 & 1 \\
\hline Jakobson,S.R. & & 1 & 1 \\
\hline Jannuzzi,C.A.S.C. & 1 & & 1 \\
\hline Japiassu,H. & 1 & & 1 \\
\hline Jimeñez,M.S. & 1 & & 1 \\
\hline Jimeno,L.A. & & 1 & 1 \\
\hline Júnior,I.P. & 1 & & 1 \\
\hline
\end{tabular}


Lena Vania Ribeiro Pinheiro / Marisa Bräscher / Sonia Burnier

...continuação (Anexo 14)

\begin{tabular}{|c|c|c|c|}
\hline Autor & Autoria principal & Autoria secundária & Total geral \\
\hline Kairalla,A.S.S. & 1 & & 1 \\
\hline Kaniski,A.L. & & 1 & 1 \\
\hline Kern,V.M. & & 1 & 1 \\
\hline Kielgast,S. & 1 & & 1 \\
\hline King,D.W. & 1 & & 1 \\
\hline Klaes,R.V. & 1 & & 1 \\
\hline Klintoe,K. & 1 & & 1 \\
\hline Kobashi,N.Y. & & 1 & 1 \\
\hline Kofnovec,L & 1 & & 1 \\
\hline Koller,S.H. & & 1 & 1 \\
\hline Kondo,E.K. & 1 & & 1 \\
\hline Kondo,R.T. & & 1 & 1 \\
\hline Kremer,J.M. & 1 & & 1 \\
\hline Krieger,E.M. & & 1 & 1 \\
\hline Krieger,M.daG. & 1 & 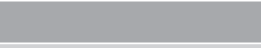 & 1 \\
\hline Kuramoto,H. & 1 & & 1 \\
\hline Lage,N.L. & & 1 & 1 \\
\hline Lago,W.G. & & 1 & 1 \\
\hline Lantré,E. & 1 & & 1 \\
\hline Launo,R. & 1 & & 1 \\
\hline Lazarte,L. & 1 & & 1 \\
\hline Lemos,A.A.B.de & 1 & & 1 \\
\hline Lemos,M.A.A.de & 1 & 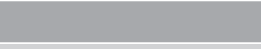 & 1 \\
\hline Levacov,M. & 1 & . & 1 \\
\hline Lima,A.M.de & & 1 & 1 \\
\hline Lima,M.F.B.F. & 1 & & 1 \\
\hline Lima,M.L.deA. & 1 & & 1 \\
\hline Lima,V.M.A. & 1 & 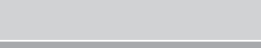 & 1 \\
\hline Linares, $R$ & 1 & 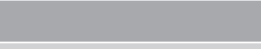 & 1 \\
\hline Lins,B.F.E. & 1 & . & 1 \\
\hline Lirani,M.deL.R. & & 1 & 1 \\
\hline LoBianco,A.C. & & 1 & 1 \\
\hline Lobo,M.D.O. & & 1 & 1 \\
\hline Lombardi,V.V. & & 1 & 1 \\
\hline Lopes,J.O. & & 1 & 1 \\
\hline Lopes,R.R.V. & 1 & & 1 \\
\hline Lopez,I.L. & 1 & & 1 \\
\hline Macedo,F. & 1 & & 1 \\
\hline Macedo-Rouet,M. & 1 & & 1 \\
\hline Machado,V.M. & & 1 & 1 \\
\hline Macias-Chapula,C.A. & 1 & & 1 \\
\hline Maciel,A.M.B. & & 1 & 1 \\
\hline Maia,E.L.S. & 1 & & 1 \\
\hline Maloff,J. & 1 & & 1 \\
\hline Mamfrim,F.P.B. & 1 & & 1 \\
\hline Marchesi,I.H. & 1 & & 1 \\
\hline Marcos,D. & 1 & & 1 \\
\hline Mariotto,F.L. & 1 & & 1 \\
\hline Marques,A. & & 1 & 1 \\
\hline Martha,M.O.B. & & 1 & 1 \\
\hline Martins,E.V. & 1 & & 1 \\
\hline
\end{tabular}


Ciência da Informação: 32 anos (1972-2004) no caminho da história e horizontes de um periódico científico brasileiro

...continuação (Anexo 14)

\begin{tabular}{|c|c|c|c|}
\hline Autor & Autoria principal & Autoria secundária & Total geral \\
\hline Martins,I.G.daS. & 1 & & 1 \\
\hline Martins,R.V.G.daS. & & 1 & 1 \\
\hline MartinsFilho,P. & 1 & & 1 \\
\hline Masiero,P.C. & 1 & & 1 \\
\hline Mateos,D.R. & 1 & & 1 \\
\hline Mattozo,V. & 1 & & 1 \\
\hline Maura,M.A. & 1 & & 1 \\
\hline Maury,P. & 1 & & 1 \\
\hline Máximo,L.F. & & 1 & 1 \\
\hline Medeiros,M.B.B. & 1 & & 1 \\
\hline Medeiros,N.L.de & & 1 & 1 \\
\hline Melo,D.G.P.de & 1 & & 1 \\
\hline Melo,G.C. & & 1 & 1 \\
\hline Melo,J.M.de & 1 & & 1 \\
\hline Melo,M.deL.deA. & 1 & & 1 \\
\hline Melo,M.GdeL. & & 1 & 1 \\
\hline Melo,P.M.A.C.de & 1 & & 1 \\
\hline Menandro,P.R.M. & & 1 & 1 \\
\hline Mendes,R.D. & 1 & & 1 \\
\hline Mendes,T.C.M. & & 1 & 1 \\
\hline Mendonça,E. & 1 & & 1 \\
\hline Mendonça,L.M.E. & 1 & & 1 \\
\hline Menezes,E.M. & 1 & & 1 \\
\hline Merlino-Santesteban,C. & 1 & & 1 \\
\hline Mesa,Y.R. & & 1 & 1 \\
\hline Michel,J. & 1 & & 1 \\
\hline Miki,H. & 1 & & 1 \\
\hline Milidin,R.L. & & 1 & 1 \\
\hline Mirabal,R.R. & & 1 & 1 \\
\hline Miranda,A. & 1 & & 1 \\
\hline Miranda,D.B.de & 1 & & 1 \\
\hline Miranda,L.M.C.de & 1 & & 1 \\
\hline Miranda,R.C.daR. & 1 & & 1 \\
\hline Monge,F. & 1 & & 1 \\
\hline Moraes,M.I.de & & 1 & 1 \\
\hline Moran,J.M. & 1 & & 1 \\
\hline Morei,C.M. & 1 & & 1 \\
\hline Moreiro,J.A. & 1 & & 1 \\
\hline Morel,C.M. & 1 & & 1 \\
\hline Morel,R.L.deM. & & 1 & 1 \\
\hline Moreno,C.M. & & 1 & 1 \\
\hline Moresi,R.L.deM. & 1 & & 1 \\
\hline Morigi,V.J. & 1 & & 1 \\
\hline Morin,M.-F. & 1 & & 1 \\
\hline MorrisJunior,T.G. & & 1 & 1 \\
\hline Mosconi,E.P. & & 1 & 1 \\
\hline Mota,T.L.N.daG. & 1 & & 1 \\
\hline Motta,D.F.da & 1 & & 1 \\
\hline Motta,M.T.da & 1 & & 1 \\
\hline Moura,L.R. & 1 & & 1 \\
\hline Moura,W. & 1 & & 1 \\
\hline
\end{tabular}

continua... 
Lena Vania Ribeiro Pinheiro / Marisa Bräscher / Sonia Burnier

...continuação (Anexo 14)

\begin{tabular}{|c|c|c|c|}
\hline Autor & Autoria principal & Autoria secundária & Total geral \\
\hline Moutinho,K. & 1 & & 1 \\
\hline Mualem,J.R.V.B. & & 1 & 1 \\
\hline Mueller,C.C. & 1 & & 1 \\
\hline Mundorf,N. & & 1 & 1 \\
\hline Muniz,J.N. & & 1 & 1 \\
\hline Mussi,R.N.F. & & 1 & 1 \\
\hline Nakayama,H. & 1 & & 1 \\
\hline Nascimento,M.deJ. & 1 & & 1 \\
\hline Nascimento,R.B.do & 1 & & 1 \\
\hline Naves,N.M.L. & & 1 & 1 \\
\hline Nayak,A. & & 1 & 1 \\
\hline Negrão,M.B. & & 1 & 1 \\
\hline Nehmy,R.M.Q. & 1 & & 1 \\
\hline Nesterov,A.V. & 1 & & 1 \\
\hline Neves,D.A.deB. & 1 & & 1 \\
\hline Neves,F.I. & 1 & & 1 \\
\hline Nunes,E.M.deA. & & 1 & 1 \\
\hline Octaviano,V.L.deC. & 1 & & 1 \\
\hline Ohira,M.L.B. & 1 & 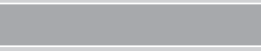 & 1 \\
\hline Ohman,E. & 1 & & 1 \\
\hline Oliveira,A.C.de & & 1 & 1 \\
\hline Oliveira,E. & 1 & & 1 \\
\hline Oliveira,E.B.P.M.de & & 1 & 1 \\
\hline Oliveira,J.A.M. & 1 & & 1 \\
\hline Oliveira,M. & 1 & & 1 \\
\hline Oliveira,M.J. & 1 & & 1 \\
\hline Oliveira,M.P. & 1 & & 1 \\
\hline Oliveira,R.de & & 1 & 1 \\
\hline Ortiz,L.C. & 1 & & 1 \\
\hline Ortiz,W.A. & & 1 & 1 \\
\hline Overmeyer,L.M. & 1 & & 1 \\
\hline Pacheco,F.deM. & & 1 & 1 \\
\hline Pacheco,F.F. & 1 & & 1 \\
\hline Pacheco,M. & & 1 & 1 \\
\hline Pacheco,R.C.dosS. & 1 & & 1 \\
\hline Paim,l. & & 1 & 1 \\
\hline Paiva,D.W.de & 1 & & 1 \\
\hline Parada,A.E. & & 1 & 1 \\
\hline Paranhos,W.M.M.daR. & 1 & 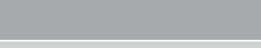 & 1 \\
\hline Passarelli,B. & 1 & & 1 \\
\hline Passarelli,M.L.R. & 1 & & 1 \\
\hline Paternostro,L.C.B. & 1 & & 1 \\
\hline Paula,A.C.M.de & 1 & & 1 \\
\hline Paulino,R.S. & 1 & & 1 \\
\hline Pavan,C. & & 1 & 1 \\
\hline Pavani,A.M.B. & 1 & & 1 \\
\hline Pecegueiro,C.M.P.deA. & & 1 & 1 \\
\hline Pellegrini,A.E. & & 1 & 1 \\
\hline Pené,M.G. & & 1 & 1 \\
\hline Pereira,MC.M. & & 1 & 1 \\
\hline Pestana,M.C. & 1 & & 1 \\
\hline
\end{tabular}


Ciência da Informação: 32 anos (1972-2004) no caminho da história e horizontes de um periódico científico brasileiro

...continuação (Anexo 14)

\begin{tabular}{|c|c|c|c|}
\hline Autor & Autoria principal & Autoria secundária & Total geral \\
\hline Petrini,M. & & 1 & 1 \\
\hline Pilnk,M. & 1 & & 1 \\
\hline Piñero,A.delaR. & & 1 & 1 \\
\hline Pinheiro,A.V.T.daP. & 1 & & 1 \\
\hline Pinheiro,M.G. & 1 & & 1 \\
\hline Pinto,V.B. & 1 & & 1 \\
\hline Pires,P.M.deS.G. & & 1 & 1 \\
\hline Plácido,C.F. & 1 & & 1 \\
\hline Polke,A.M.A. & 1 & & 1 \\
\hline Pommer,C.V. & & 1 & 1 \\
\hline Pontual,M.deA.C. & 1 & & 1 \\
\hline Porter,A. & & 1 & 1 \\
\hline Pozzenbon,M. & 1 & & 1 \\
\hline Prado,A.M.M.daC. & & 1 & 1 \\
\hline Prado,N.S. & & 1 & 1 \\
\hline Prysthon,C.F. & & 1 & 1 \\
\hline PucciJunior,A. & 1 & & 1 \\
\hline Quéau,P. & 1 & & 1 \\
\hline Queiroz,S.deS. & 1 & & 1 \\
\hline Quesada,B.V. & 1 & & 1 \\
\hline Raabe,A.L.A. & 1 & & 1 \\
\hline Ramos,P.A.B. & 1 & 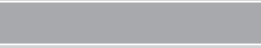 & 1 \\
\hline Rattner,H. & 1 & & 1 \\
\hline Rebello,M.A.deF.R. & & 1 & 1 \\
\hline Reenen,J.van & 1 & & 1 \\
\hline Rezende,A.P.de & 1 & & 1 \\
\hline Ribeiro,G.L. & 1 & & 1 \\
\hline Ribeiro,L.A. & 1 & & 1 \\
\hline Richmond,P.A. & 1 & & 1 \\
\hline Rios,R.delos & 1 & & 1 \\
\hline Rocha,E.daC. & 1 & & 1 \\
\hline Rocha,E.M.P.da & 1 & & 1 \\
\hline Rocha,J.G.C.da & & 1 & 1 \\
\hline Rodrígues, E.M.M. & 1 & & 1 \\
\hline Rodrigues,G.M. & 1 & & 1 \\
\hline Rodrigues,N.S.S. & & 1 & 1 \\
\hline Rousseau,R. & 1 & & 1 \\
\hline Sá,E.S.de & 1 & & 1 \\
\hline Saenger,J.C. & & 1 & 1 \\
\hline Salem,A.D.C. & & 1 & 1 \\
\hline Sampaio,M.I.C. & 1 & & 1 \\
\hline Sañchez,M.L.L. & & 1 & 1 \\
\hline Santana,I.V. & 1 & & 1 \\
\hline Santos,L.C. & 1 & & 1 \\
\hline Santos,M.deL.C. & & 1 & 1 \\
\hline Santos,M.V.R. & 1 & & 1 \\
\hline SantosJr.,J.N. & 1 & & 1 \\
\hline Sanz-Casado,E. & 1 & & 1 \\
\hline Schiel,U. & & 1 & 1 \\
\hline Schimidt,S. & 1 & & 1 \\
\hline Schlie,T.W. & 1 & & 1 \\
\hline
\end{tabular}


Lena Vania Ribeiro Pinheiro / Marisa Bräscher / Sonia Burnier

...continuação (Anexo 14)

\begin{tabular}{|c|c|c|c|}
\hline Autor & Autoria principal & Autoria secundária & Total geral \\
\hline Schukste,M.R.C. & & 1 & 1 \\
\hline Sebastián,M.C. & 1 & & 1 \\
\hline Segawa,H. & 1 & & 1 \\
\hline Sely,M.deS.C. & & 1 & 1 \\
\hline Senso,J.A. & 1 & & 1 \\
\hline Sicsu,A.B. & 1 & & 1 \\
\hline Silva,A.I.B.da & & 1 & 1 \\
\hline Silva,E.O. & 1 & & 1 \\
\hline Silva,G.L.da & 1 & & 1 \\
\hline Silva,H.P.da & 1 & & 1 \\
\hline Silva,I.L.G.da & & 1 & 1 \\
\hline Silva,J.F. & 1 & & 1 \\
\hline Silva,M.P.da & & 1 & 1 \\
\hline Silva,P.A.daS. & & 1 & 1 \\
\hline Silva,W.T.da & 1 & & 1 \\
\hline Silveira,A. & 1 & & 1 \\
\hline Silveira,F.R.daS. & 1 & & 1 \\
\hline Silveira,H.F.daS. & 1 & & 1 \\
\hline Silveira,H.F.R.da & 1 & & 1 \\
\hline Simão,J.B. & & 1 & 1 \\
\hline Skolimovski,E.B. & & 1 & 1 \\
\hline Sorte,G. & & 1 & 1 \\
\hline Souza,C.L.deM.V. & 1 & & 1 \\
\hline Souza,D.B. & & 1 & 1 \\
\hline Souza,H.deM.R.e & 1 & & 1 \\
\hline Souza,M.daP.N.de & 1 & & 1 \\
\hline Souza,M.I.F. & 1 & & 1 \\
\hline Souza,R.R. & 1 & & 1 \\
\hline Spinak,E. & 1 & & 1 \\
\hline Stepanenko,A. & 1 & & 1 \\
\hline Stubbs,E.A. & 1 & & 1 \\
\hline Stumf,I.R.C. & 1 & & 1 \\
\hline Suaiden,E.J. & 1 & . & 1 \\
\hline Tardin, $\mathrm{H}$. & 1 & & 1 \\
\hline Taruhn,R. & & 1 & 1 \\
\hline Tasca,C.C. & 1 & & 1 \\
\hline Tavares,C. & 1 & & 1 \\
\hline Teixeira,C.M.deS & 1 & & 1 \\
\hline Teixeira,I.L.R. & 1 & & 1 \\
\hline Tenopir,C. & & 1 & 1 \\
\hline Thiollent,M. & 1 & & 1 \\
\hline Tiratel,S.R.de & 1 & & 1 \\
\hline Tolosa,G.H. & 1 & & 1 \\
\hline Triska,R. & 1 & & 1 \\
\hline Trompieri,N.F. & & 1 & 1 \\
\hline Trzesniak,P. & 1 & & 1 \\
\hline Urdaneta,I.P. & 1 & & 1 \\
\hline Utuyama,A.S. & & 1 & 1 \\
\hline Valcárcel,J.V.I. & & 1 & 1 \\
\hline Valentim,M.L.P. & & 1 & 1 \\
\hline Valle,B.deM. & 1 & & 1 \\
\hline
\end{tabular}


Ciência da Informação: 32 anos (1972-2004) no caminho da história e horizontes de um periódico científico brasileiro

...continuação (Anexo 14)

\begin{tabular}{|c|c|c|c|}
\hline Autor & Autoria principal & Autoria secundária & Total geral \\
\hline Valls,V.M. & 1 & & 1 \\
\hline Valois,E.C. & 1 & & 1 \\
\hline Vanti,N.A.P. & 1 & & 1 \\
\hline Vargas,I.V. & 1 & & 1 \\
\hline Vargas,L. & & 1 & 1 \\
\hline Varvakis,G. & & 1 & 1 \\
\hline VeigaFilho,J.P.da & 1 & & 1 \\
\hline Velho,L.M.L.S. & 1 & & 1 \\
\hline Vendrusculo,L.G. & & 1 & 1 \\
\hline Viana,C.L.deM. & 1 & & 1 \\
\hline Vianna,R.A.S.P. & 1 & & 1 \\
\hline Vidili,A.L. & & 1 & 1 \\
\hline Vieira,A.E.daR. & 1 & & 1 \\
\hline Vieira,A.S. & 1 & & 1 \\
\hline Vieira,S.B. & 1 & & 1 \\
\hline VilanFilho,J.L. & 1 & & 1 \\
\hline Villela,M.C.O. & & 1 & 1 \\
\hline Viruez,G.V. & & 1 & 1 \\
\hline Wanderley,A.V.M. & 1 & & 1 \\
\hline Weil,P. & 1 & & 1 \\
\hline Werthein,J. & 1 & & 1 \\
\hline Whitehall,T. & 1 & & 1 \\
\hline Wilson,T.D. & 1 & & 1 \\
\hline Wongtchowski,P. & & 1 & 1 \\
\hline Xaochu,W. & & 1 & 1 \\
\hline Yahn,V.G. & 1 & & 1 \\
\hline Yamachita,M.M. & 1 & & 1 \\
\hline Yamamoto,O.H. & 1 & & 1 \\
\hline Zani,R.M.F. & & 1 & 1 \\
\hline Zhaodong,L. & 1 & & 1 \\
\hline Zhu,D. & 1 & & 1 \\
\hline Zorita,C.G. & & 1 & 1 \\
\hline Total Global & 614 & 242 & 856 \\
\hline
\end{tabular}

ANeXo 15 - AfiliaÇão dos AUtores da REVISTA CIÊNCIA DA INFORMaÇão (1998-2000)

\begin{tabular}{l|c|}
\hline Instituição & N. de autores \\
\hline UFMG & 18 \\
\hline USP & 17 \\
\hline Ibict & 17 \\
\hline UNB & 16 \\
\hline PUC/PR & 11 \\
\hline UFRGS & 10 \\
\hline UFPI & 8 \\
\hline BIREME & 7 \\
\hline EMPRESA PRIVADA & 4 \\
\hline UNICAMP & 4 \\
\hline EMBRAPA & 4 \\
\hline FAPESP & 2 \\
\hline FINEP & 2 \\
\hline IPT & 2 \\
\hline
\end{tabular}

continua... 


\begin{tabular}{|c|c|}
\hline Instituição & N. de autores \\
\hline PUCCAMP & 2 \\
\hline UFF & 2 \\
\hline UFRJ/SIBI & 2 \\
\hline UFSC & 2 \\
\hline UFSCAR & 2 \\
\hline UNESCO (Oficina Brasil) & 2 \\
\hline CNPQ & 1 \\
\hline EUVALDO LODI & 1 \\
\hline IME & 1 \\
\hline MCT & 1 \\
\hline MUNICIPIO RJ & 1 \\
\hline MUSEU ARTE RS & 1 \\
\hline PUC/MG & 1 \\
\hline PUC/RS & 1 \\
\hline SEBRAE & 1 \\
\hline TCU & 1 \\
\hline UERJ & 1 \\
\hline UESC & 1 \\
\hline UFBA & 1 \\
\hline UFEI & 1 \\
\hline UFPB & 1 \\
\hline UNIPI & 1 \\
\hline UNIRP & 1 \\
\hline 40 instituições & 149 \\
\hline Exterior NÃO ESPECIFICADO & 9 \\
\hline UNIVERSIDADE CARLOS III MADRID & 3 \\
\hline UNIVERSIDADE DO MEXICO & 2 \\
\hline CONYCIT, Chile & 1 \\
\hline Escola Real de Biblioteconomia, Copenhague & 1 \\
\hline HOSPITAL GELA DE MEXICO & 1 \\
\hline IDICT /Cuba & 1 \\
\hline UNIVERSIDADE DE COSTA RICA & 1 \\
\hline UNIVERSIDADE NA BELGICA & 1 \\
\hline ISI /Estados Unidos & 1 \\
\hline UNIVERSIDADE DE PARIS & 1 \\
\hline UNIVERSIDADE DE STANFORD & 1 \\
\hline URUGUAI (Consultor independente) & 1 \\
\hline UNIVERSIDADE DE TENESSE & 1 \\
\hline 15 instituições internacionais & 25 \\
\hline 55 Instituições - $\quad$ Total Geral autores & 174 \\
\hline
\end{tabular}

\section{Fonte: Ibict. GT 15 -Serviços de informação e Publicações para Especialistas em ICT. Relatório Final, Rio de Janeiro, Brasília, maio de 2001}

Observação: A UFRJ não aparece porque a vinculação institucional dos autores é com o Ibict, o Programa de Pós-graduação em Ciência da Informação é que tinha convênio com a UFRJ.

ANeXo 16 - Produtividade De AUtores oriundos De CURSOS E PROGRAMAS DE PÓS-GRADUAÇão POR TIPO DE AUTORIA

\begin{tabular}{|l|c|c|c|}
\hline Produção PG & Autoria única & Co-autoria & Total por Universidade \\
\hline Ibict/UFRJ & 72 & 10 & 82 \\
\hline UNB & 46 & 7 & 53 \\
\hline UFMG & 32 & 14 & 46 \\
\hline USP & 19 & 5 & 24 \\
\hline
\end{tabular}


Ciência da Informação: 32 anos (1972-2004) no caminho da história e horizontes de um periódico científico brasileiro

\begin{tabular}{|l|c|c|c|}
\hline PUCCAMP & 10 & 1 & 11 \\
\hline UFSC & 6 & 2 & 8 \\
\hline UFBA & 3 & & 3 \\
\hline UNESP & 1 & 203 & 1 \\
\hline Sem informação & 411 & 242 & 614 \\
\hline Total geral & 600 & 842 \\
\hline
\end{tabular}

Anexo 17 - Produtividade de Autores POR Países de ORigem, INCluindo BRASIL, 1972-2004, DISTRIBUÍDOS POR DÉCADAS

\begin{tabular}{|c|c|c|c|c|c|}
\hline País & $1972-1979$ & 1980-1989 & 1990-1999 & 2000-2004 & Total geral \\
\hline Brasil & 69 & 116 & 308 & 238 & 731 \\
\hline Estados Unidos & 18 & & 11 & 5 & 34 \\
\hline Espanha & & & 2 & 19 & 21 \\
\hline França & 8 & 2 & 5 & 1 & 16 \\
\hline Argentina & & & 2 & 9 & 11 \\
\hline Cuba & & & 1 & 6 & 7 \\
\hline Inglaterra & 3 & 1 & 1 & & 5 \\
\hline China & & 2 & & & 2 \\
\hline Dinamarca & & & 2 & & 2 \\
\hline Portugal & & & 2 & & 2 \\
\hline Alemanha & 1 & & & & 1 \\
\hline Bélgica & & & 1 & & 1 \\
\hline Canadá & & & 1 & & 1 \\
\hline Checoslováquia & 1 & & & & 1 \\
\hline Colombia & 1 & & & & 1 \\
\hline Costa Rica & & & 1 & & 1 \\
\hline Finlândia & & & 1 & & 1 \\
\hline Holanda & & & & 1 & 1 \\
\hline Itália & & & & 1 & 1 \\
\hline México & & & 1 & & 1 \\
\hline Paraguai & & & & 1 & 1 \\
\hline Porto Rico & & & 1 & & 1 \\
\hline URSS & & & 1 & & 1 \\
\hline Uruguai & & & 1 & & 1 \\
\hline Venezuela & & & 1 & & 1 \\
\hline Não identificado & & & 10 & & 10 \\
\hline Total geral & 101 & 121 & 353 & 281 & 856 \\
\hline
\end{tabular}

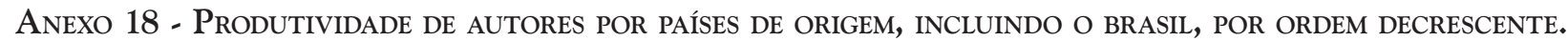

\begin{tabular}{|c|c|c|c|c|}
\hline País & Produção & $\%$ & Autores & $\%$ \\
\hline Brasil & 731 & $85,8 \%$ & 523 & $82,9 \%$ \\
\hline Estados Unidos & 34 & $4,0 \%$ & 26 & $4,1 \%$ \\
\hline Espanha & 21 & $2,5 \%$ & 20 & $3,2 \%$ \\
\hline França & 16 & $1,9 \%$ & 12 & $1,9 \%$ \\
\hline Argentina & 11 & $1,3 \%$ & 11 & $1,7 \%$ \\
\hline Cuba & 7 & $0,8 \%$ & 7 & $1,1 \%$ \\
\hline Venezuela & 7 & $0,8 \%$ & 7 & $1,1 \%$ \\
\hline Inglaterra & 5 & $0,6 \%$ & 5 & $0,8 \%$ \\
\hline China & 2 & $0,2 \%$ & 2 & $0,3 \%$ \\
\hline Dinamarca & 2 & $0,2 \%$ & 2 & $0,3 \%$ \\
\hline Portugal & 2 & $0,2 \%$ & 2 & $0,3 \%$ \\
\hline
\end{tabular}


Lena Vania Ribeiro Pinheiro / Marisa Bräscher / Sonia Burnier

...continuação (Anexo 15)

\begin{tabular}{|c|c|c|c|c|}
\hline País & Produção & $\%$ & Autores & $\%$ \\
\hline Alemanha & 1 & $0,1 \%$ & 1 & $0,2 \%$ \\
\hline Bélgica & 1 & $0,1 \%$ & 1 & $0,2 \%$ \\
\hline Canadá & 1 & $0,1 \%$ & 1 & $0,2 \%$ \\
\hline Checoslováquia & 1 & $0,1 \%$ & 1 & $0,2 \%$ \\
\hline Colombia & 1 & $0,1 \%$ & 1 & $0,2 \%$ \\
\hline Costa Rica & 1 & $0,1 \%$ & 1 & $0,2 \%$ \\
\hline Finlândia & 1 & $0,1 \%$ & 1 & $0,2 \%$ \\
\hline Holanda & 1 & $0,1 \%$ & 1 & $0,2 \%$ \\
\hline Itália & 1 & $0,1 \%$ & 1 & $0,2 \%$ \\
\hline México & 1 & $0,1 \%$ & 1 & $0,2 \%$ \\
\hline Paraguai & 1 & $0,1 \%$ & 1 & $0,2 \%$ \\
\hline Porto Rico & 1 & $0,1 \%$ & 1 & $0,2 \%$ \\
\hline URSS & 1 & $0,1 \%$ & 1 & $0,2 \%$ \\
\hline Uruguai & 1 & $0,1 \%$ & 1 & $0,2 \%$ \\
\hline Não identificado & 10 & $1,2 \%$ & 10 & $1,6 \%$ \\
\hline Total & 852 & $100,0 \%$ & 631 & $100,0 \%$ \\
\hline
\end{tabular}

